Rodrigo dos Santos Francisco

\title{
Unidades de Seleção nos Genes
}

\section{HLA}

\section{Units of Selection in HLA Genes}

São Paulo 
Rodrigo dos Santos Francisco

\section{Unidades de Seleção nos Genes} HLA

\section{Units of Selection in HLA Genes}

Tese apresentada ao Instituto de Biociências da Universidade de São Paulo, para a obtenção de Título de Doutor em Ciências, na Área de Genética.

Orientador(a): Diogo Meyer

São Paulo 


\section{Ficha Catalográfica}

Francisco, Rodrigo dos Santos

Unidades de Seleção nos Genes HLA- 97

páginas

Tese (Doutorado) - Instituto de

Biociências da Universidade de São Paulo.

Departamento de Genética e Biologia Evolutiva.

1. MHC 2. Evolução 3.Seleção.

Universidade de São Paulo. Instituto de

Biociências. Departamento de Genética e Biologia Evolutiva.

\section{Comissão Julgadora:}




\section{Sumário}

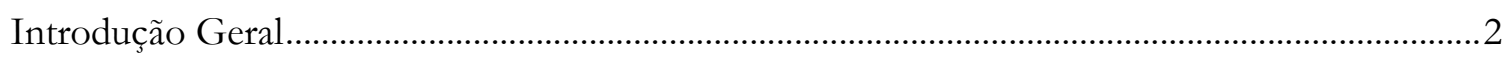

1.1. Genes HLA: Estrutura, Função e Evidências da atuação da Seleção Natural. ...............3

Capítulo 1: A classificação em supertipos e a seleção sobre aminoácidos específicos da fenda apresentadora de peptídeos dos genes HLA de classe I clássicos ..................................................... 8

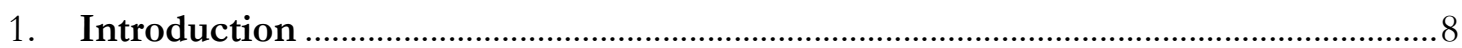

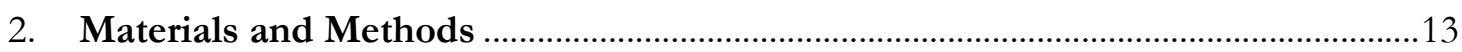

2.1. Population data........................................................................................................13

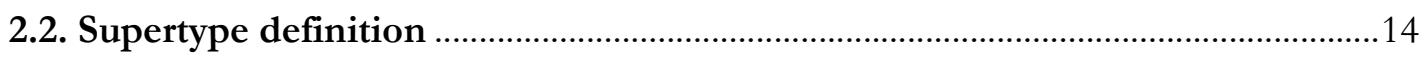

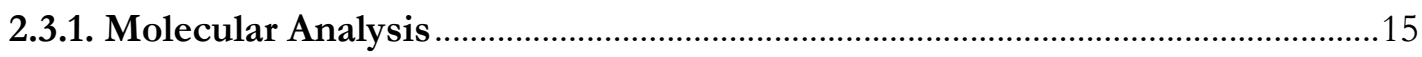

2.3.2. Test for supertype differentiation between populations....................................16

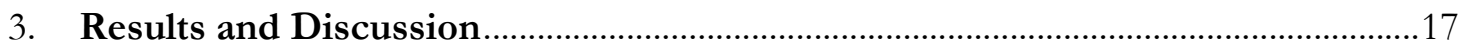

3.1. Superpetype frequency and differentiation........................................................17

3.2. Heterozygosity, interpopulational differentiation and correlation with

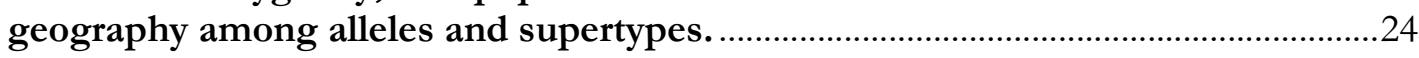

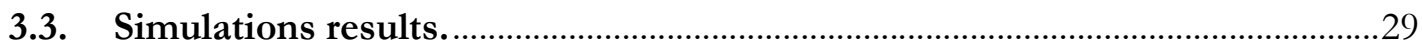

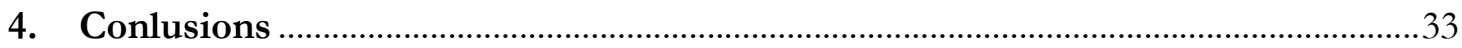

Capítulo 2: Evolution of HLA genes in the American continent.....................................................34

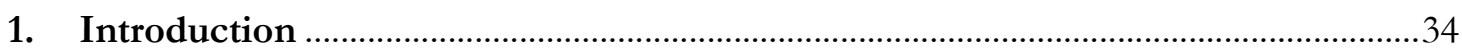

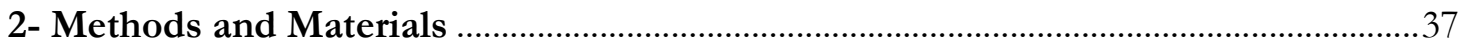

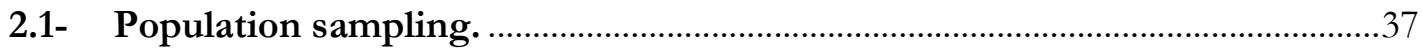

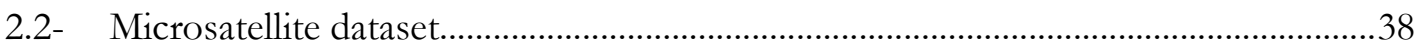

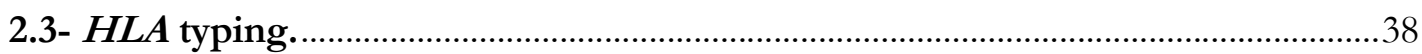

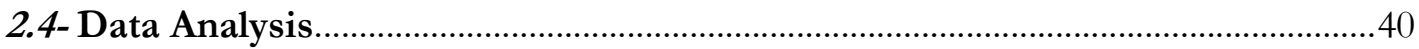

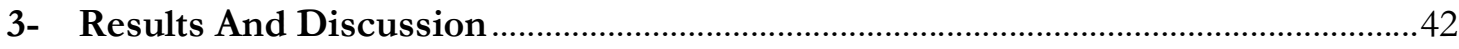

3.1. Deviations from Hardy-Weinberg proportions.................................................... 42

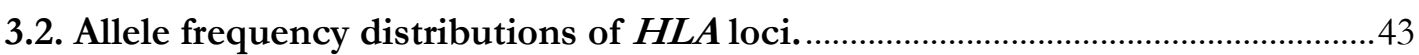

3.3. Correlation between diversity indeces and the geographic distance from the

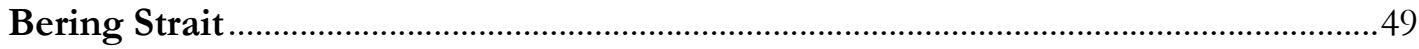

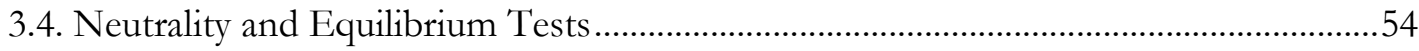

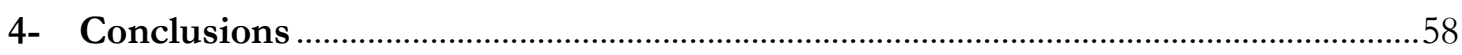

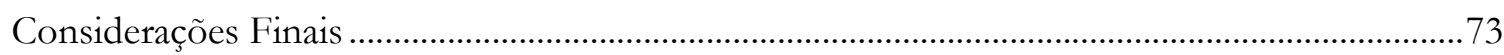




\section{Introdução Geral}

O entendimento da contribuição relativa dos processos estocásticos e da seleção natural na evolução e manutenção da variação genética é um dos principais objetivos da pesquisa em biologia evolutiva (Piertney and Oliver 2006). Dentre os loci que apresentam sinais de evolução por seleção natural, podemos citar os genes HLA (Human Leukocyte Antigen), que apresentam níveis de diversidade incompatíveis com o esperado de acordo com o modelo de evolução neutra em humanos. Além das evidências populacionais, os resultados de estudos de associação com doenças infecciosas indicam que os genes $H L A$ estão evoluindo sob seleção natural dirigida por patógenos (Meyer and Thomson 2001).

Apesar do grande número de estudos, ainda há debate a respeito de diversos aspectos do processo seletivo que molda a variação dos genes $H L A$. Nosso objetivo no presente trabalho foi entender qual ou quais foram os principais alvos da atuação da seleção natural dentro desse sistema gênico. Alvos plausíveis incluem desde aminoácidos específicos, até genes inteiros. Esses dois níveis de análise, o intra e intergênico, motivaram a organização do presente trabalho em dois capítulos no formato de manuscritos. Porém, antes de entrarmos nas questões especificas exploradas em cada um desses capítulos, nós faremos uma breve contextualização do tema, descrevendo a estrutura e função dos genes HLA e apresentando as evidências de que esses genes estão evoluindo sob a ação da seleção natural. 
1.1. Genes HLA: Estrutura, Função e Evidências da atuação da Seleção Natural.

Os genes HLA encontram-se no MHC (o Complexo Principal de Histocompatibilidade), localizado no braço curto do cromossomo 6 (6p21.3) (Figura 1). O MHC é uma das regiões mais bem conhecidas do genoma humano, apresentando altos níveis de diversidade e uma alta concentração gênica (The MHC sequencing consortium 1999). Esse complexo é organizado em três regiões, definidas de acordo com a função dos genes localizados em cada uma delas: classe I, II e III.

Na região de classe I estão localizados os genes $H L A-A$, -B e $-C$, também conhecidos como genes HLA de classe I clássicos, que codificam respectivamente as moléculas HLA-A, B e -C. As moléculas HLA de classe I são formadas por duas subunidades: a cadeia $\alpha$ e a $\beta 2$ microglobulina. A cadeia $\alpha$ é codificada pelos genes HLA de classe I e apresenta três domínios extracelulares: $\alpha 1, \alpha 2$ e $\alpha 3$. Os domínios $\alpha 1$ e $\alpha 2$ formam a fenda de ligação de peptídeos (Saper, Bjorkman, and Wiley 1991).

$\mathrm{Na}$ região $\mathrm{MHC}$ de classe II estão localizados os genes HLA-DPA1 e -DPB1 que codificam a molécula HLA-DP; os genes HLA-DQA1 e -DQB1 que codificam a molécula HLA-DQ; e os genes HLA-DRA e o complexo dos genes -DRB (HLA-DRB1, -DRB3, -DRB4 e -DRB5) que codificam as moléculas HLA-DR. As moléculas de classe II são também formadas por duas subunidades: as cadeias $\alpha$ e $\beta$, entretanto, diferentemente das moléculas de classe I, ambas as subunidades são codificadas por diferentes genes $H L A$ (ex: as cadeias $\alpha$ e $\beta$ da molécula HLA-DRB1 são codificadas pelos genes HLA-DRA e HLA-DRB1, respectivamente. Cada uma das subunidades das moléculas de classe II apresentam dois domínios: a cadeia $\alpha \operatorname{com} \alpha 1$ e $\alpha 2$; e a cadeia $\beta \operatorname{com} \beta 1$ e $\beta 2$. Os domínios $\alpha 1$ e $\beta 1$ formam a fenda de ligação do peptídeo (Figura 2). 


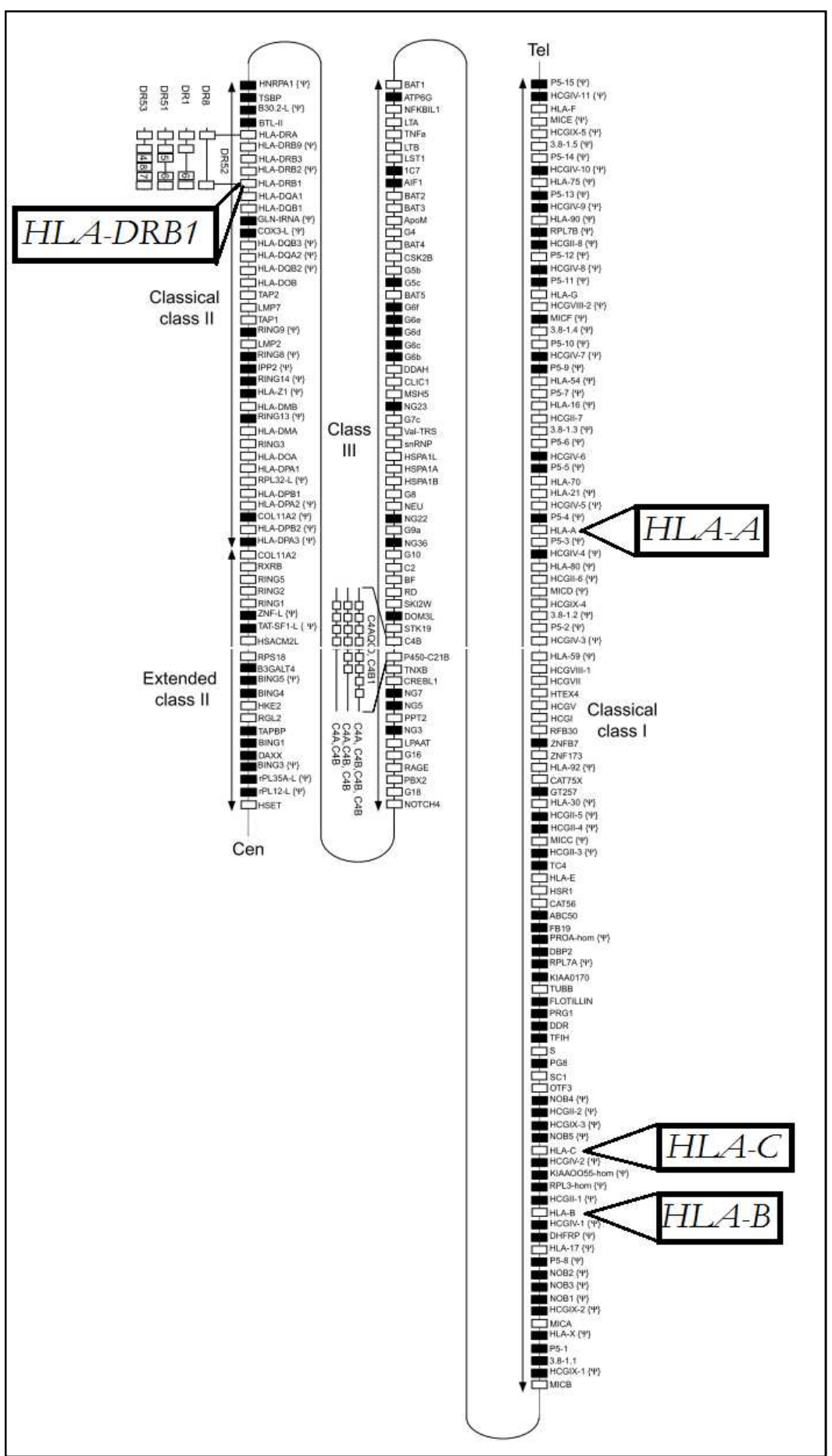

Figura 1. Mapa esquemático do MHC humano: as caixas indicam os genes que foram estudados no presente trabalho HLA-A, $-B$ e $-C$ e $-D R B$. Fonte: (The MHC sequencing consortium 1999). 


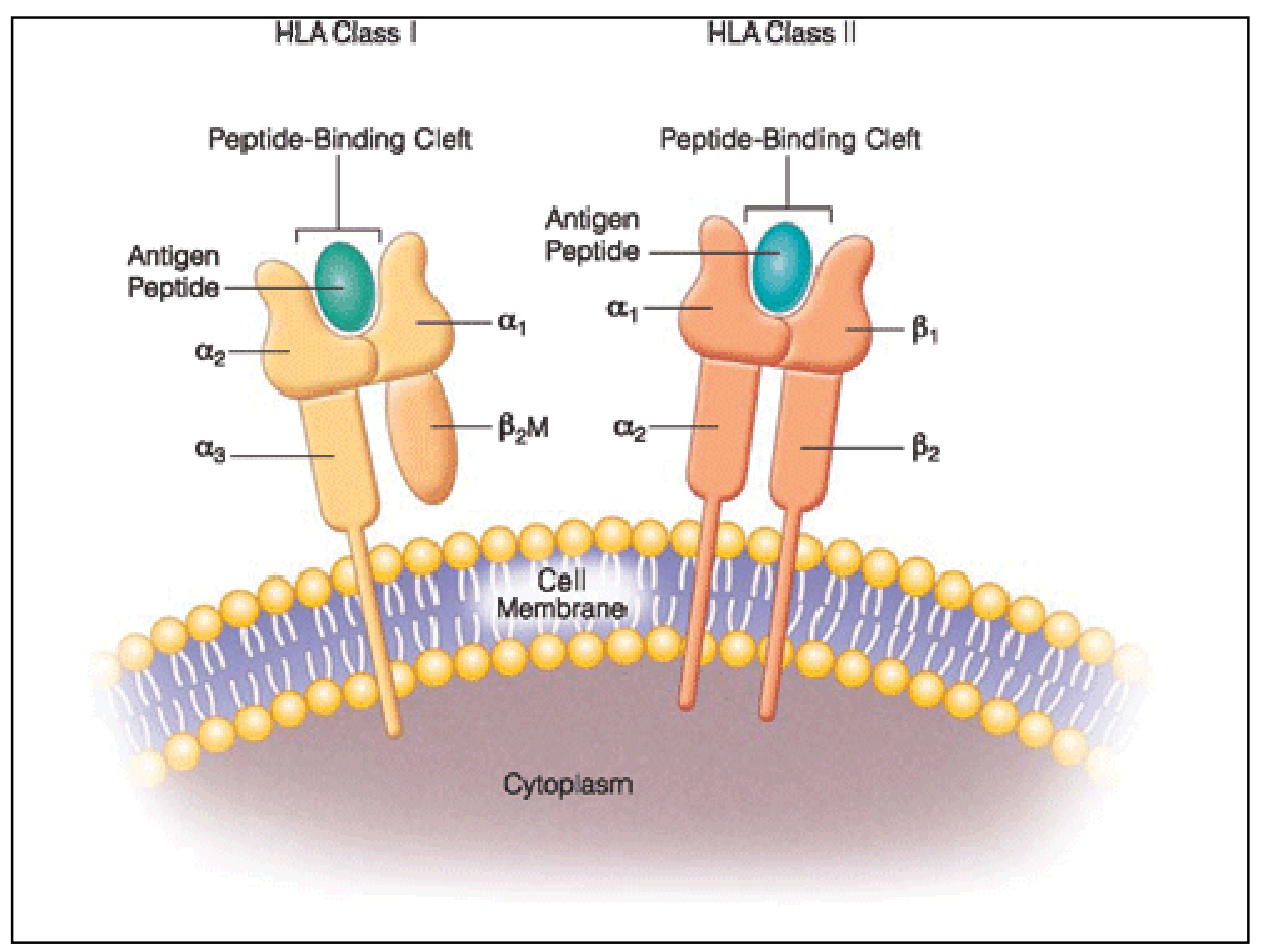

Figura 2. Imagem ilustrando as estruturas das moléculas HLA de classe I e classe II: (veja descrição no texto).

Inicialmente, acreditava-se que a função dos genes HLA estava correlacionada apenas com a compatibilidade tecidual observada durante transplantes (PONTES and PORTO 2007). A verdadeira função fisiológica desses genes somente foi compreendida posteriormente: as moléculas codificadas pelos genes $H L A-A,-B$ e $-C$ apresentam peptídeos citoplasmáticos na superfície da maioria das células nucleadas aos linfócitos T CD8+ (Doherty and Zinkernagel 1975) e também são ligantes dos receptores KIR (Killer cell immunoglobulin-like receptors) expressos pelas células natural killers, ou NK (Parham 2005). Já as moléculas de classe II são constitutivamente expressas pelas chamadas células apresentadoras de antígeno profissionais (APC) (Watts 1997, Varney, Gavrilidis, and Tait 1999) e apresentam peptídeos orindos do exterior das células (que foram previamente fagocitados ou pinocitados) aos linfócitos $\mathrm{T}$ CD4+ (Varney et al., 1999). 
Normalmente as moléculas HLA são expressas associadas a peptídeos oriundos de proteínas próprias. Porém, na presença de proteínas não próprias, moléculas HLA com peptídeos antigênicos são levadas à superfície celular onde são reconhecidas por linfócitos $\mathrm{T}$ (ABBAS e LICHTMAN 2005). A sobrevivência dos patógenos está atrelada à presença de variantes antigênicas que permitem a evasão da apresentação pelas moléculas HLA, enquanto que a sobrevivência dos hospedeiros está atrelada à capacidade de apresentação de antígenos dos patógenos.

A consequência do elo evolutivo entre hospedeiros e patógenos faria com que as moléculas HLA e antígenos coevoluam. Os patógenos tenderiam a acumular mutações de escape, que são aquelas que evitam a apresentação de seus peptídeos pelas moléculas HLA mais comuns na população de hospedeiros. Por outro lado, novas moléculas HLA, capazes de apresentar de forma eficiente essas mutações de escape, seriam adaptativas e aumentariam de freqüência na população de hospedeiros, recomeçando o ciclo. Portanto, os microrganismos patogênicos seriam a fonte da seleção atuante nos genes HLA. Essa hipótese evolutiva é conhecida como seleção dirigida por patógenos (Gillespie 1977).

Simulações computacionais mostraram que a seleção dirigida por patógenos explica de maneira satisfatória várias das características observadas nos dados reais para genes $H L A$, tal como o grande número de alelos, altas taxas de heterozigose e longa persistência dos alelos nas populações ao longo das gerações (Borghans, Beltman, and De Boer 2004). Esse mecanismo evolutivo também seria capaz de explicar as altas taxas de identidade podescendencia descritas para genes os genes HLA (Albrechtsen, Moltke e Nielsen 2010).

Estudos de associação com doenças infecciosas corroboram a hipótese de seleção dirigida por patógenos. Por exemplo, foram descritas associações entre alelos HLA e resistência à malária em populações do oeste africano (Hill et al. 1997). Alelos de HLA-B 
foram associados a uma maior ou menor progressão à infecção por HIV (Carrington et al. 1999; Kaslow et al. 1996). Além disso, Prugnolle et al. (2007), Qutob et al. (2011) e SanchezMazas et al. (2012) mostraram que populações localizadas em regiões com grande diversidade de patógenos, possuem em média, uma maior diversidade nos loci $H L A$.

Todas esses resultados indicam que os genes HLA estão evoluindo sob ação da seleção natural e que a provável fonte da pressão seletiva atuante nesses loci vem da interação com os patógenos presentes no ambiente.

Baseando-se nessas premissas nós desenvolvemos as duas principais questões que motivaram o desenvolvimento do presente trabalho:

1) As regiões das moléculas HLA que interagem de forma direta com os antígenos patogênicos foram os alvos principais da atuação da seleção natural?

2) Quais foram os genes HLA mais impactados durante a ocupação de novos ambientes pelas populações humanas? 


\title{
Capítulo 1: A classificação em supertipos e a seleção sobre
}

\section{aminoácidos específicos da fenda apresentadora de peptídeos}

\author{
dos genes HLA de classe I clássicos
}

\section{Introduction}

The HLA (Human Leukocyte Antigen) classical class I genes are extremely polymorphic, with thousands of alleles, most of them coding for different proteins $(1,612$, 2,211 and 1,280 non-synonymous variants for $H L A-A,-B$ and $-C$ loci, respectively, (Robinson et al. 2011). The HLA class I genes play a central role in the immune response, presenting processed peptides derived from proteins present in the intracellular environment (including foreign ones, derived from intracellular parasites such viruses and some bacteria) to cytotoxic T lymphocytes, and also functioning as ligands for the killer Immunoglobulin-like receptor (KIR) of natural killer cells (Parham 2005).

Almost all the HLA class I polymorphism is clustered in exons 2 and 3, that code for the $\alpha 1$ and $\alpha 2$ extracellular domains, which form a groove-like structure known as the peptide binding region (PBR), which engages the peptides (Saper, Bjorkman, and Wiley 1991). The PBR codons show several striking features regarding their variaton, including a high heterozygosity (Parham et al. 1989; Lawlor et al. 1990; Hedrick et al. 1991) as high rates of non-synonymous substitutions (Hughes and Nei 1988, Takahata et al. 1992). Both of these features support the hypothesis that these codons are under a regime of balancing selection, which can be defined as any selective mechanism that results in increased polymorphism with respect to neutral expectations (Bamshad and Wooding 2003). 
Different selective processes can explain balancing selection, including heterozygote advantage, frequency dependent selection and host-pathogen coevolution (Apanius et al, 1997; Meyer and Thomson, 2001), and considerable effort in recent research has centred on distinguish between these alternative regimes. In support of pathogen driven selection hypothesis, which states that the pathogenic microorganisms were the main evolutionary force shaping HLA variation (Gillespie 1977), several studies have demonstrated a positive correlation between the diversity levels of both HLA genes and environmental pathogens (Prugnolle et al., 2005; Qutob et al. 2011; Sanchez-Mazas et al. 2012). In addition, simulation studies have shown that a regime of host-pathogen co-evolution provides a better explanation for high levels of heterozygosity than a regime of heterozygote advantage, which doesn't account for the coevolutionary dynamic (de Boer et a., 2004; Borghans et al., 2004).

Although it has been well established that the codons which make up the PBR constitute the main target of balancing selection within HLA genes, the analyses performed to date generally treat this region as a homogeneous block, with no concern regarding the contributions of individual substructures inside the PBR to the patterns of $H L A$ variation. The PBR can be further subdivided into six pocket-like structures (A, B, C, D, E and F). Each pocket accommodates one of the nine amino acid residues of the bound peptide $\left(1^{\text {st }}, 2^{\text {nd }}, 3^{\text {rd }}\right.$, $6 \mathrm{t}^{\mathrm{h}}, 7^{\mathrm{th}}$ and $9^{\text {th }}$, respectively)(Saper, Bjorkman, and Wiley 1991) and the binding affinity between an HLA molecule and a specific peptide is a function of the chemical properties provided by each of the PBR pockets (Saper, Bjorkman, and Wiley 1991).

The strongest interaction between the HLA molecules and the bound peptide is accounted by the interactions between the $\mathrm{B}$ and $\mathrm{F}$ pockets and the second and ninth amino acid residues of the peptide, respectively (Saper, Bjorkman, and Wiley 1991). As the amino acids composing B and F pockets play a central role in the peptide recognition by the HLA 
molecules, Sidney et al. (1996) proposed the supertype classification of HLA alleles. Supertypes are groups of alleles sharing chemical properties at the B and F pockets, and the logic behind such pooling is that alleles within supertypes are expected to have largely overlapping peptide repertoires, and contrasts between supertypes will be those associated to important phenotypic differences.

Supertypes were originally difined by examining motifs from binding data, the sequencing of endogenously bound ligands, as well analyses of the structure of the HLA molecules (Sette and Sidney 1999; Sidney et al. 1996, 2008). Four supertypes were described for $H L A-A$ (A1, A2, A3 and A24) and five for $H L A-B(B 7, B 27, B 44, B 58$ and B62) and they were originally assigned to $31 H L A-A$ and $57 H L A-B$ alleles whose peptide binding specificities were experimentally defined. These alleles were used to construct a reference panel for the B and F amino acid sequences. A set of 945 HLA-A and -B alleles with unknown binding specificietes were checked for matches to the sequences in this panel (Sidney et al. 2008). Among the 945 previously unclassified alleles, 57\% presented a full match in both B and $\mathrm{F}$ pockets with some allele from the reference panel, with known supertype status. Another 23.8\% presented partial matches with residues found at the B and F pockets.

In line with the expectation that supertypes constitute a functionally relevant definition of HLA variation, several researchers have found that in association studies involving HLA loci it is useful to group alleles into supertypes, and test associations between the later and disease status (Chakraborty et al. 2013; Cordery et al. 2012; Gilchuk et al. 2013; Karlsson et al. 2012, 2013; Kuniholm et al. 2013; Trachtenberg et al. 2003; Xavier Eurico de Alencar et al. 2013).

On an evolutionary scale, the selection upon B and F pockets and, consequently, upon the genotype defined by the supertype, is also expected to leave a visible signature. For 
example, under the assumption that pathogen driven selection shapes supertype frequencies, we expect genetic variation defined at the supertype level to show patterns of polymorphism and differentiation indicative of balancing selection.

The prediction that selection on supertype level variation would result in observable genetic signatures was raised by Sette and Sidney (1999), who argued that "supertype frequencies were high and fairly conserved among different ethnicities, a pattern consistent with balancing selection acting upon supertype-level variation". With a similar reasoning, Naugler and Liwski (2008) argued that "natural selection should favor maximization of the heterozygosity of allele supertypes instead of the heterozygosity of individual alleles", making explicit the hypothesis that the supertypes, as defined by of $\mathrm{B}$ and $\mathrm{F}$ pocket variation, are targets of natural selection.

Such conservation of supertype frequencies between populations, and increased heterozygosity at the supertype level would lead to a pattern of low population differentiation when compared with that observed in analyses of variation and differentiation defined at the allelic level. Another expected effect of the action of balancing selection at the supertype level would be the maximization of the variation of $B$ and $F$ pockets compared with the remaining regions of the PBR, increasing the chances of the antigen recognition by the immune system.

The methodological challenge involved in testing these hypotheses lies in the direct comparison between differentiation and variability for genetic variation defined at the level of $H L A$ alleles and supertypes. The problem arises because genetic variation at the allele level is nested within that at the supertype level (since supertypes are composed of sets of alleles) and heterozygosity at the supertype level is thus mathematically constrained to be lower or equal to that of the allele-level definition. Further, because genetic differentiation measured by statistics related to Wright's Fst is strongly determined by intrapopulation variability (Jost 2008), we 
similarly expect higher levels of differentiation at the supertype level, simply as a consequence of the decreased polymorphism associated to this level of allelic definition.

In the present study we investigate if the supertype definition at HLA loci reduces interpopulation differentiation and increases heterozygosity, while controlling for the effect of the inherent difference in polymorphism associated to supertype and allele-level definitions. Our approach consisted of creating null distributions for heterozygosity and differentiation indeces by creating randomized sets of alleles (herein referred to as "random supertypes"), that match the true supertypes in sampling properties (number of supertypes, and number of alleles per supertype), but lack the biological criteria for the pooling of the alleles.

By testing if true supertype definitions have significantly different measures of variation and differentiation when compared to randomly created supertypes, we were able to test the hypothesis that the grouping of alleles, as defined by supertype classification, and ultimately in the variation of $\mathrm{B}$ and $\mathrm{F}$ pockets, is able to account for an increase in heterozygosity and decrease in differentiation beyond those expected by random groupings, thus supporting the hypothesis that supertypes are a functional category that defines a selected phenotype, and accounts for patterns of variation in addition to what is explained by analyzing the data exclusively at the allele level.

Finally, we also analysed the supertype variation at nucleotide level, partitioning the sequences into segments corresponding to the different pockets. Our hypothesis was that because $\mathrm{B}$ and $\mathrm{F}$ pockets, the ones defining supertypes, are the major determinants of the peptide binding specificities, they will therefore constitute the main targets of balancing selection, showing higher levels of diversity when compared with the other pockets. 


\section{Materials and Methods}

\subsection{Population data.}

We used a database generated for the $13^{\text {th }}$ International Histocompatibility Workshop (IHW) (Mack et al. 2006), excluding populations which presented allelic resolution lower than two sets of digits (because the two first set of digitis are necessary for the identification of the unique protein-level alleles), genotypic ambiguities and deviation from Hardy-Weinberg expectations, resulting in a dataset of 6,435 and 6,409 individuals for $H L A-A$ and $-B$ respectively, from 55 populations (seven Sub-Saahara African (SSA), two North African (NAF), eight South East Asian (SWA), four European (EUR), 23 South East Asian (SEA), four Pascific islanders (PAC), four aborigean Australian (AUS), two North Asian (NEA) and two Native American (AME) populations) (table 1 - Suplementary Material 1(S1)).

We tested the samples for deviation from Hardy-Weinberg equilibrium using the Gene[rate] program which estimates the fitting of the observed genotypes with the hypothesis of population equilibrium (Nunes. 2006).

Our dataset has a bias towards populations from regions that are well documented to have experienced extreme founder events, with a total of 24 out of 55 populations fitting this definition (Oceania, Taiwan and the Americas, with 7,15 and 2 populations, respectivel) which represent groups that experienced extreme founder effects, which could contribute disproportionately to the overall patterns of differentiation, reducing the visibility of global trends in reduction of diversity associated to human migrations from Africa for instance. To deal with this effect we carried out analyses for two sets of populations: (a) a complete dataset, 
comprising all 55 populations; (b) and a reduced dataset of 32 populations, which excludes Oceania, Taiwan and the Americas.

\subsection{Supertype definition}

We assigned all alleles to their specific supertype using the classification described in figures 1 and 2 from Sidney et al. (2008). The alleles not assigned to any specific supertype were maintained at their allele-level definition for analyses of population differentiation and were pooled into groups of non-classified alleles (NCA and NCB for $H L A-A$ and $-B$, respectively) for the description of variation. We included $A * 29: 02, A * 29: 01, A * 29: 03$, $A * 30: 01, A * 30: 08$ and $A * 68: 06$ in the NCA group because of their ambiguous supertype allocation (Sidney et al. 2008). We also included $B^{*} 08$ alleles in the non-classified group of $H L A-B$ alleles because of their unique PBR structure which make the peptide biding profile unpredictable (Sidney et al. 2008).

\subsection{Data analyses}

We wrote $\mathrm{R}$ scripts for the estimation of frequencies, summary statistics (the number of alleles (k), and sample expected heterozygosity $(\mathrm{H})$ ) and genetic differentiation between pairs of populations (measured by $\left.\mathrm{G}_{\mathrm{ST}}\right)(\mathrm{Nei}$ and Chesser 1983). We calculated the geographic distances between the population pairs using a great circle routes approach. The mantel test for the significance of correlations between genetic and geographic distances was carried out using the ade4 $\mathrm{R}$ package and all graphs were generated using $\mathrm{R}$ as well. We performed a hierarchical analysis of molecular variance (AMOVA) for each supertype, considering all other alleles as a unique group. In this way we obtained estimates for both the diversity among populations (Fst), the diversity among populations within geographic regions (Fsc) and the 
diversity among geographic regions (Fct) for each supertype separately. The AMOVA was implemented using the Arlequin 3.5 peckage (Excoffier and Lischer 2010).

\subsubsection{Molecular Analysis}

We analyzed the molecular variation at each pocket using the coding sequences of the six (A to F) pockets which make up the HLA class I peptide biding region. The definition of these codons was taken from of Saper et al. (1991)(table 1.1). The B and F pockets were analyzed individually because of their central role in engaging peptides and in defining supertype. The C, D and E pockets together form the central region of the PBR and are shorter compared to other pockets, justifying pooling them for the present analysis. The A pocket was also analysed individually because of its position at one end of the PBR.

We estimated nucleotide diversity $(\pi)$ ( Nei. 1987) for each population, and refer to this as "total $\pi$ ". We also computed the within and between supertypes $\pi$, the later calculated using the following formula:

$$
\pi_{s t}=\frac{\pi_{\text {total }} \pi_{\text {within }}}{\pi_{\text {total }}}
$$

The total, within and between supertype $\pi$ were calculated in two ways; (a) excluding the non-classified alleles or (b) including them as a single group. The use of the dataset at two digits resolution presented a challenge since it lacks information about the synonimous mutations. We addressed this problem applying the same strategy described by Buhler and Sanchez-Mazas (2011), treating as a missing data the the nucleotide positions which were previously described as synonimous (Robinson et al. 2011). We excluded sites with more than 
$5 \%$ missing data .

Table 1.1. Codons compositions of the PBR pockets.

\begin{tabular}{lll}
\hline Pockets & Codons & Total size in base pairs (bp) \\
\hline A & $5,7,59,63,66,99,159,163,167$ and 171 & $30 \mathrm{pb}$ \\
B & $7,9,45,63,66,67,70$ e 99 & $24 \mathrm{pb}$ \\
C, D and E & $9,70,73,74,97,99,114,147,152,155,156,159$ and 160 & $39 \mathrm{pb}$ \\
F & $77,80,81,84,116,123,143,146$ e 147 & $27 \mathrm{pb}$ \\
\hline
\end{tabular}

\subsubsection{Test for supertype differentiation between populations}

To test whether the levels of genetic differentiation among population pairs differs from those expected under the null hypothesis that supertypes are equivalent to random sets of alleles, we randomized the assignment of alleles into supertypes and and calculated $\mathrm{He}$ and Gst. The randomized assignment of alleles to supertypes was perfomed using two different approaches:

1) We created randomized supertypes with the same number of alleles per supertype as observed in the original dataset, considering the total number of populations;

2) We randomized the assignment of alleles to supertypes, but did not impose any constraint on the number of alleles associated to a specific supertype, also considering the total number of populations.

The randomizations were repeated 10,000 times and p-values were estimated empirically by determining the number of randomized datasets with Gst values lower or $\mathrm{He}$ values higher than observed for the true data. 


\section{Results and Discussion}

\subsection{Superpetype frequency and differentiation}

In the only previous study to address differentiation at the supertype level, Sidney et al (1996) used five populations and reported a pattern in which all supertypes were present in all world regions, something not supported by our analysis. Some supertypes are completely absent in some populations and reach a frequency of more than $50 \%$ in others (figures $2 \mathrm{~A}, 2 \mathrm{D}$, 3 and 4). Among the HLA-A supertypes, A1 was the rarest, showing frequencies smaller than $9 \%$ in more than a half of the populations (figure 1.1A) and absent in five of them (figure 1.1D). A1 alleles were found with high frequencies (22\% in average) in Africa, South West Asia and Europe (Figure 1.2), resulting in a significant geographic structure (with most of the variation between populations being found among geographic regions (Fct $>$ Fsc); table 1.2). The A1 supertype was represented by a small number of alleles, with more than half of the populations exhibiting less than three alleles (figure 1.1B) and 14 of them showing a single one (figure 1.1C).

The A2 and A3 supertypes have a more even distribution, with half of the populations exhibiting frequencies ranging from 14 to $29 \%$ for A2 and 14 to $32 \%$ for A3 (figures $1.1 \mathrm{~A}$ and 1.2). As consequence, $\mathrm{A} 2$ and $\mathrm{A} 3$ supertypes presented the lowest structure among HLA-A supertypes (Fct < Fsc; table 1.2). All populations presented at least one A2 allele (with eight showing just one A2 allele) but the A3 supertype was represented by a large number of alleles (figure $1.1 \mathrm{~B}$ and $1.1 \mathrm{C}$ ).

The A24 supertype was found in all populations (figure 1.1D), presenting frequencies ranging from 13 to $40 \%$ in half of them (figure 1.1A). Despite the broad distribution, the A24 supertype was almost alaways represented by just 2 alleles, $A * 23: 01$ and $A * 24: 02$, with 26 and 
10 populations showing just one or both of these alleles (figure 1.1B and 1.1C). This supertype was found in higher frequencies (40\% in average) in South East Asia (SEA), Pacific Islands (PAC), Australia (AUS), North East Asia (NEA) and Americas (AME) (figure 1.2). Despite the higher levels of populations differentiation for this supertype (Fst $=11 \%, \mathrm{p}<0.0001$ ), most of the variation was found within geographic regions.

The frequencies of $H L A-A$ non-classified alleles (NCA) varied greatly between populations, ranging from 2 to $14 \%$ in half of them (figure 1.1A). These alleles presented a large geographic structure, with $72.8 \%$ of the variation among populations being detected between geographic regions (table 1.2). The African and Australian populations were those which presented the highest frequencies for the NCA (averages of 16 and $43 \%$, respectively)(figure 1.2).

The HLA-B supertypes fell into two main categories regarding the frequency distributions. On one hand, B7 and B44 showed a pattern resembling A2 and A3, with higher average frequencies (figures $1.1 \mathrm{~A}$ and 1.3) and relatively lower levels os geographic structure (table 1.2). Half of the population presented frequencies ranging from 18 to $31 \%$ and 21 to $32 \%$ for the B7 and B44 supertypes, respectively (figures 1.1A and 1.3). Both B7 and B44 were present in all populations (except for the Yami population, which lacks B7 alleles; figures 1.1D and 1.3), and exibted large number of alleles per population (figure 1.1B and 1.1C).

On the other hand, B58 and B62 exibited very low frequencies, with half of the popularion ranging from zero to $5.8 \%$ and 2.9 to $18 \%$, respectively (figures $1.1 \mathrm{~A}$ ). The $\mathrm{B} 62$ supertype presented the highest level of population differentiation (Fst $=11.38 \%, \mathrm{p}<0.0001$; table 1.2), but without a clear geographic structure (Fct $<$ Fsc; table 1.2). On the other hand, B58 presented the highest geographic structure among $-B$ supertypes $(F c t=0.05594$; table 1.2), being found among Sub-Saharan (SSA) populations at an average frequency of 33\% (ranging 
from 23 to $60 \%$, figure 1.3) against the $4.2 \%$ in the remaning regions (figure 1.3). B58 was also the supertype that was absent from the highest proportion of populations (18 of 53; figure 1.3).

The B27 supertype presented an intermediate pattern, with relatively lower frequencies (half of the populations exhibited frequencies from 7 to 19\%; figure 1.1A), a higher level of population differentiation when compared with B7 and B44 (Fst $=7.5 \%, \mathrm{p}<0.0001$; table 1.2), but without geographic structure (Fct very close to zero; table 1.2).

Contrasting with what was observed for the NCA, the non-classified alleles for $H L A-B$ locus $(\mathrm{NCB})$ were quite frequent, with half of the populations presenting frequencies ranging from 10 to $17 \%$ (figure 1.1A). More than $75 \%$ of the populations have at least two different NCBs (figure 2B) with just two populations lacking one of these alleles (figure 1.1D). We also observed a pattern of geographic structure, although it was not as strong as for NCA.

Based in the observed data we can allocate supertypes into two main categories: A2, A3, B7, B27 and B44 fits the classical view that supertypes are evenly distributed (figures 1.1A, 1.2 and 1.3 and table 1.2), poorly geographically structured (table 1.2) and represented by a large number of alleles (figure 1.1B, 1.1C and 1.1D). On the other hand, A1, A24, B58 and B62 presented a higher frequency variation among populations (figures 1.2, 1.3 and table 1.2) in some cases with a significant geographic structure (in the case of A1 and B58, both bing very common inside Africa) end represented by a few number of alleles. 
Table 1.2. Supertype differentiation indeces among populations (Fst), within geographic regions (Fsc) and among geographic regions (Fct).

\begin{tabular}{|c|c|c|c|}
\hline Supertypes & Fst & Fsc & Fct \\
\hline$\overline{\mathbf{A 1}}$ & $0.09952 * * *$ & $0.02674 * * *$ & $0.07478^{* * *}$ \\
\hline A2 & $0.04851 * * *$ & $0.03391 * * *$ & $0.01511 *$ \\
\hline A3 & $0.06476^{* * *}$ & $0.06478^{* * *}$ & -0.00003 \\
\hline A24 & $0.11144^{* * *}$ & $0.06662^{* * *}$ & $0.04802 * * *$ \\
\hline NCA & $0.15897 * * *$ & $0.04899 * * *$ & $0.11565^{* * *}$ \\
\hline B7 & $0.05115^{* * *}$ & $0.03208^{* * *}$ & $0.01970^{*}$ \\
\hline B27 & $0.07543 * * *$ & $0.07105^{* * *}$ & 0.00471 \\
\hline B44 & $0.03208^{* * *}$ & $0.01725^{* * *}$ & $0.01509^{* *}$ \\
\hline B58 & $0.08337 * * *$ & $0.02906^{* * *}$ & $0.05594^{* *}$ \\
\hline B62 & $0.11382^{* * *}$ & $0.07355^{* * *}$ & $0.04347^{*}$ \\
\hline NCB & $0.07018^{* * *}$ & $0.02902^{* * *}$ & $0.04240 * * *$ \\
\hline
\end{tabular}

$*: \mathrm{p}<0.01 ; * * \mathrm{p}<0.001 ;{ }^{* *}: \mathrm{p}<0.0001$ 

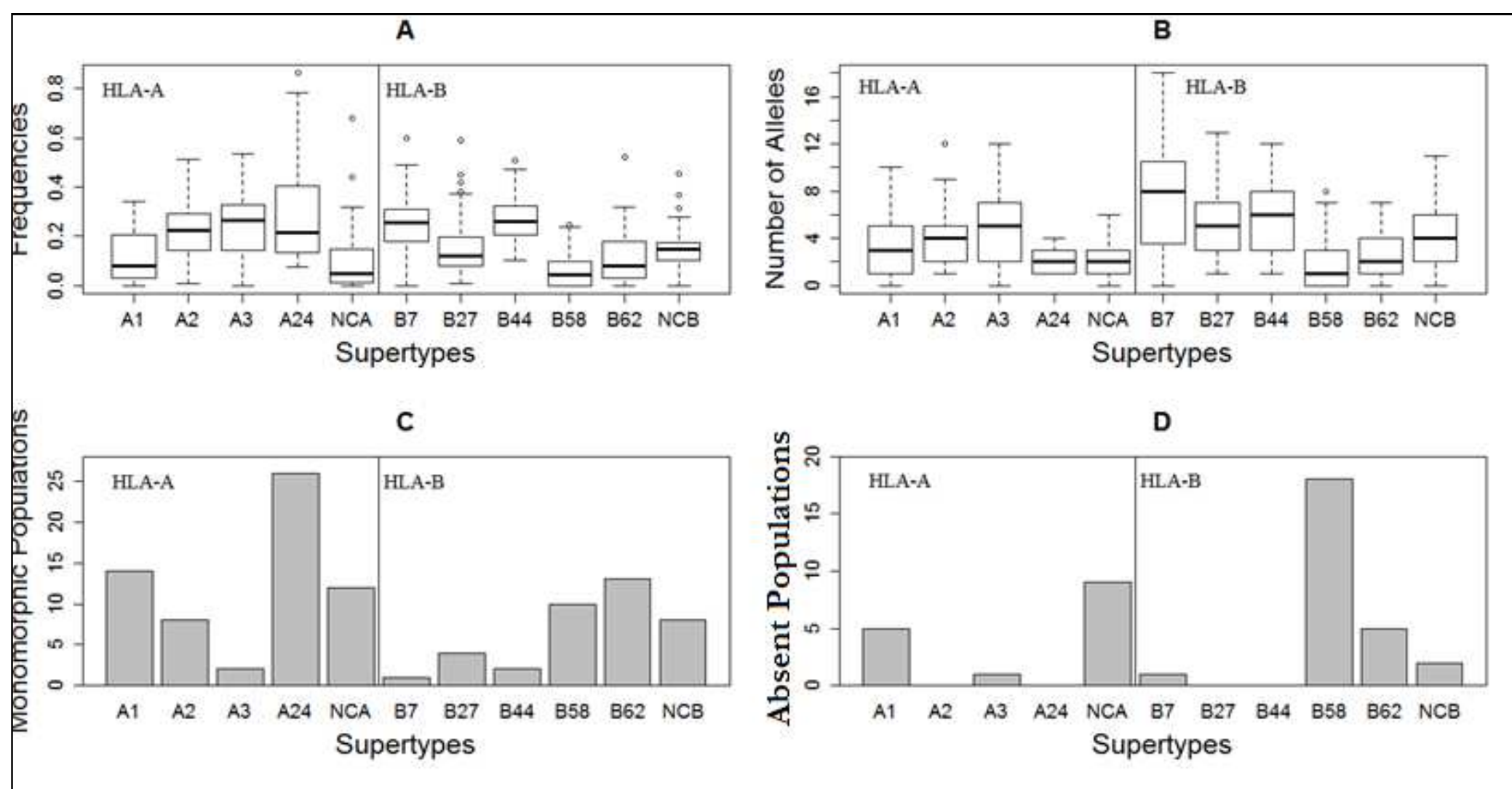

Figure 1.1. Patterns of supertypes observed variation: A. The distributions of frequencies for each of the four $H L A-A$ and $-B$ supertypes and the non-classified alleles; B. Number of observed individual alleles per population belonging to each of the supertypes; C. Number of populations showing just one allele for the referred supertype; D. Number of population lacking the referred supertype. 


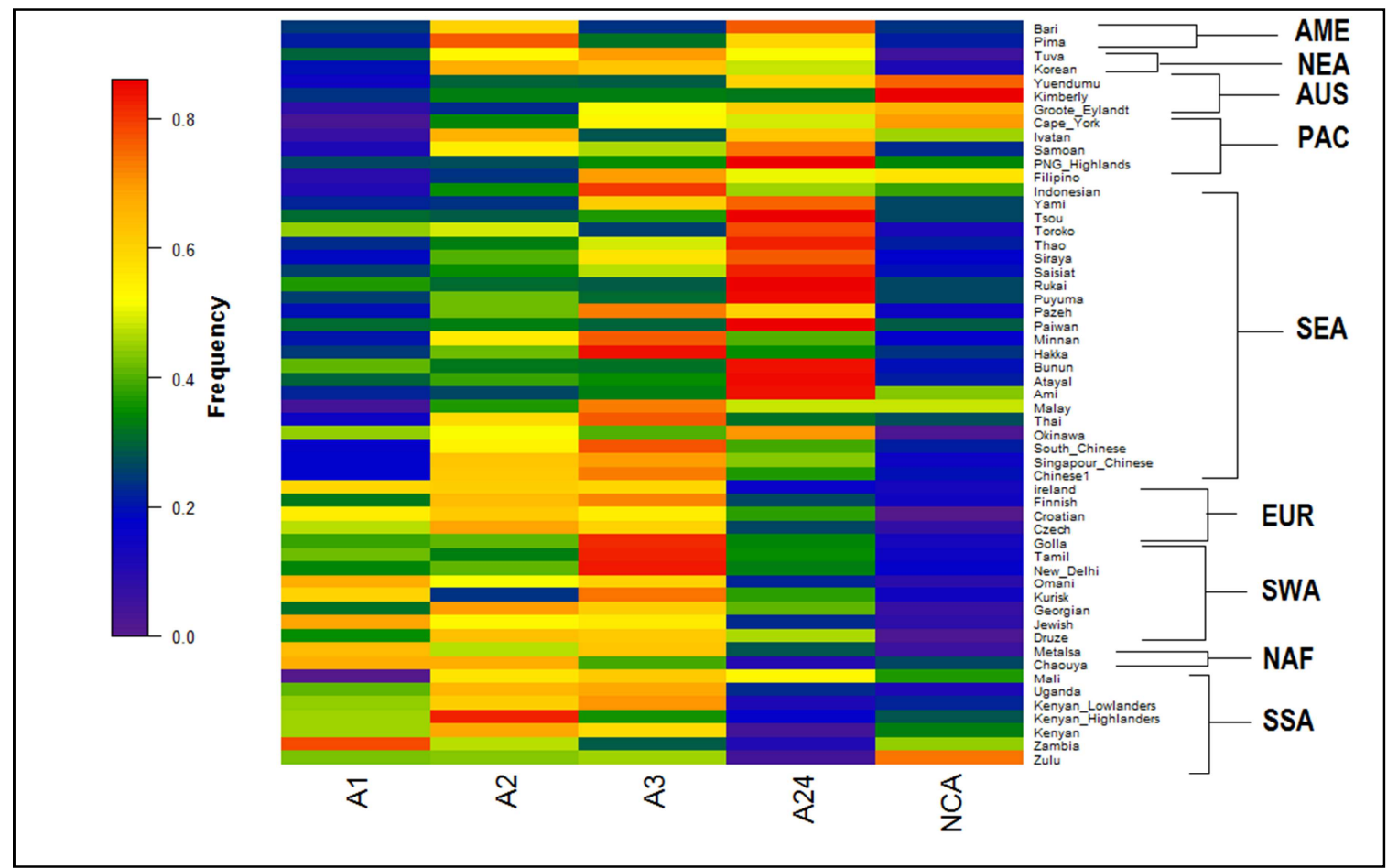

Figure 1.2. HLA-A supertypes frequencies. Color matrix summarizing the frequencies of the four HLA-A supertypes and the group of non-classified alleles. Population names are shown at the right side with the codes for populations regions: SSA, NAF, SWA, EUR, SEA, PAC, AUS, NEA and AME (Sub-Saara Africa, North Africa, South West Asia, Europe, South East Asia, Pacific, Autralia, North East Asia and Americas). 


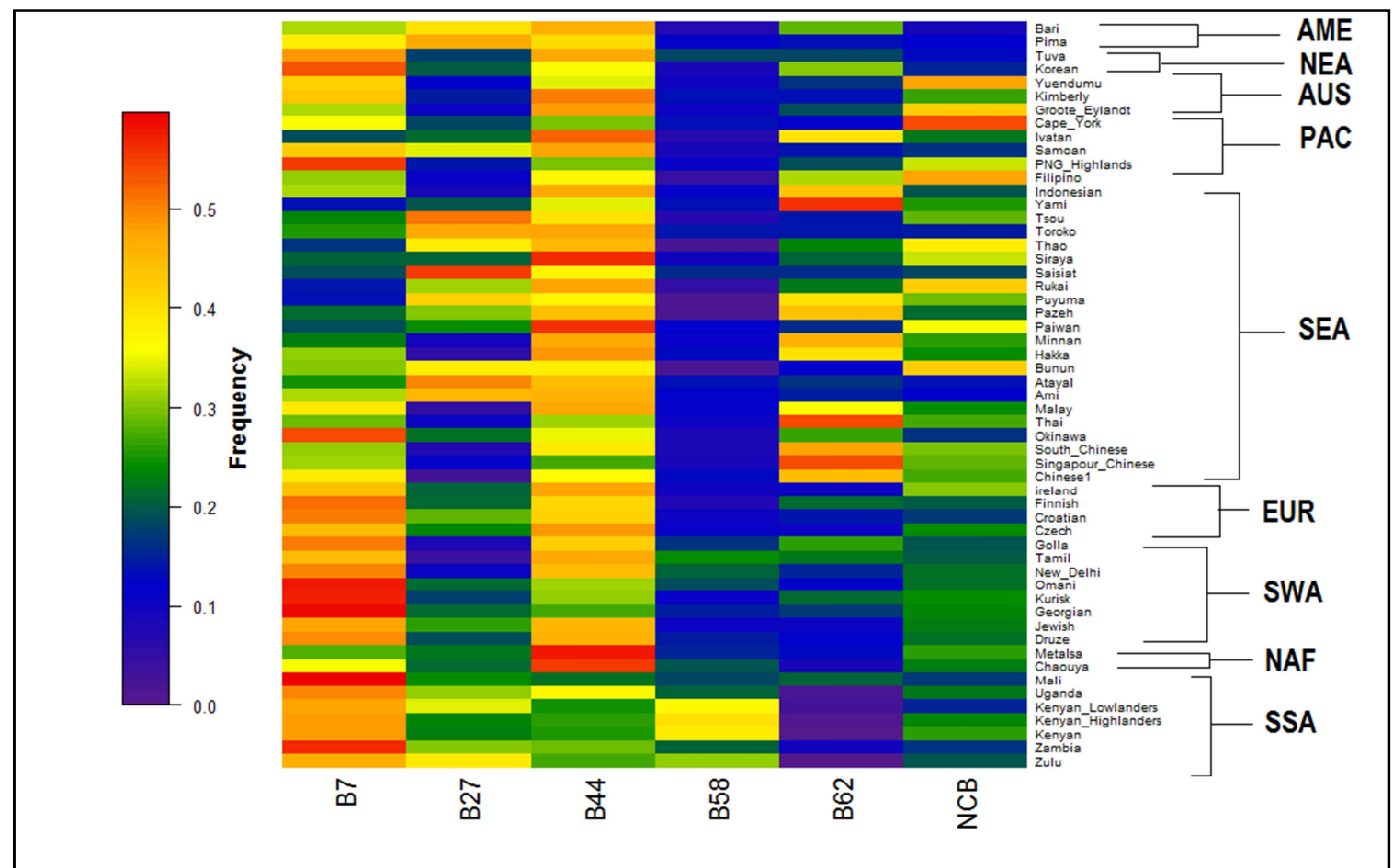

Figure 1.3. $\boldsymbol{H} \boldsymbol{L A}-\boldsymbol{B}$ supertype frequencies. The color matrix summarizes the frequencies of the four $H L A-B$ supertypes and the group of non-classified alleles. Populations names are shown at the right side as the codes for populations regions: SSA, NAF, SWA, EUR, SEA, PAC, AUS, NEA and AME (Sub-Saara Africa, North Africa, South West Asia, Europe, South East Asia, Pacific, Autralia, North East Asia and Americas. 


\subsection{Heterozygosity, interpopulational differentiation and correlation with geography among alleles and supertypes.}

The observed heterozygosity for the data treated at the allelic level of variation was always larger than that obtained for at the supertype level, using both complete and partial datasets. This is expected because alleles are nested within supertypes, so the heterozygosity of superpetypes is constrained to be equal to or smaller than the allelic (table 1.3).

In order to define the degree to which genetic differentiation at the supertype and allelic levels were concordant, we estimated the correlation between these measures for genetic differentiation for all population. Much of the differentiaton among populations measured at the supertype level can be explained by the allele-level differentiation, especially for the $H L A-A$ locus, with as correlation index higher than $0.95(\mathrm{p}<0.0005$, figure 1.4A). A similar pattern was observed for the HLA-B locus (rxy $=0.75, \mathrm{p}<0.0005$, figure 1.4B). The removal of the Pacific, Australian, Tawianese and American Populations provoked an overall drop of the Fst values and correlations. Despite this decrease, we still observed a strong correlation between the levels of differentiation obtained from HLA-A alleles and supertypes ( $\operatorname{rxy}=0.62, \mathrm{p}<0.0005$, figure $1.4 \mathrm{C})$. However, this pattern of correlation was reduced in the reduced dataset for the $H L A-B$ locus, with a reduction of correlation index to $0.30(\mathrm{p}<0.0005$, figure $1.4 \mathrm{D})$.

The decrease in correlation after the removal of the Islanders and Americans was expected because these populations contribute with the large differentiation values. Furthermore, they also have few alleles per supertype, which probably increases the correlations between alleles and supertypes. When these populations were removed we observed a drastic reduction in the correlations in $H L A$ - 
$B$, but not in $H L A-A$, because the later already presents in general a small number of alleles per supertype (figure 1.1B and 1.1C).

Table 1.3. Expected Heterozygosity $(\mathrm{He})$ of alleles and supertypes.

\begin{tabular}{llcc}
\hline Loci & Dataset & Average Allelic He & Average Supertype He \\
\hline $\boldsymbol{H} \boldsymbol{L} \boldsymbol{A}-\boldsymbol{A}$ & Complete & 0.7761 & 0.6774 \\
$\boldsymbol{H} \boldsymbol{L} \boldsymbol{A}-\boldsymbol{A}$ & Reduced & 0.8974 & 0.7504 \\
$\boldsymbol{H} \boldsymbol{L} \boldsymbol{A}-\boldsymbol{B}$ & Complete & 0.8948 & 0.7577 \\
$\boldsymbol{H} \boldsymbol{L} \boldsymbol{A}-\boldsymbol{B}$ & Reduced & 0.9429 & 0.7766 \\
\hline
\end{tabular}



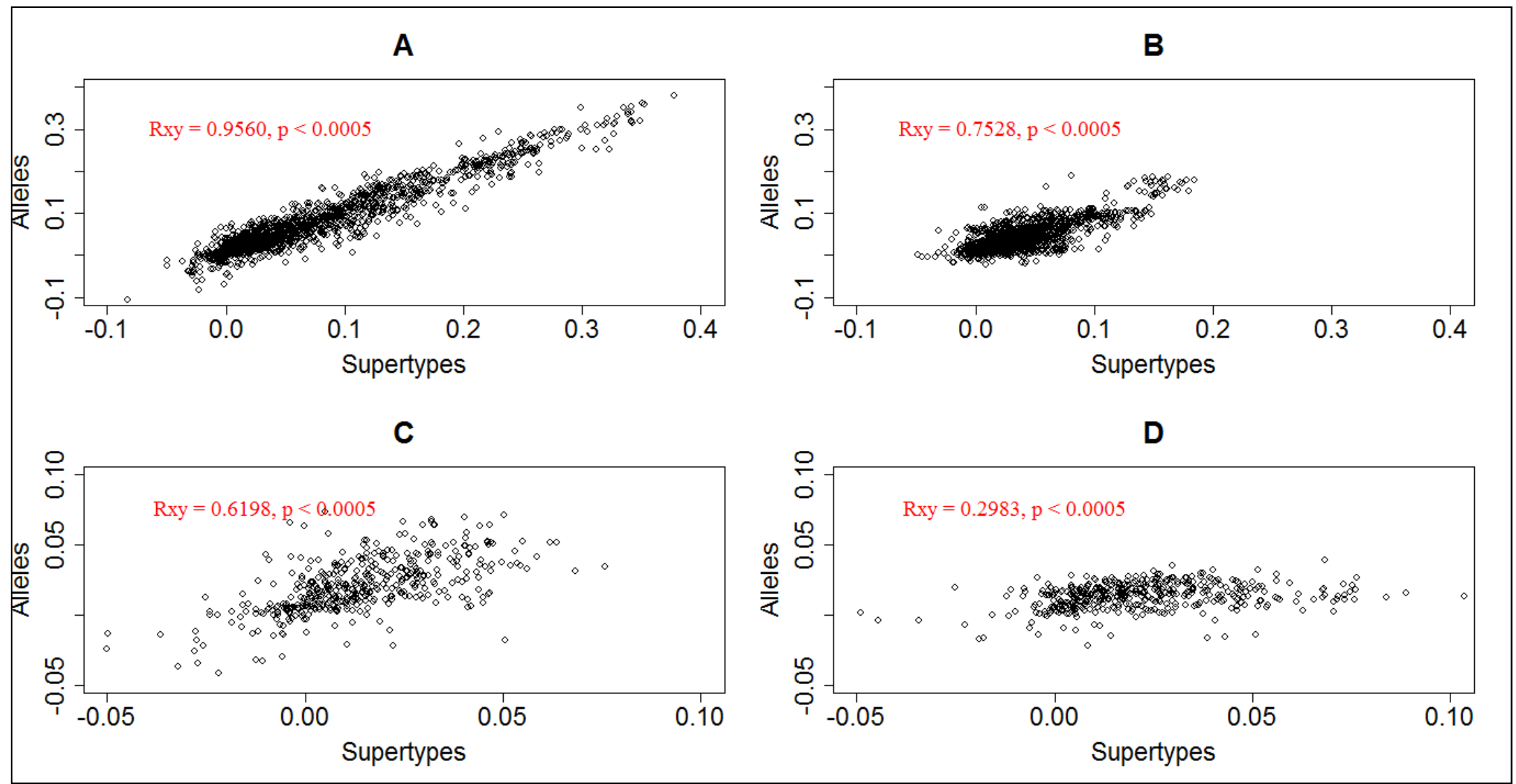

Figure 1.4. Correlation between the Gst among all population pairs, obtained with the alleles and supertypes. The correlation (Rxy) and significance were obtained using a mantel test. A. Correlation from $H L A-A$ loci using the complete dataset; B. Correlation from $H L A$-B loci using the complete dataset; C. Correlation from HLA-A loci using the continental dataset; D. Correlation from HLA-B loci using the continental dataset. 


\subsection{Patterns of molecular variability for different pockets of $H L A$ genes.}

Our goal with the molecular analysis of $H L A-A$ and $-B$ peptide biding region (PBR) was to test the prediction that $\mathrm{B}$ and $\mathrm{F}$ pockets have the highest levels of variation, as a consequence of of their role in peptide binding and consequently of a stronger intensity of balancing selection.

First we compared the global levels of observed variation at $H L A-A$ and $-B$ PBR and observed significantly higher levels of nucleotide diversity $(\pi)$ in the later compared with former locus $(\mathrm{p}<0.0000005$, Wilcoxon rank sum test). Moreover, these genes differed in the way the variation is distributed within the PBR (figure 1.5). The rank order of $\pi$ levels in $H L A-A$ and $-B$ was $\mathrm{pCDE}>>\mathrm{pB}>>\mathrm{pA}>\mathrm{pF}$ and $\mathrm{pB}>>\mathrm{pF}>$ $\mathrm{pCDE}>>\mathrm{pA}$, respectively (where $\mathrm{p}$ is an abbreviation for "pocket", $>>$ indicates a significant difference $(\mathrm{p}<0.00001$, Wilcoxon rank sum test) and $>$ indicates nonsignificant differences; figure 1.5). Among the $H L A-B$ pockets, $\mathrm{pB}$ presented by far the highest variation inside the PBR, with half of the populations exhibiting $\pi$ values ranging from 0.18 to 0.21 (figure 1.5).The remaining $H L A-B$ pockets exhibited a relatively narrow $\pi$ distribution, ranging from 0.10 to 012 in half of the populations (figure 1.5).

Among the $H L A-A$ pockets, most of the variation was found at pCDE pockets, which compose the central region of the PBR, with half of the populations exhibiting $\pi$ values ranging from 0.14 to 0.15 (figure 1.5). The $\mathrm{pB}$ was the second most variable with half of the populations presenting $\pi$ values ranging from 0.11 to 012 (figure 1.5). The pA and $\mathrm{pF}$ showed the smallest levels of variation, with half of the populations exhibiting $\pi$ values ranging from 0.07 to 0.09 (figure 1.5).

The hypothesis that the pockets involved in the supertype specification are the main targets of balancing selection was partially supported for $H L A-B$, since $\mathrm{pB}$ presented by far the highest levels of nucleotide diversity. On the other hand, $\mathrm{pF}$ 
exhibited relatively lower $\pi$ levels in both loci, but it was not significantly different from $\mathrm{pA}$ and $\mathrm{pCDE}$ in $H L A-A$ and $-B$, respectively, indicating that $\mathrm{pF}$ does not present a signature of balancing selection comparable to the remaining regions of the PBR. It is important to note that these results were obtained independently of the alleles classification into supertypes, since the determination of the pockets codons were obtained from the classical study of Saper, Bjorkman, and Wiley (1991).

Finally, we analyzed how the nucleotide diversity is distributed between supertypes. Since the supertype categorization is based on the variations of $\mathrm{pB}$ and $\mathrm{pF}$, it was expected that these pockets would present most of the differences between supertypes. Indeed, this prediction was confirmed in both loci, since $\mathrm{pF}$ and $\mathrm{pB}$ concentrate most of the differences between $H L A-A$ and $-B$ supertypes, respectively (figure 1.6). As $\mathrm{pB}$ presents the highest levels of variation in $H L A-B$ and also accounts for most of the the differences between $H L A-B$ supertypes, we conclude that variation between HLA-B supertypes accounts for most of the differences observed between $H L A-B$ alleles. In other words, alleles classified into the same $H L A-B$ supertype share more similarities than alleles assigned to different supertypes.

On the other hand, as most of the differences between $H L A-A$ supertypes lie at $\mathrm{pF}$, the pocket presenting the lowest pi values for this gene, most of the variation between alleles are not accounted by the HLA-A supertypes (figure 1.6). In other words, $H L A-A$ locus present more variation within supertypes then between them. 


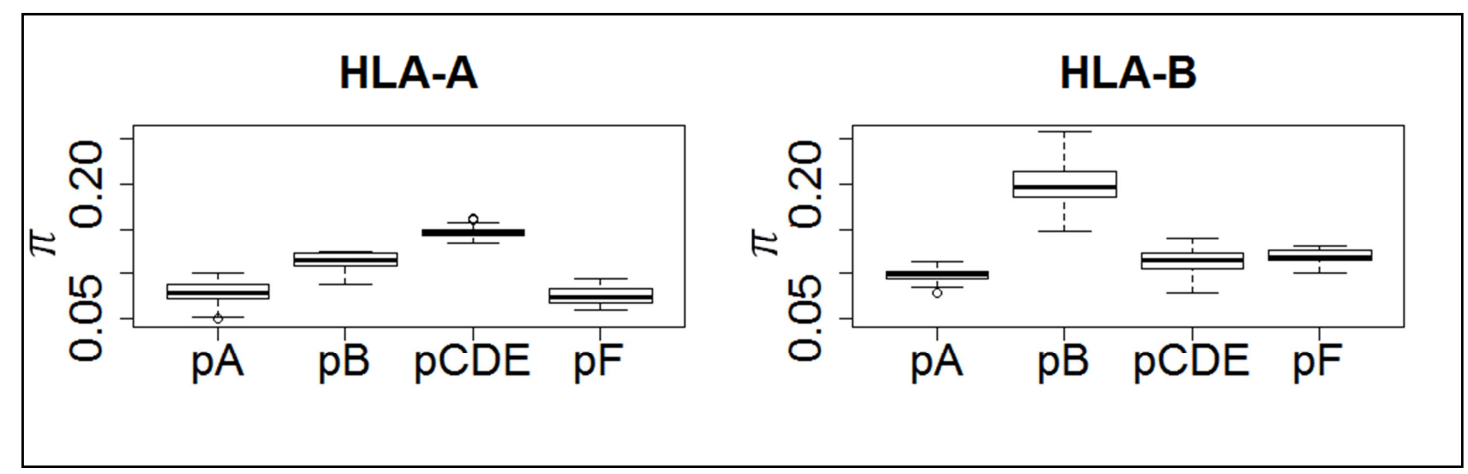

Figure 1.5. Nucleotide diversity ( $\pi$ ) distribution among $H L A-A$ and $-B$ pockets: each box represents the nucleotide diversity distribution among the populations of the complete dataset.

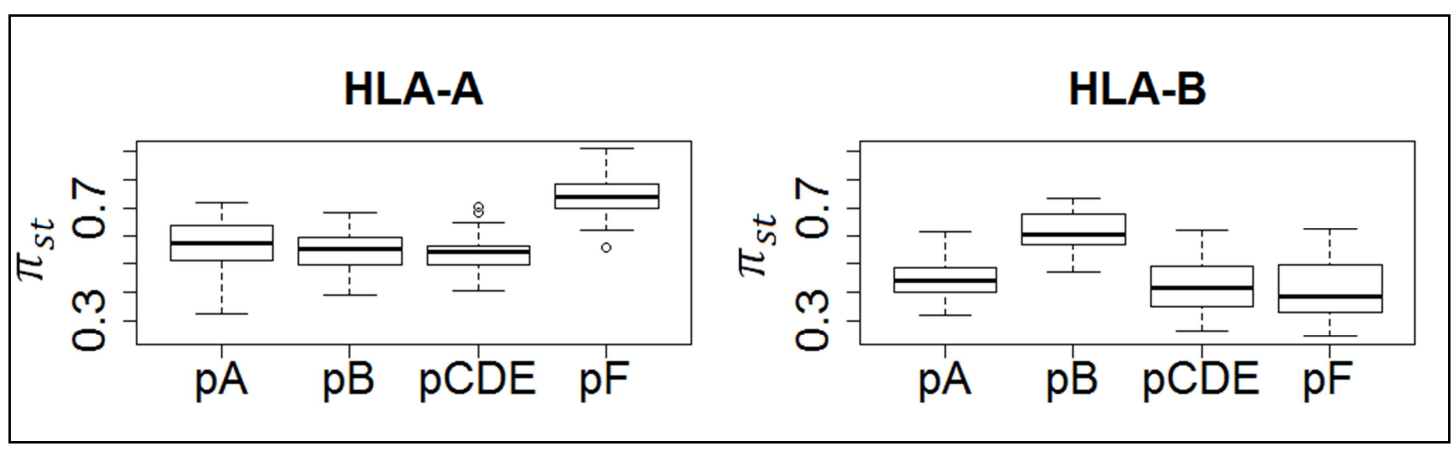

Figure 1.6. Proportion of $=$ nucleotide diversity between supertypes $\left(\pi_{\mathrm{st}}\right)$ for $\boldsymbol{H L A}$ $\boldsymbol{A}$ and $-\boldsymbol{B}$ pockets: each box represents the proportion of nucleotide diversity distribution among between supertypes among the populations of the complete dataset.

\subsection{Simulations results.}

Alleles included in the same supertype have overlapping peptide biding specificities. The assignment of alleles to supertypes was randomized by permuting the supertype labels attributed to each allele motif allowing us to test the effect of supertype classification upon heterozygosity and differentiation. As the same patterns were obtained using the two different simulation approaches (see materials and methods), we will present the results generated with the second one, in which we did not impose constraints on the number of alleles associated to a specific supertype. 
For $H L A-B$, we observed six out of 55 populations exhibiting significant lower expected heterozygosities $(\mathrm{He})$ than the predicted by the simulations $(\mathrm{p}>0.95$; figure 1.7) and the same six populations also showed significant deviation at the reduced dataset. For $H L A-A$, we did not observe any significant results. Because the number of populations with individually significant p-values in either direction is low in our dataset, we investigated if the distribution of the p-values themselves are informative about a selective regime. To do this, we tested whether the entire distribution of $\mathrm{p}$-values deviated from the expectation of equal numbers of values to either side o 0.5 , by implementing an exact binomial test; figure 1.7). Doing this, we found that for $H L A-B$ there is a significant skew towards $p$-values greater than $0.5(\mathrm{p}<0.05$ and $\mathrm{p}<0.005$ for the complete and reduced datasets), indicating that observed datasets tend to have lower He than the simulated ones. On the other hand, at the $H L A-A$ locus, there was no clear tendency of higher or smaller simulated He values when compared with the observed dataset.

We did not obtain significant departures from the simulated Gst values with the complete dataset, for both $H L A-A$ and $-B$. However, with the reduced dataset, the observed Gst was higher than $98 \%$ of the simultations for $H L A$-B (figure 1.8). For $H L A-A$, we did not observe significant departures from the simulations distributions even with the reduced dataset (figure 1.8).

Although this result seems counterintuitive based on Sidney et al. (1996) who predicted an overall decrease in differentiation at the supertype level, it is in agreement with our description of the observed data. In our simulations, alleles were randomly assigned to groups, creating randomized supertypes with similar contents of common and rare alleles. The common alleles are expected to be assigned to different randomized supertypes in most of the simulations, just because they are less numerous than rare alleles. This is the same patterns we described for real HLA-A supertypes, which 
presented a low number of common alleles per populations (figure $1.1 \mathrm{~B}$ and $1.1 \mathrm{C}$ ). As we already discussed, this pattern also explains the high correlation between the Fst measured at the allelic and supertype levels (figure 1.4). Finally, as we discussed for molecular data, there is less variation between $H L A-A$ supertypes than within them, indicating that $-A$ supertypes are composed by a heterogeneous set of alleles with few similarities at the $\mathrm{pF}$ (figures 1.5 and 1.6), which facilitates the reproduction of the observed patterns of variation by the simulations.

On the other hand, HLA-B supertypes seem to be composed by alleles which share more sequences similarities between each other, as demonstrated by the molecular analysis (figures 1.5 and 1.6). In a simple way, $H L A-B$ supertypes are sets of alleles which share B pockets resemblances. These similarities can be interpreted directly in terms of the peptide presentation profiles, since $H L A-B$ supertypes exhibit profound differences in the chemical properties of $\mathrm{pB}$. Thus our results of increased differentiation at the observed $H L A-B$ supertypes may reflect the local adaptation of populations to different pathogen environments.

The simulations disrupted the patterns of allelic structure exhibited by $H L A-B$ supertypes, creating randomized groups in the same way we described for $H L A-A$. The frequent allocation of common alleles into different randomized supertypes during the simulations provoked an increase of the He and decrease of population differentiation, when compared with the observed data at the HLA-B locus (figures 1.7 and 1.8).

The inclusion of the Islanders and American populations reduced this effect, because the patterns of variation for $H L A-B$ at these populations resembles the observed for $H L A-A$, with a relatively low number of alleles belonging to different supertypes. 

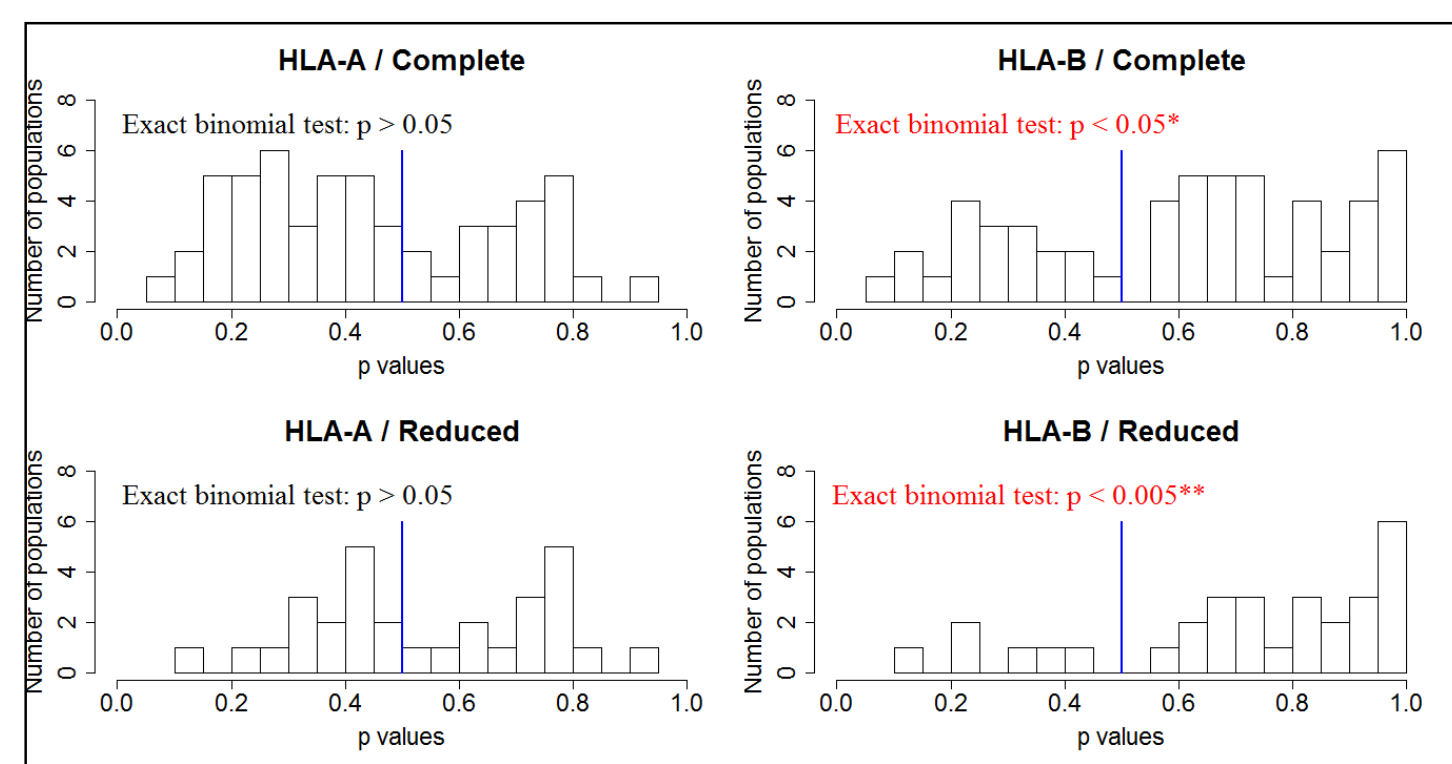

Figure 1.7. Histograms of p-value distributions obtained with simulations involving the expected Heterozygosity $(\mathrm{He})$ for each of the analysed populations: each bar represents the number of populations which presented a p-value included into a 0.05 interval delimited by the $\mathrm{X}$ axis. The $\mathrm{p}$-value was defined as the proportion of simulated datasets with He larger than the observed He. Results obtained with the complete and reduced dataset are shown.

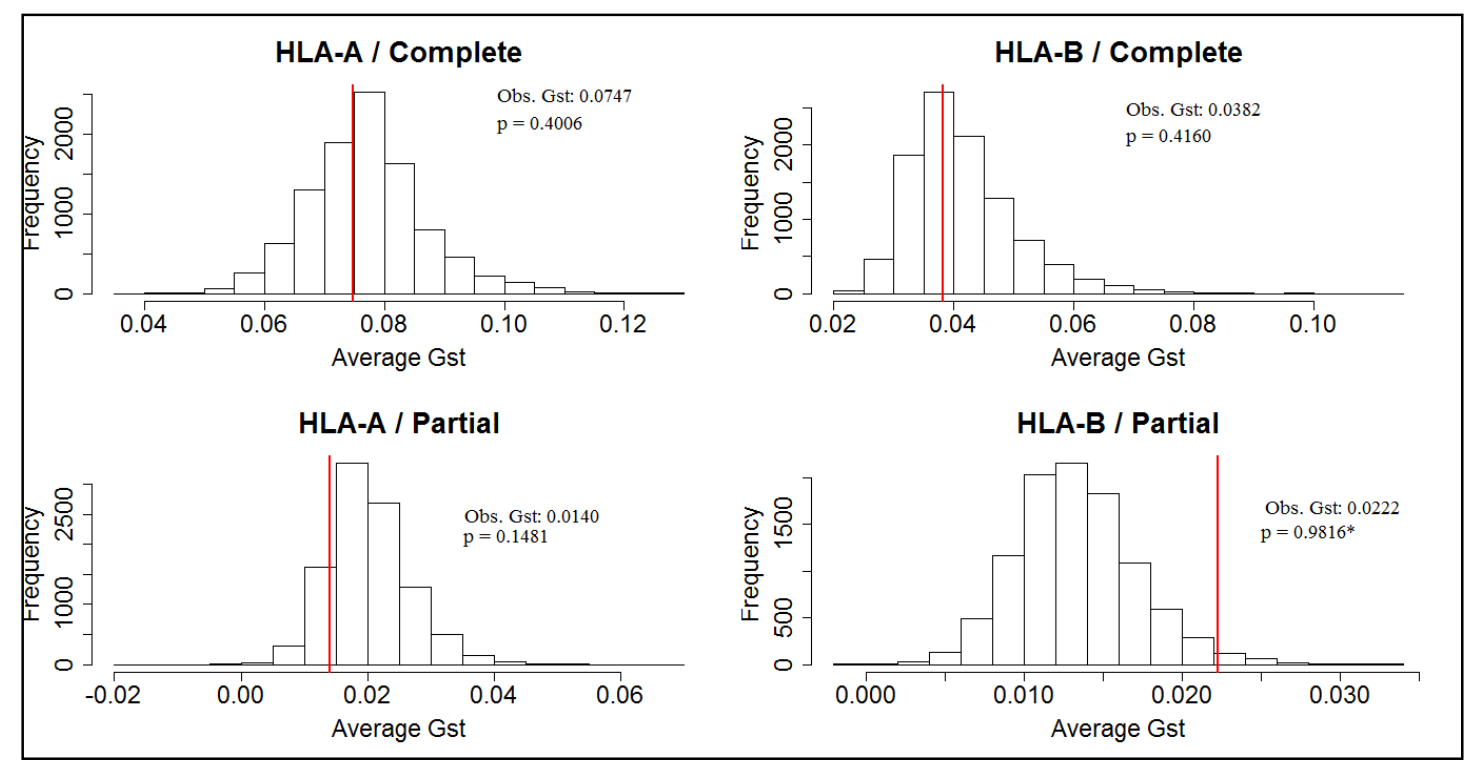

Figure 1.8. Simulations results for Gst. The red line represents the average observed Gst. We calculated the average Gst value for each simulated step and then determined the significance as the proportion of simulated values smaller than the observed.

The results with the complete and reduced (partial dataset are shown). 


\section{Conlusions}

The supertype classification of $H L A-A$ and $-B$ alleles has been widely used in medical reseach, with the report of supertype variants contributing with the progression and/or resistence of series of pathogenic desease. This classification was proposed in the 90s as an attempt to find, as described by Sette and Sidney (1999): "the common denominators and similarities hidden within this very large degree of polymorphism". These same authors also stated that: "the overall frequency of each of these supertypes is remarkably high and fairly conserved among very different ethnicities. Thus, there might be some advantage for human populations to present approximately five to ten main binding specificities, and that each one of these is maintained at relatively high frequency".

Indeed, at least for $H L A-B$ locus, supertypes seem to reflect the common denominator of an incredible amount of diversity, since most of the molecular variability we found at the PBR for this locus is accounted by differences between supertypes. We also demonstrated that the B pocket is probably the main target of the natural selction at this locus, presenting the highest levels of variation at $H L A-B$, and accounting for the main differences in the peptide presentation profiles from this gene.

On the other hand, HLA-A supertypes appear to be composed by few representative alleles in terms of frequencies and most of the differences between alleles at this locus are not structured between supertypes.. 


\section{Capítulo 2: Evolution of HLA genes in the}

\section{American continent.}

\section{Introduction}

The HLA genes (human leucocyte antigens), located in the human Major Histocompatibility Complex (MHC) are among the most polymorphic loci in the human genome (The MHC sequencing consortium 1999). A large number of studies have been performed trying to disentangle the evolutionary mechanisms which drive such high levels of diversity (Albrechtsen, Moltke, and Nielsen 2010; Apanius et al. 1997; Bustamante et al. 2005; Hughes and Nei 1988; Knowles 2003; Meyer and Thomson 2001; Solberg et al. 2008). The role of the HLA molecules in the presentation of antigens to $\mathrm{T}$ lymphocytes during the first steps of the adaptive immune response (Doherty and Zinkernagel 1975) and their regulatory effect on natural killer (NK) cells via interaction with KIR receptor make the pathogen driven selection one of the most accepted mechanisms for the maintenance of the high levels of diversity in these genes (Gillespie 1977).

There is a substantial body of work showing the association between HLA polymorphism and the resistance or susceptibility to infectious deceases (Carrington et al. 1999; Kaslow et al. 1996; Hraber, Kuiken, e Yusim, 2007; Campos-Lima et al. 1997), as well as correlations between levels of HLA allelic variation and regional pathogen diversity (Prugnolle et al. 2005; Qutob et al. 2011; Sanchez-Mazas, Lemaître, and Currat 2012). These studies corroborate the idea that pathogens probably played a central rule in HLA evolution, leaving signs strong enough to surpass the dominant effect of human demographic history. 
Among the evolutionary models of natural selection that can account for the increased diversity at HLA loci, strong support is found for those the invoke the coevolution of pathogens and HLA (Borghans, Beltman, and De Boer 2004). Computer simulations have shown that these models predict that populations settling at different geographic locations would present distinct $H L A$ allelic profiles providing adaptation to local immune challengers (Borghans, Beltman, and De Boer 2004).

In this context, studies involving Native American populations can be extremely valuable for understanding how the HLA genes have evolved recently on a regional scale. Multiple lines of evidences indicate that the occupation of the American continent occuried relatively recently, making it the last large continental regions to be occupied by modern humans. During the north-south occupation, the ancestral Amerindian population was exposed to a striking variety of biomes, from the Nearctic region to the tropical landscapes from eastern South America, which probably was associated with a change on the pathogen profile faced by these populations. Based on the co-evolution hypothesis, we would expect to find genetic differences among Native American populations from different regions, which would indicate local adaptations.

In the early 90s, Belich et al (1992) and Watkins et al (1992), described a series of $H L A-B$ alleles found only in south American populations, and completely absent in all other world regions, contrasting with the general pattern obtained with others genetic markers like mitochondrial DNA, Y chromosome and even other $H L A$ genes like $H L A$ $A$ and $H L A-C$, in which the American variation is a subset of what is observed in Asia. Most of these new $H L A-B$ alleles were originated by gene conversion involving Asiatic alleles.

To explain these observations these authors proposed the hypothesis of allelic turnover, which has a point of departure the fact that ancestors of the native South American populations would have left the glacial environment from North 
America and started to face the higher levels of biodiversity of endemic pathogens during the colonization of the southern reaches of the American continent. This process would have resulted in the selective pressures favoring new alleles, which were adaptive in the face of novel pathogens. The new alleles eventually replaced the old ones and the small effective population size associated with low levels of gene flow between populations would have contributed to the process of replacement of the old alleles by new ones. (Belich , Madrigal et al , 1992; Watkins , Mcadam et al ., 1992; Cadavid and Watkins , 1997; Parham Arnett et al. 1997).

Although, previous studies have described the frequencies of HLA alleles in American population, none has explicitly tested the turnover hypothesis. Here, we investigate the turnover model by analyzing the correlation between the presence of alleles originated by gene conversion at high frequencies and deviations from neutral expecations. Our expectation is that under the turnover model, the rise of the new alleles would result from natural selection.

In order to examine the geographic distribution, allele frequencies and evidence for selection at $H L A$ loci we investigated the variation of three $H L A$ genes $(-B,-C$ and DRB1) using a large dataset consisting of samples from 32 Native American populations, increasing the number of population of the eastern region of the South American continent (13 populations), which was systematically underrepresented in previous research on HLA variation.

Another challenge we faced, common to all studies that deal with natural selection in the context of populations with unknown and complex demographic histories, consists in devising approaches to diesentangle the effects of selection and demographic history upon the observed variation. Various studies, using both genetic and morphological data, indicate that Eastern South America has marked differences in its distribution of genetic variation, with lower levels of diversity and distinct genetic 
makeup, with respect to other native American populations, indicating the important role of genetic drift and the lower levels of gene flow could have in the constructions of the patterns of variation in this region of the American continent.

In our study, we used a dataset consisting of 61 microsatellite markers, spread throughout the genome in the same populations as were typed for the HLA loci. This data gave us insights about specific demographic events (e.g., recent bottlenecks resulting in loss of diversity) allowed us to create the background scenario for the discussion on the patterns of variation at the HLA loci.

\section{2- Methods and Materials}

\section{1- Population sampling.}

We analyzed 32 populations which were divided into five groups based on geographic and linguistic criteria, following Yang et al. (2010). The groups and populations are North America (NAM): Chipewyan, Cree and Ojibwa; Meso-America (MAM): Mixtec, Mixe, Zapotec, Quiche and Wayuu; Northwest South America (NWSAM): Cabecar, Guaymi, Kogi, Arhuaco, , Zenu, Embera, Waunana; West South America (WSAM): Inga, Quechua, Aymara, Huilliche; East South America (ESAM): Arara do Iriri, Arara, Kayapo Krokaimoro, Kayapo Xicrim, Kaigang, Parakanã, Araweté, Urubu Kaapor, Asurini, Guarani Kaiowá, Ticuna Arara, Ticuna Tarapaca, Ache.

All populations belong to the Amerindian linguistic group except the Chipewyan, a Na Dene population, which was included in the North American group due to the high level of genetic similarity with Cree and Ojibwa Populations (Wang et al. 2007)(Reich et al. (2012). 


\section{2- Microsatellite dataset.}

We used a subset of 61 out of the 678 autosomal microsatellites extracted from the dataset analysed by Wang et al. (2007). The data from non-Brazilian samples was obteined directaly from the dataset presented by Wang et al. (2007) whereas the Brazilians dataset was generated by the post graduate student Kelly Nunes during her Phd thesis (data nor published yet). The final microsatellites dataset we used in the presente study consited in 32 populations, 22 of them obteined from the Wang et al. (2007) and the remaining ten populations generated by our group (Suplementary Material)

\section{3- $H L A$ typing.}

The region comprising the exons 2 and 3 from $H L A-B$ and $-C$ was amplified and alleles typing were carried for each individual. In-house PCR primers were used to amplify each locus (SumpkeS2). Applied Biosystems Big Dye terminator chemistry and sequencing primers were used to obtain the sequences of both strands of exons 2 and 3 . The HLA-DRB1 locus was amplified and sequenced using the AlleleSEQR class II kit (Abbott Molecular Inc, Des Plaines, IL). Reaction products were identified with Applied Biosystems 3730xl DNA analyzer (PE Applied Biosystems, Foster City, CA) and sequence interpretation used Assign software (Conexio Genomics, Applecross, Western Australia).

\section{HLA nomenclature:}

The nomenclature of HLA alleles follows the rules of the World Health Organization (WHO) Nomenclature Committee (Robinson et al. 2011). An HLA allele corresponds to a unique sequence comprising at least exons 2 and 3 for class I and exon 2 for class II loci. The allele name carries the information of which locus the corresponding allele 
belongs followed by an "*" and an unique number ranging from two to four sets of

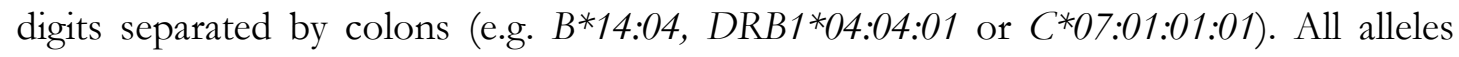
receive a name with at least two sets of digits. The digits before the first colon describe the lineage, which often corresponds to the serological HLA antigen (e.g. $B^{* 51}$ or

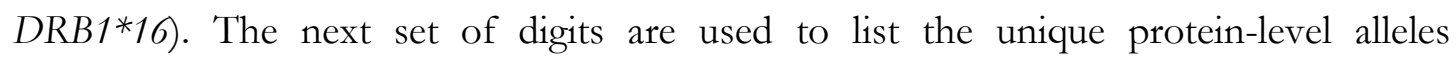
belonging to the same linage (e.g. $B^{* 15: 04}$ and $B^{* 15: 08)}$ ). Alleles whose names differ on the first two sets of digits must differ by one or more non-synonymous mutations. Alleles that differ only by synonymous mutations are distinguished by the use of the third set of digits (e.g. $C^{*} 03: 04: 02$ and $\left.C^{*} 03: 04: 03\right)$. Alleles that only differ by sequence polymorphisms in non-coding regions (introns and/or in the $5^{\prime}$ or $3^{\prime}$ untranslated regions) are distinguished by the use of the fourth set of digits $(D R B 1 * 15: 01: 01: 01$ and $D R B 1 * 15: 01: 01: 02)$.

The HLA alleles whose sequences differ outside the exons 2 and 3 for class I and exon 2 for class II loci are grouped and identified using an upper case 'G' after the third set of digits of the lowest numbered allele in the group (e.g. $B^{* 15: 01: 01 G}$ and $\left.C^{*} 08: 01: 01 G\right)$.

As we discussed before, the dataset we used in this study was generated by sequencing of exons 2 and 3 for class I genes and exon 2 for HLA-DRB1. Therefore, we will present results at the highest possible typing resolution level. Eventually, we have found genotype ambiguities, when more than one pair of alleles is compatible with the observed sequence. These ambiguities were resolved with allele specific primers and in some cases applying the following frequency criteria: 1) an internal criterion based on the allelic composition of non-ambiguous genotypes we have found in the same populations in which the ambiguity were observed. In this case, the inferred genotype was composed by alleles we found in homozigose and/or non-ambiguous combinations; 2) An external criterion using published datasets (Gonzalez-Galarza et al. 2011; Solberg et al. 2008), 
taking into account the alleles frequencies in populations at the same region than the one in which the ambiguities were observed.

\section{4- Data Analysis}

Population variability: We used the Arlequin software package (Excoffier and Lischer 2010) to estimate the allele frequencies from the genotypes using the ExpectationMaximization (EM) algorithm (Slatkin and Excoffier 1996) the number of alleles (k), and the observed and expected sample heterozygosity (Ho and He respectively). We also used Arlequin to perform the test for deviations from Hardy-Weinberg proportions using an exact test developed by Guo and Thompson (1992).

Haplotype inference: Haplotypes were inferred using the EM algorithm as implemented in Arlequin. Haplotypes with estimated frequency lower than the standard error were disregarded from subsequent analyses.

Allele Sharing between Populations: We estimated the degree of allele sharing between all pairs of populations using the Prevosti's Distance (Prevosti, Ocaña, and Alonso 1975; Wright 1978), defined as:

$$
D=\frac{1}{2} \sum_{i=1}^{k}\left|p_{i}-q_{i}\right|
$$

where $\mathrm{p}$ and $\mathrm{q}$ are the frequencies of the ith allele on populations 1 and 2 and $\mathrm{k}$ is the number of observed alleles in these populations. A value of Prevosti's Distance (D) equal to 1 is obtained from pairs of populations that do not share alleles while a $D=0$ is obtained when the same alleles are observed at the same frequencies in both populations. Thus the prevosti's D value represents the direct proportion of differences on the 
observed allele frequencies between a pair of populations. We implemented this measure using the R package (S2).

Tests of neutrality. We tested for departure from neutrality-equilibrium using two methods implemented in Arlequin 3.5, which capture different time scales of selection:

1) The Ewens-Watterson test (Ewens 1972; Watterson 1978), which utilizes the sample's homozygosity $(\mathrm{Fo})$ as an estimator of the allelic distribution and compares it with the expected homozygosity $(\mathrm{Fe})$. The Fe is estimated based on the sampling theory of alleles proposed by Ewens 1972, which predicts that populations evolving under neutrality and equilibrium would present no significant differences between Fo and Fe. Based on this theory, it is expected to find $\mathrm{Fo}>\mathrm{Fe}$ in samples containing one or two higher frequencies alleles followed by many lower frequency alleles, which is compatible with the action of directional selection or population expansion. On the other hand, $\mathrm{Fo}_{\mathrm{O}}<\mathrm{Fe}$ is expected from samples containing alleles in intermediate frequencies, which is compatible with the action of balancing selection, recent population bottlenecks or cases when two isolated populations are merged together.

2) Tajima's-D test (Tajima 1983) which compares two estimators parameter $\theta$ $(4 \mathrm{~N} \mu), \pi$ (the average number of nucleotide differences between pairs of sequences) and $\mathrm{S}$ (the number of segregating sites in the sample, normalized by a value proportional to the sample size). Tajima (1989) demonstrated that under neutrality and equilibrium the expectation of the difference between these estimators (Tajima's D) is equal to zero. It is expected to obtain positive Tajima's $\mathrm{D}$ values when polymorphisms at intermediate frequencies are present in the samples, which is expected under the action of balancing selection or recent population bottlenecks. Negative values D are obtained from samples containing 
a large proportion of lower frequencies polymorphisms in its sequences, which expected under directional and/or negative selections or population expansion.

\section{3- Results And Discussion}

\subsection{Deviations from Hardy-Weinberg proportions.}

We performed a total of 96 Hardy-Weinberg tests (32 populations at 3 loci) and three, one and two deviations were detected at the 5\% significance level at $H L A-B,-C$ and $-D R B 1$ loci respectively (only one deviation at $1 \%$ level for both $H L A-B$ and $-D R B 1$ loci) (table 1-S2). Deviations are due to an excess of homozygotes except for Kogi population. This overall result would indicate the presence of null alleles. However, six deviations spread for all loci are very close to that expected by chance alone (5 deviations) and none of them have remained significative after the correction for multiple tests, suggesting the absence of null alleles and the eficience of our methodology. 


\subsection{Allele frequency distributions of $H L A$ loci.}

\subsubsection{General patterns.}

The HLA-B locus exhibited the highest differentiation, with $50 \%$ of the pairs of populations presenting a Prevosti's Distance ranging from 0.74 to 0.92 (with a median value of 0.86 ; figure 2.1). On the other hand, $H L A-C$ locus exhibited the smallest Prevosti's D median (0.59) and a broader distribution, with $50 \%$ of the pairs of population presenting a Prevosti's D ranging from 0.48 to 0.73 (figure 2.1). The HLADRB1 locus showed an intermediate pattern, with 50\% of the populations pairs presenting a Prevosti's D ranging from 0.58 to 0.82 with a median of 0.70 (figure 2.1).

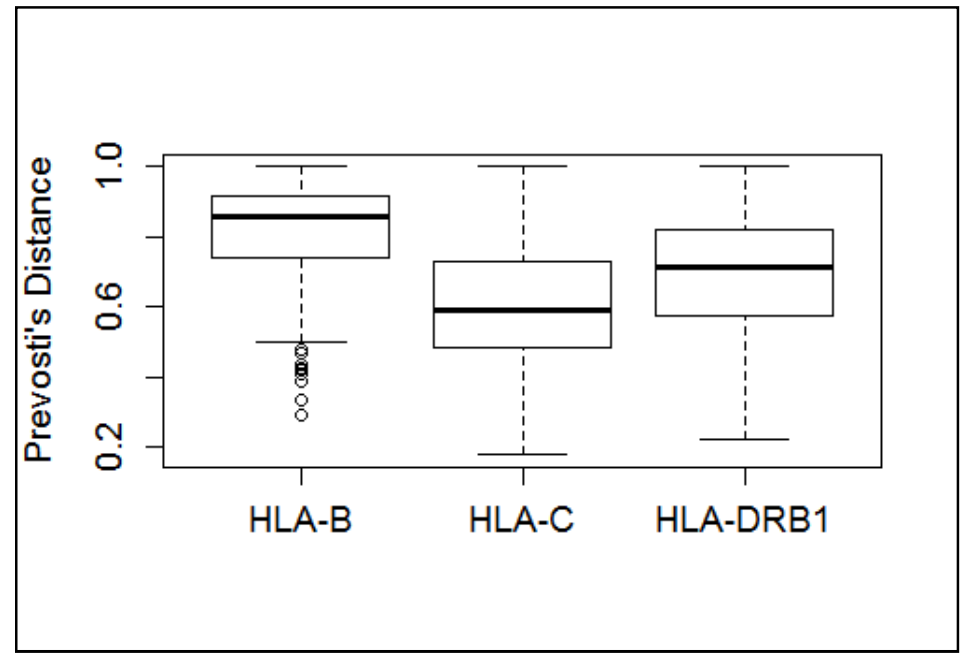

Figure 2.1. Prevosti's Distance distributions between pairs of populations for $H L A-B,-C$ and $-D R B 1$ loci.

The HLA-B locus displayed the highest number of populations pairs in which we did not observe sharing of alleles (Prevosti's $D=1$ ), with a total of 44 pairs against 4 and 6 for HLA-C and -DRB1 loci, respectively (figures 2.3 to 2.5). A total of 39 out of these 44 pairs included a population from the eastern region of South America (SAE), making this region the highest contributor for the elevated Prevosti's D values we obtained on the HLA-B and -DRB1 analysis (figures 2.3 to 2.5 ). 
The distinct HLA-B allelic component we observed in SAE were generated by gene conversion or in some cases recombination involving the $B^{*} 15: 01: 01 G$, $B * 27: 05: 02 G, \quad B * 35: 01: 01 G, \quad B * 37: 01: 01, \quad B * 39: 01: 01 G, \quad B * 40: 02: 01 G, \quad B * 44: 02: 01 G$, $B * 48: 01: 01 G$ and $B * 51: 01: 01 G$ alleles, as shown in Figure 1-S2. (hereinafter called parental alleles) which were found in North American populations (S2) and previously described in Northeast Asia (Gonzalez-Galarza et al. 2011; Robinson et al. 2011; Solberg et al. 2008). An alternative hypothesis to explain the emergence of the recombination/gene conversion alleles would require an incredible level of homoplasy to account the small stretches of sequences shared by them and the parental alleles (S2).

The HLA-B recombination/gene conversion alleles were practically absent in North American populations and start to appear in the Mesoamerican region (figure 2.6A and 2.6B). On the other hand, SAE populations exhibit the highest frequencies of these alleles except for Ticuna_N, Ticuna_S, Kaigang, Urubu Kaapor and Arara do Iriri, which presented cumulative frequencies of the recombination/gene conversion smaller than 0.50 (figure $2.6 \mathrm{~A}, 2.6 \mathrm{~B}$ and $2.6 \mathrm{C}$ ).

We tested for a correlation between the frequencies of recombination/gene conversion alleles and the distance from the Bering Strait. A weak but significant correlation was obtained when all populations were considered $\left(\mathrm{r}^{2}=0.34, \mathrm{p}<0.001\right)$ but it was lost after the removal of the North American populations $\left(\mathrm{r}^{2}=0.07, \mathrm{p}<0.15\right)$ (figure 2.6C). This result indicates that the frequencies of the recombination/gene conversion $H L A-B$ alleles are not gradually increasing from north to south on the American continent, but they show a small [ rise in frequency starting from the Mesoamerican (MAM) region, and then reach their maximum in the SAE populations (figure 2.6). Furthermore, according to the Prevostis's D results, different sets of recombination/gene conversion alleles were found in distinct regions of the American 
continent (we will present a detailed description of the allelic content in the American populations in the next section).

The differences in the allelic frequencies we observed for HLA-DRB1 locus between the American regions could not be associated with the emergence of new alleles, except by $D R B 1 * 08: 07$ (which we will discuss in the next section). For both HLA-C and -DRB1 loci, the same alleles were found along different American regions and except for $D R B 1 * 08: 07$, all of them were previously described in Asian populations (see next section). Moreover, we could not distinguish any clear signal of recombination/gene conversion involving the observed alleles for either HLA-C and -DRB1 loci. 


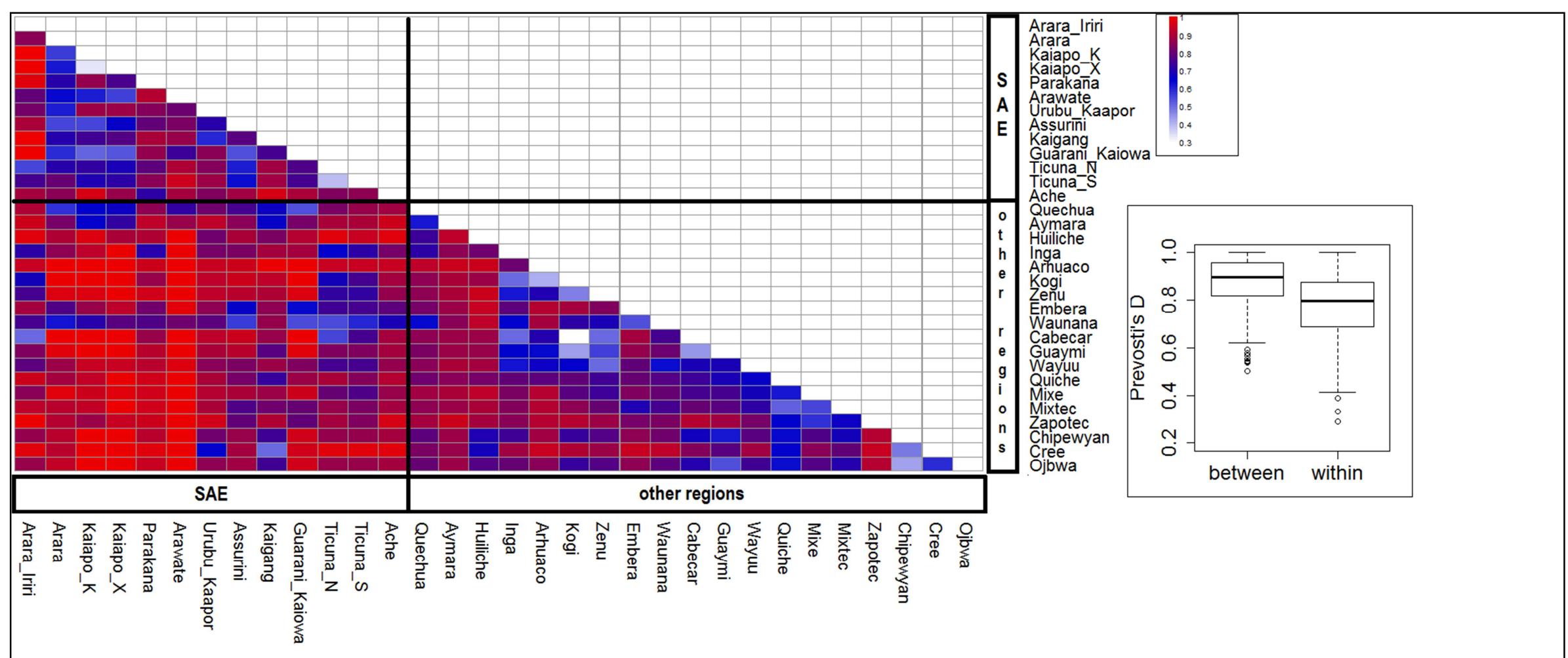

Figure 2.2. Color grid representing the $\boldsymbol{H} \boldsymbol{L A}-\boldsymbol{B}$ pairwise Prevosti's Distance. The difference between the Prevosti's D values obtained from the comparisons between and within groups was significant (Mann-Whitney test, $\mathrm{p}<2.2 \times 10^{-16}$ ). 


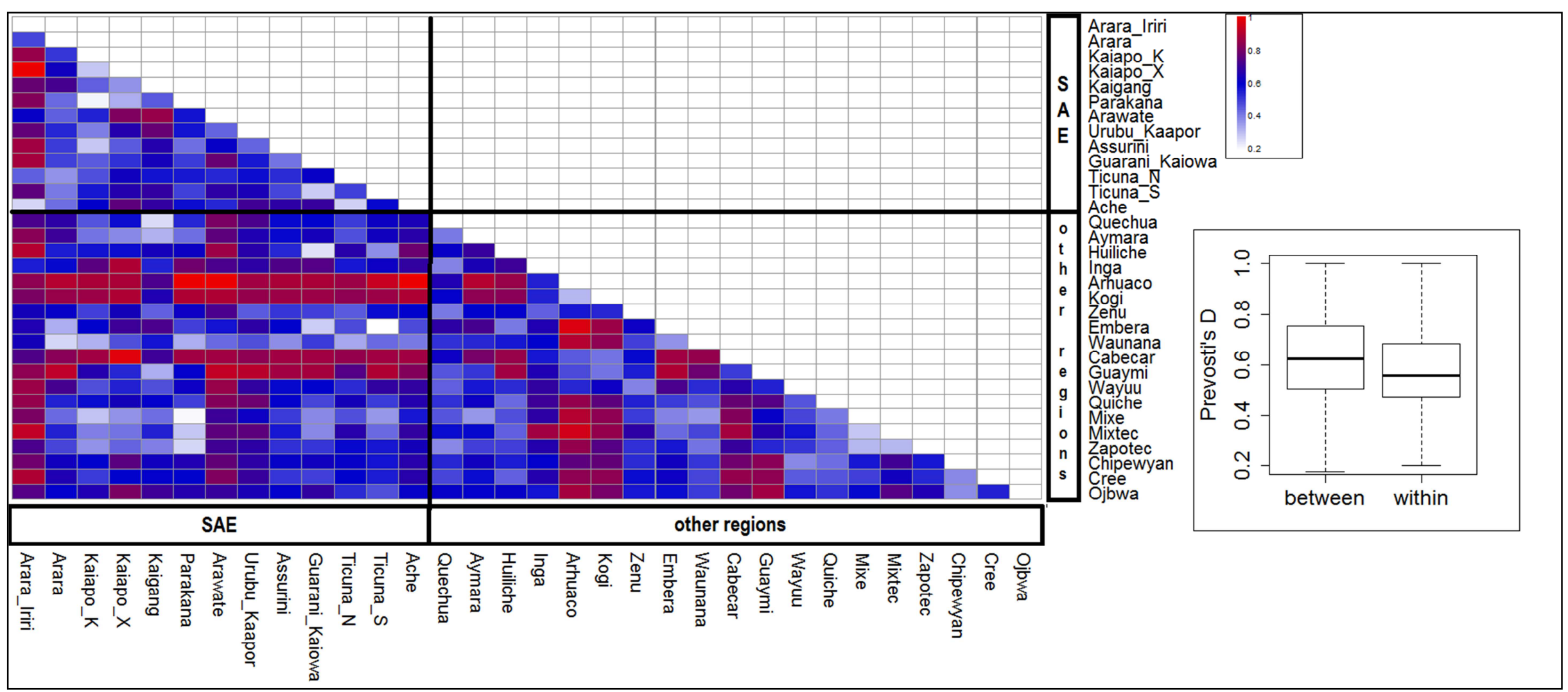

Figure 2.3. Color grid representing the $\boldsymbol{H L A} \boldsymbol{C}$ pairwise Prevosti's Distance: in this figure, the populations are separated into two sets: 1) The eastern South American population (SAE) and the remaining populations. The difference between the Prevosti's D values obtained from the comparisons between and within groups was significant (Mann-Whitney test, $\mathrm{p}>0.001$ ). 


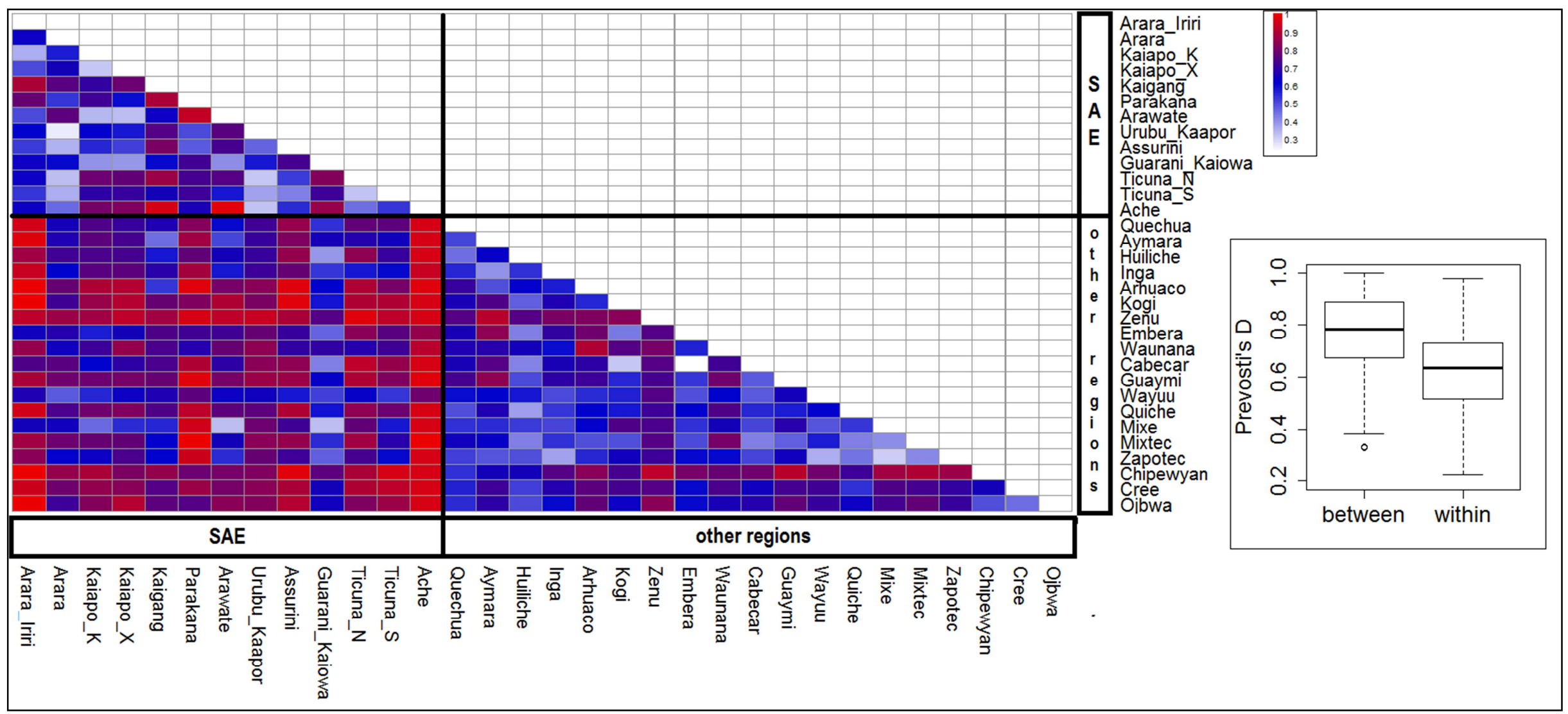

Figure 2.4. Color grid representing the $H L A-D R B 1$ pairwise Prevosti's Distance: in this figure, the populations are separated into two sets: 1) The eastern South American population (SAE) and the remaining populations. The difference between the Prevosti's D values obtained from the comparisons between and within groups was significant (Mann-Whitney test, $\mathrm{p}<2.2 \times 10^{-16}$ ). 
A

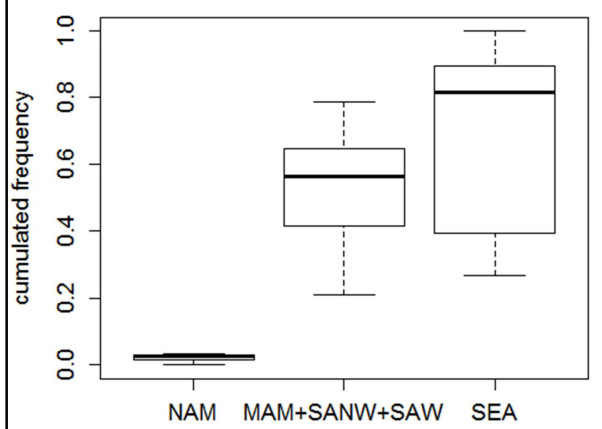

B

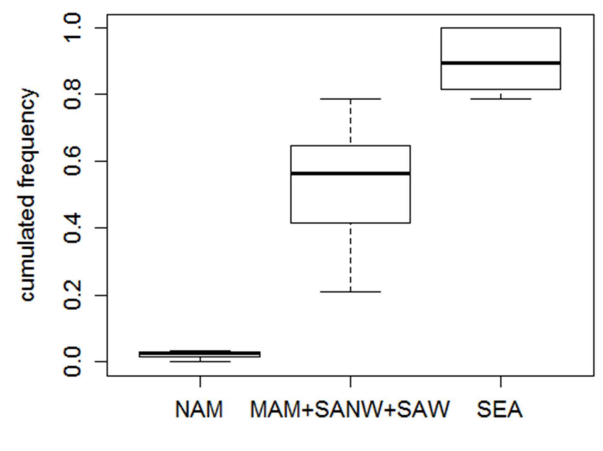

C

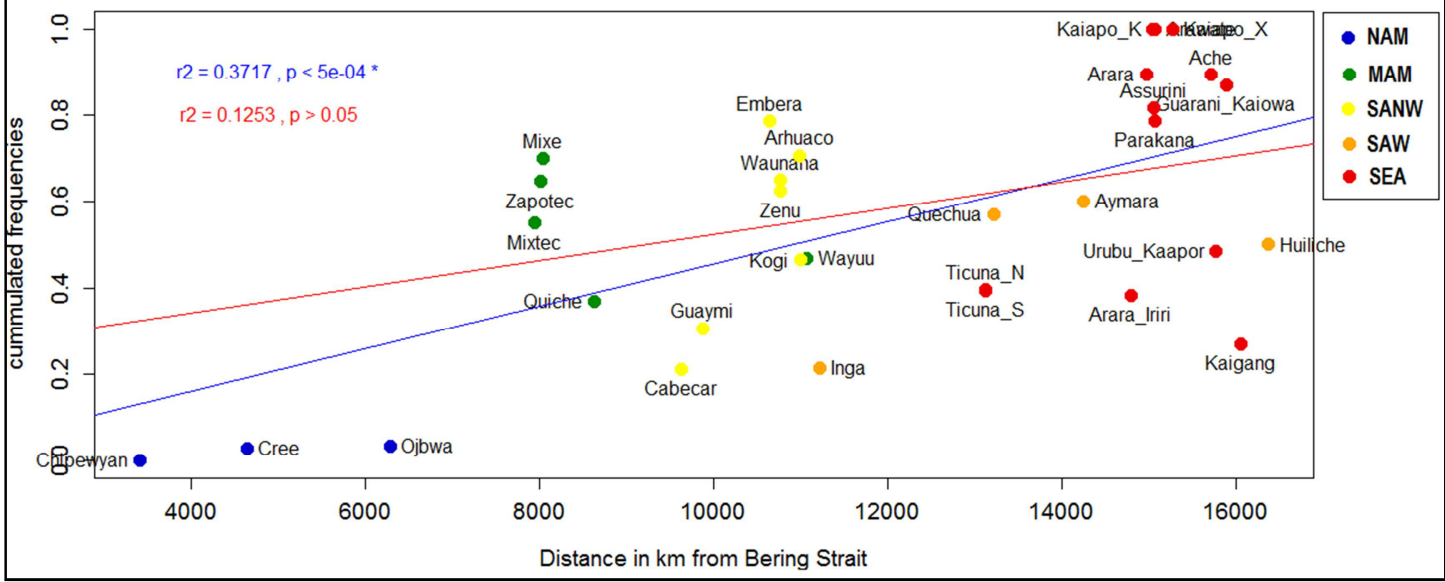

Figure 2.5. Cumulative frequencies distributions of the recombination/gene conversion alleles in the American continent: North America (NAM), Mesoamerica (MAM), Northwest South America (SANW), West South America (SAW) and East South America (SAE), respectively; A. Frequency distributions of the recombination/gene conversion alleles, using complete set of populations; B. Frequency distribution of the recombination/gene conversion alleles, excluding the Ticuna_N, Ticuna_S, Kaigang, Urubu Kaapor and Arara do Iriri populations (which presented higher frequencies of parental alleles, see text); C. Linear regression between the cumulative frequency of recombination/gene conversion alleles and the distance in $\mathrm{km}$ from Bering Strait. $\left(\mathrm{r}^{2}=0.12, \mathrm{p}>0.05\right.$, tendency line shown in red $)$, indicating an anchoring effect generated by these populations. We also can note the four red dots below the tendency lines which represent the Ticuna_N, Ticuna_S, Kaigang, Urubu Kaapor and Arara do Iriri populations (the dots representing the Ticuna populations overlap).

\subsection{Correlation between diversity indeces and the geographic distance from} the Bering Strait

We compared the patterns of variation obtained for autossomal microsatellites with those estimated for the HLA loci, attempting to disentangle the signs left by the 
demographic history and natural selection. First, we tested for the presence of correlations between the expected heterozygozity $(\mathrm{He})$ with the distance from Bering Strait for both HLA and microsatellites loci. Wang et al. (2007), reported a significant negative correlation He at microsatellite loci and distance from Bering Strait $\left(\mathrm{r}^{2}=0.436\right)$, which is in agreement with a main North-South colonization route for the American Continent. Here, we did not reproduce this result, although we also obtained a negative and significant correlation between the He and distance from Bering Strait, the intensity of the correlation was much smaller than the obtained by Wang et al. $(2007)\left(\mathrm{r}^{2}=0.133\right.$, $\mathrm{p}<0.05 ;$ data not shown)

We can point out three reasons to explain the divergence between our result and the one obtained by Wang et al. (2007): 1) we are working with a different dataset, with the introduction of ten more population of the eastern South American region; 2) we also are working with a subset of 61 out of the 678 microsatellites used by Wang et al. (2007); 3) and finally, we applied a much more simple approach to infer the distances between populations and the Bering Strait, using a great circle routes approach, not taking into account possible costal routes or obligatory way points, like the Isthmus of Panama, which led us to underestimate the distances between populations and the Bering Strait. We tested the weight of the first and third hypothesis removing the additional eastern South American populations and inferring manually the distances between populations and the Bering Strait using the software google earth (4.3.7284.3916 beta).

The introduction of way points on the Pacific coast led to an increasing of the correlation index $\left(\mathrm{r}^{2}=-0.1957, \mathrm{p}<0.05\right.$; figure $\left.2.7 \mathrm{~A}\right)$, although it was still not as large as the one obtained by Wang et al. (2007). On the other hand, the removal of eastern South American populations (SAE) led to the loss of the correlation $\left(\mathrm{r}^{2}=-0.037, \mathrm{p}>0.80\right.$; figure 2.7A). The same effect was not achieved when only the outlier populations (Arara 
do Iriri and Ache) were removed $\left(\mathrm{r}^{2}=-0.1891, \mathrm{p}<0.05\right.$; data not shown), indicating that the loss of significance caused by taking the SAE populations cannot be accounted by the outliers.

The negative correlation between $\mathrm{He}$ and the increasing of the distance from Africa is a well-established result for humans, with correlations larger than 0.8 using different genetic markers (Prugnolle et al. 2005; Sanchez-Mazas, Lemaitre, and Currat 2012; Wang et al. 2007). However, an important aspect of these studies, not previously discussed, is the fact that the American continent is the geographic region presenting the largest variance in the residuals of the correlation between genetic variation and distance from Africa.

According to our results, there is no a correlation between microsatellite diversity and of distance from Bering Strait, unless SAE populations were included in the analysis (figure $2.7 \mathrm{~A}$ ). As already discussed, the removal of SAE populations led to loss of the correlation, probably due to an anchoring effect provoked by the significantly lower $\mathrm{He}$ we observed in these populations, when compared with the remaining American populations (figure $2.7 \mathrm{~B}, \mathrm{p}<0.00001$, Wilcoxon rank sum test). The stable levels of $\mathrm{He}$ we observed for microsatellites along the American continent support the hypothesis of rapid colonization through the Pacific coast followed by lower levels of genetic drift outside SAE. This result is also supported by others genetic markers as Y chromosome and mitochondrial DNA.

We applied this same approach on the HLA dataset, testing for correlation between He and the distance from Bering Strait. We observed the same patterns as for microsatellites at the $H L A-C$ and $-D R B 1$ loci, with a modest but significant negative correlation between the loss of diversity and the increase of distance $\left(\mathrm{r}^{2}=-0.2261(\mathrm{p}<\right.$ $0.01)$ and $\mathrm{r}^{2}=-0.2637(\mathrm{p}<0.005)$ for HLA-C and -DRB1 loci, respectively; figure 2.13E 
and $2.13 \mathrm{G}$ ), which persisted even after the removal of the outliers Arara do Iriri and Ache populations (data not shown).

The removal of SAE populations also provoked the loss of the correlation with distance $\left(\mathrm{r}^{2}=-0.1594(\mathrm{p}>0.05)\right.$ and $\mathrm{r}^{2}=-0.0937(\mathrm{p}>0.20)$ for HLA-C and $-D R B 1$ loci, respectively; figure $2.13 \mathrm{E}$ and $2.13 \mathrm{G}$ ) which can also be explained by the significantly lower levels of He in SAE populations when compared with other American populations (figure $2.13 \mathrm{~F}$ and $2.13 \mathrm{H}, \mathrm{p}<0.05$ and $\mathrm{p}<0.01$, for HLA-C and $-D R B 1$ loci, Wilcoxon rank sum test). These results indicate that the genetic drift was probably the main force governing the HLA-C and -DRB1 patterns of variation in the American continent, since they did not deviate from the general genome profile evidenced by the microsatellites.

We did not observe correlations between the levels of He of the HLA-B locus and the increase of the distance from Bering Strait $\left(r^{2}=-0.1117, p>0.05\right.$; figure 2.7C) even before the removal of SAE populations. In agreement with this result, we also did not find significant differences in He between SAE and other Native American populations (figure $2.7 \mathrm{D}, \mathrm{p}>0.15$, Wilcoxon rank sum test). Differently from findings for $H L A-C$ and $-D R B 1$ and microsatellites, the expected heterozygosity of $H L A-B$ locus it is not significantly changing along the American continent, even in the Eastern South American region.

The patterns of variation of microsatelittes and the HLA-C and -DRB1 loci are in agreement with which was decribed for other genetic markers and morphological data. All these evidences state that the populations at the Eastern South American region have probably suffered with more intense levels of genetic drift, which led to a significant decrease of the genetic diversity. This effect could be detected even in the high polymorphic $H L A$ genes, except in $H L A$ - $B$, which conserved the levels of diversity even under the general trend of loss of variability. 


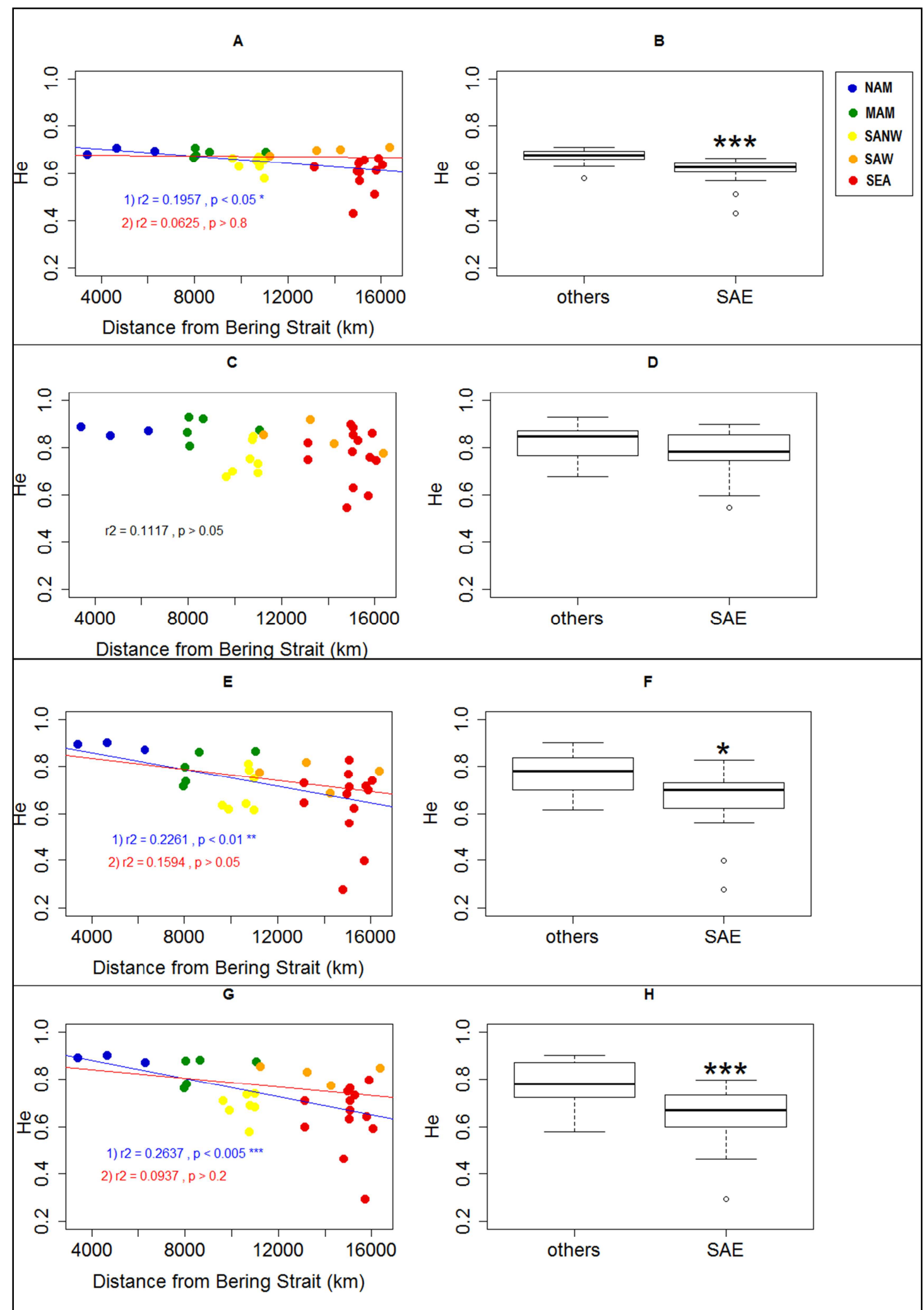

Figure 2.6. Distribution of the expected Heterozygosity $(\mathrm{He})$ of microsatellites and $H \boldsymbol{L A}$ loci along the American continent. The correlations between $\mathrm{He}$ and distance from Bering Strait for the microsatellites, HLA-B, HLA-C and HLA-DRB1 loci are shown in $A, C, E$ and $G$, respectively. The correlation indexes $\left(\mathrm{r}^{2}\right)$, p-values and vestfit linear regression lines obtained with all populations are shown in blue while the ones obtained after the removal of eastern South American population (SAE) are shown in 
red. The distribution of the He of SAE and the other American populations are shown in $\mathrm{B}, \mathrm{D}, \mathrm{F} . *$ for $\mathrm{p}<0.05$; $* * *$ for $\mathrm{p}<0.005$.

\subsection{Neutrality and Equilibrium Tests}

We first tested for deviations from the infinite alleles model by applying a two tailed Ewens-Watterson test. We observed three, four and one population presenting significant deviations $(\mathrm{p}<0.025)$ for $H L A-B,-C$ and $-D R B 1$ loci, respectively (table 2.3, SUPLEMENTARY). All these deviations were in the direction of $\mathrm{Fo}<\mathrm{Fe}$, which is expected for loci under balancing selection, which motivated us to conduct a one tailed Ewens-Watterson test (which would increase our power with respect to the alternative hypothesis of balancing selection). We observed three, five and two significant deviations $(\mathrm{p}<0.05)$ for $H L A-B,-C$ and $-D R B 1$ loci, respectively (figure 2.8).

Furthermore, because we observed a higher number of populations presenting $\mathrm{Fo}_{\mathrm{O}}<\mathrm{Fe}$ in our dataset, we tested whether the entire distribution of normalized differences (Fnd) deviated from the expectation of equal numbers of values to either side of zero, by implementing an exact binomial test (figure 2.8). We found that the three loci, $H L A-B,-C$ and $-D R B 1$ presented a moderate but significant skew towards negative Fnd values ( $\mathrm{p}=0.05$ for $H L A-B$ and $\mathrm{p}<0.05$ for $H L A-C$ and $-D R B 1$ (figure 2.8).

The Ewens-Watterson test has important limitations, which were discussed by Garrigan and Hedrick (2003). Importantly, starting from allele frequencies which are approximately at equilibrium (as may be expected after periods of intense genetic drift), the attainment of statistical significance with respect to the null hypothesis of neutrality may take tens to hundreds of generations, making it plausible that recent selection will not have shaped extant patterns of diveristy. In addition, as previously discussed, demographic events, including recent bottlenecks or expansion events, can influence the allele frequencies and thus influence the results. This lack of robustness of the EW test 
implies that interpretation of its findings needs to be discussed in the light of demographic inferences.

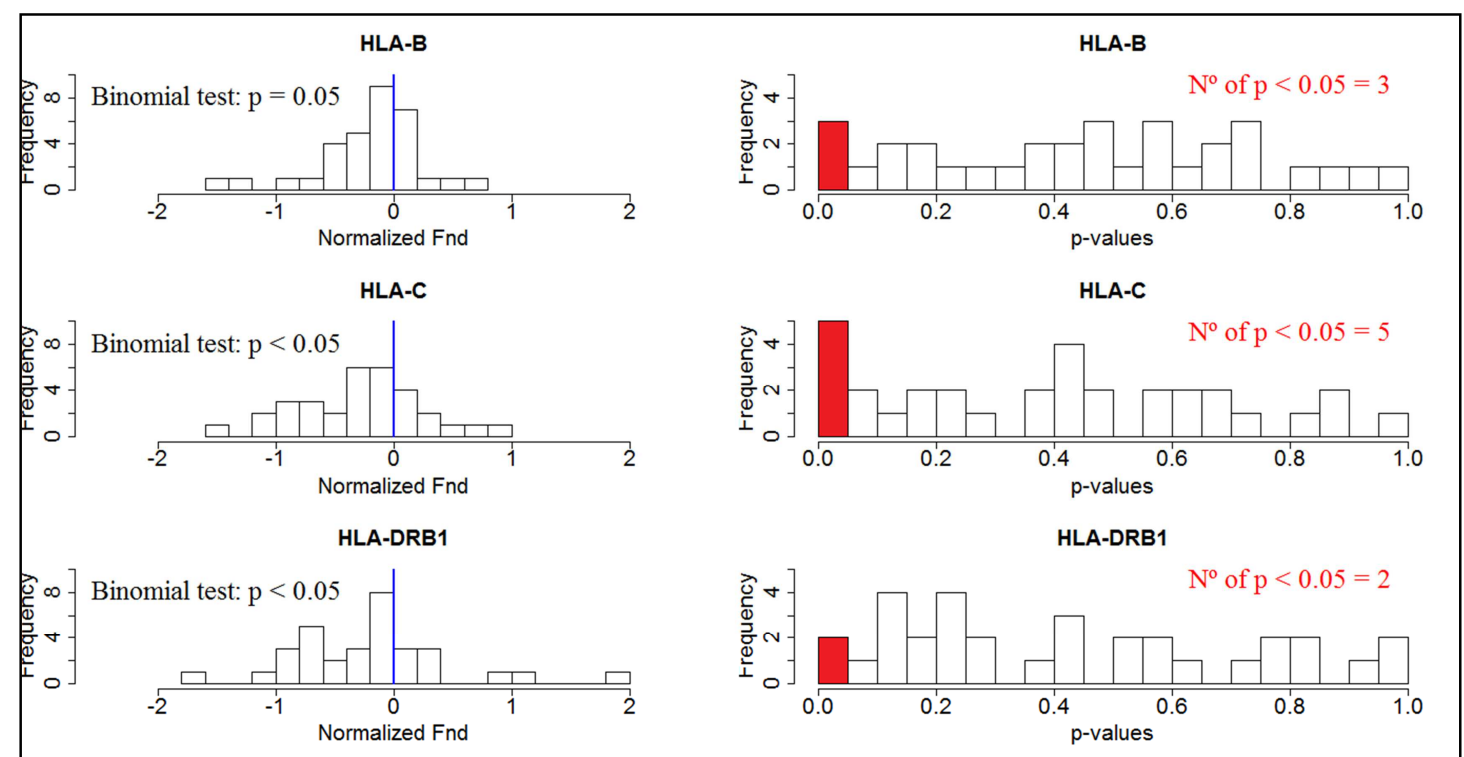

Figure 2.7. Summary of Ewens-Watterson results: 1. distributions of normalized differences between Fo e Fe (Fnd) are shown on the histograms to the left. The blue line represents the value of zero, around which obsrved Fnd values should be destributed symmetrically under the null hypothesis. 2. The distribution of p-values for the EwensWatterson test is shown in the histograms to the right. The p-values for this test are defined are as the number of simulated samples with the same size and number of alleles than the observed one, which presented homozygosities smaller or equal to the observed one.

An additional way to interpret the findings is to compare the results of different neutrality tests, which are sensitive to selection on different timescales. In this light, application of a test of the infinite sites model, such as Tajima's D, is highly informative (Garrigan and Hedrick 2003). Deviation from the null hypothesis can result from long term selection events, and the shared evidences for selection across populations can be attributed to events that occurred in ancestral populations. On the other hand, selection events that are are not shared due to common ancestry, are more likely to show lower patterns of sharing.

The analysis of Tajima's D revealed that all populations except for one for HLA$B$, one for $H L A-C$ and two for $H L A-D R B 1$, exhibited D>0 (SUPLEMENTARY), 
which is very unlikely for genes evolving under neutrality $(p<0.0000005$, applying an exact binomial test to the entire set of populations). In fact, the excess of positive Tajima's D is even more unusual when we consider knowledge of the demographic history of human populations, and Native Americans in particular, which commonly show evidence of having experienced recent expansions, which drive the overall distribution of Tajima's D to negative values (Hammer et al. 2003; Jaruzelska et al. 1999) [Para o paper temos que buscar referências mais atuais e completas].

This result indicates that the Native American populations we studied inherited a polymorphic array of HLA alleles from their Asian ancestors, and this set of divergent sequences had been evolving under balancing selection long before the divergence of the populations that occupied the Americas (Garrigan and Hedrick 2003). On the other hand, the highest and most significant positive Tajima's D values are not evenly distributed among the Native American populations. The Eastern South American populations (SAE) presented Tajima's D which are significantly higher compared to populations from other regions (figure $2.8 \mathrm{~A}, \mathrm{p}<0.001$, Wilcoxon rank sum test). The HLA-C and -DRB1 loci did not present the same patterns, showing similar Tajima's D values among regions (figures $2.8 \mathrm{~B}$ and $\mathrm{C}, \mathrm{p}>0.30$ for both loci, Wilcoxon rank sum test). Moreover, taking into account only the significant results, the SAE populations concentrates the majority of the deviations observed for HLA-B locus, with 11 out of the total of 14 significant Tajima's D values (which was marginally significant with $\mathrm{p}=$ 0.06, applying an exact binomial test). This pattern was not seen at HLA-C and -DRB1, which presented four out of 13 and seven out of 14 siginificant deviations in SAE, respectively ( $p>0.25$ for both loci, exact binomial test).

We have demonstrated that SAE populations exhibit gene conversion/ recombination alleles in high frequencies (figure 2.6). These alleles are very divergent, differing in multiple nucleotide sites from the parental alleles involved in their origin 
(figure 1-S2). The presence of these divergent alleles in intermediate frequencies accounts for the elevated Tajima's D values we obtained for $H L A-B$ locus in SAE populations. Therefore, the increased departures from neutral expectations we observed in SAE population at the HLA-B locus can be directed associated with the presence of the gene conversion / recombinations alleles.

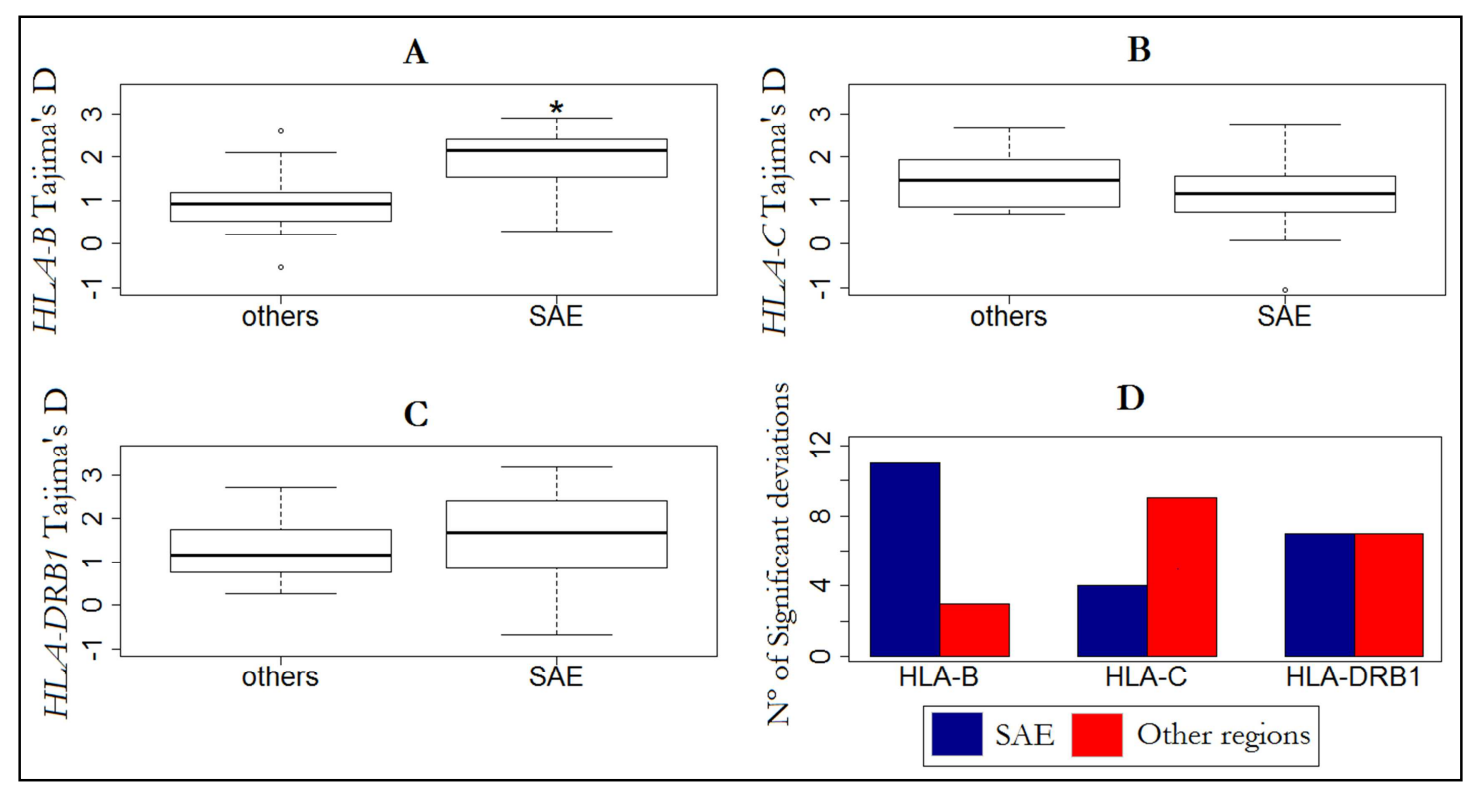

Figure 2.8. Tajima's $\mathbf{D}$ for Eastern South American (SAE) and remaining populations for $H L A-B$ (A), HLA-C (B) and HLA-DRB1 (C) loci. A significant difference was observed for $H L A-B$ locus $(\mathrm{p}<0.001$, Wilcoxon rank sum test). (D) Differences in the amount of significant results fo Tajima's D test. 


\section{4- Conclusions}

The distinct HLA-B allelic profile of Central and South Native American populations was a remarkable discovery during the 90 s. The relevance of this find lies in the contrast with other genetic markers, including other HLA genes, whose diversity in Central and South America seems to be a subset from which is found in North America and Northeast Asia. To explain such unusual pattern, Parham et al. (1997) proposed the allelic turnover hypothesis, which claims that the repleicement of the ancestral alleles by the new ones, products of recombinations and gene conversion, occurred under the selective pressures imposed by the endemic pathogens of the American tropical regions. The authors also postulated that the genetic drift had an important role, enhancing the efficiency of the replacement process.

In the present study we revisited the turnover model and demonstrated that the Eastern South American (SAE) populations are those exhibiting the highest frequencies of the gene conversion / recombination $H L A-B$ alleles (figure 2.6). These same populations also presented a significant increase of measures like the Tajima's D and expected heterozygosity at the $H L A-B$ locus, when compared with other populations from the American continent. These same patterns were not observed at the other HLA loci, reforcing the interpretation that these results are due to the increased frequencies of gene convertion / recombination alleles. 


\section{Detailed Frequencies Descriptions.}

In this section we will provide a detailed description of the HLA-B, $-C$ and DRB1 allelic distribution in the American continent. We found 91, 28 and 40 different alleles for these three loci respectively, taking into account the complete set of populations. The allele frequencies for each locus are summarized in figures 2.7 to 2.10 . Starting with the HLA-B locus, about $74.1 \%$ of the allelic distribution in North American populations was comprised by the parental alleles $(B * 15: 01: 01 G, B * 27: 05: 02 G$, $B * 35: 01: 01 G, B * 37: 01: 01, B * 39: 01: 01 G, B * 40: 02: 01 G, B * 44: 02: 01 G, B * 48: 01: 01 G$ and $B^{*}$ 51:01:01G)(figure 2.7).

Some of the parental alleles were still found at high frequencies in the Mesoamerican region $(B * 35: 01: 01 G, B * 40: 02: 01 G$ and $B * 51: 01: 01 G$, at the accumulative frequency of $21 \%$ ) but a second allelic component comprised by recombination/gene conversion alleles $(B * 35: 12: 01, B * 35: 14: 01, B * 35: 17, B * 35: 43: 01 G, B * 3549, B * 39: 02: 02$ and $B^{*} 39: 05: 01$, at the cumulative frequency of $47.8 \%$ ) were observed (figure 2.7 ).

The populations located at the Isthmus of Panama and northwest of the South American Continent (the ones belonging to the Chibcha-Paezan linguistic group(SANW)) presented two different sets of alleles. The more common alleles exhibited by the Chibcha populations (Guaymi, Cabecar, Arhuaco, Kogi and Zenu) were the parental $B^{*}$ 15:01:01G, $B * 35: 01: 01 G$ and $B^{*} 40: 02: 01 G$ (at the cumulative frequency of $46.4 \%$ ) added by the recombined $B * 35: 43: 01 G$ allele (30.4\%)(figure 2.7). On the other hand, the more frequent alleles at the Paezam populations (Embera and Waunana) were the parental $B * 40: 02: 01 G(19.1 \%)$ followed by $B * 15: 04, \quad B * 35: 10, \quad B * 40: 04$ and $B * 39: 05: 01$, the latter were probably generated by gene conversion and were found at the accumulated frequency of $60.3 \%$ (figure $2-3$ ). 
The West South America region (Andean region or SAW) collects a heterogeneous set of populations regarding the allelic content for the HLA-B locus. We found the parental alleles $B * 15: 01: 01 G, \quad B * 35: 01: 01 G, \quad B * 40: 02: 01 G, \quad B * 48: 01: 01 G$ scattered along this geographic region but some populations missed one or another of these alleles (the Inga, Aymara and Huilliche populations lack $B^{*} 35: 05: 01, B^{*} 15: 01: 01 G$ and $B^{*} 48: 01: 01 G$ alleles respectively)(figure $2-3$ ). On the other hand, these populations differed from each other on the gene conversion/recombination allele content. The Inga population presented the $B * 35: 43: 01 G$ allele at $10.7 \%$ while the more common allele at the Aymara population was the $B^{*} 35: 05: 01(37.5 \%)$. At the Huilliche population we observed $B * 39: 09(43.5 \%)$ and finally, for the Quechua population we observed $B * 15: 04$ and $B^{*}$ 35:05:01 alleles at the frequencies of 16.7 and 14.3\%, respectively (figure 2-3).

As we discussed before, we observed the alleles resulting from gene conversion/recombination at high frequencies in the eastern region of the South American (figure 2.2 and S2). Only two parental alleles were observed in more than one population at elevated frequencies: $B * 40: 02: 01 G$ (reaching its maximum frequency on the region, $61.8 \%$, at the Arara do Iriri population, figure 2.2) and $B * 51: 01: 01 G$ (reaching its maximum frequency on the region, $40.9 \%$, at the Urubu Kaapor population, figure 2.3). The $B^{*}$ 15:01:01G and $B * 35: 01: 01 G$ alleles were also observed, but only in the Parakana and Kaigang populations, at the frequencies of 19 and 19.2\%, respectively (figure 2-3). The $B * 15: 04, \quad B * 15: 08, \quad B * 15: 20, \quad B * 35: 04: 01, \quad B * 35: 05: 01, \quad B * 39: 05: 01$, $B * 39: 09, B * 40: 04, B * 48: 02: 01$ and $B * 52: 01: 02$ (at the accumulated frequency of $64.8 \%$ in the region) comprise most of the variation of $H L A-B$ at the eastern regions of the south American continent, and markedly contrast with the allelic composition we observed in North American Populations (figure 2-3).

There is a vast list of other alleles for $H L A-B$ which we did not discuss (figure 24). Most of these alleles were found at low frequencies and/or exclusive to only one 
population. Some of these rare alleles were also the result of recombination and gene conversion and are listed on figure S2. Other alleles, for instance the $B^{*}$ 14:01:01, $B * 14: 02: 01, \quad B * 18: 01: 01 G$ and $B^{*} 50: 01: 01$, which were observed at relatively high frequencies in our sample (figure 2-4) were probably introduced on the Amerindian population by recent gene flow with Africans and Europeans. The global distribution of these alleles is in agreement with this explanation, since they were described at high frequencies in Africans and Europeans and at very low frequencies in other populations (Gonzalez-Galarza et al. 2011; Solberg et al. 2008). 


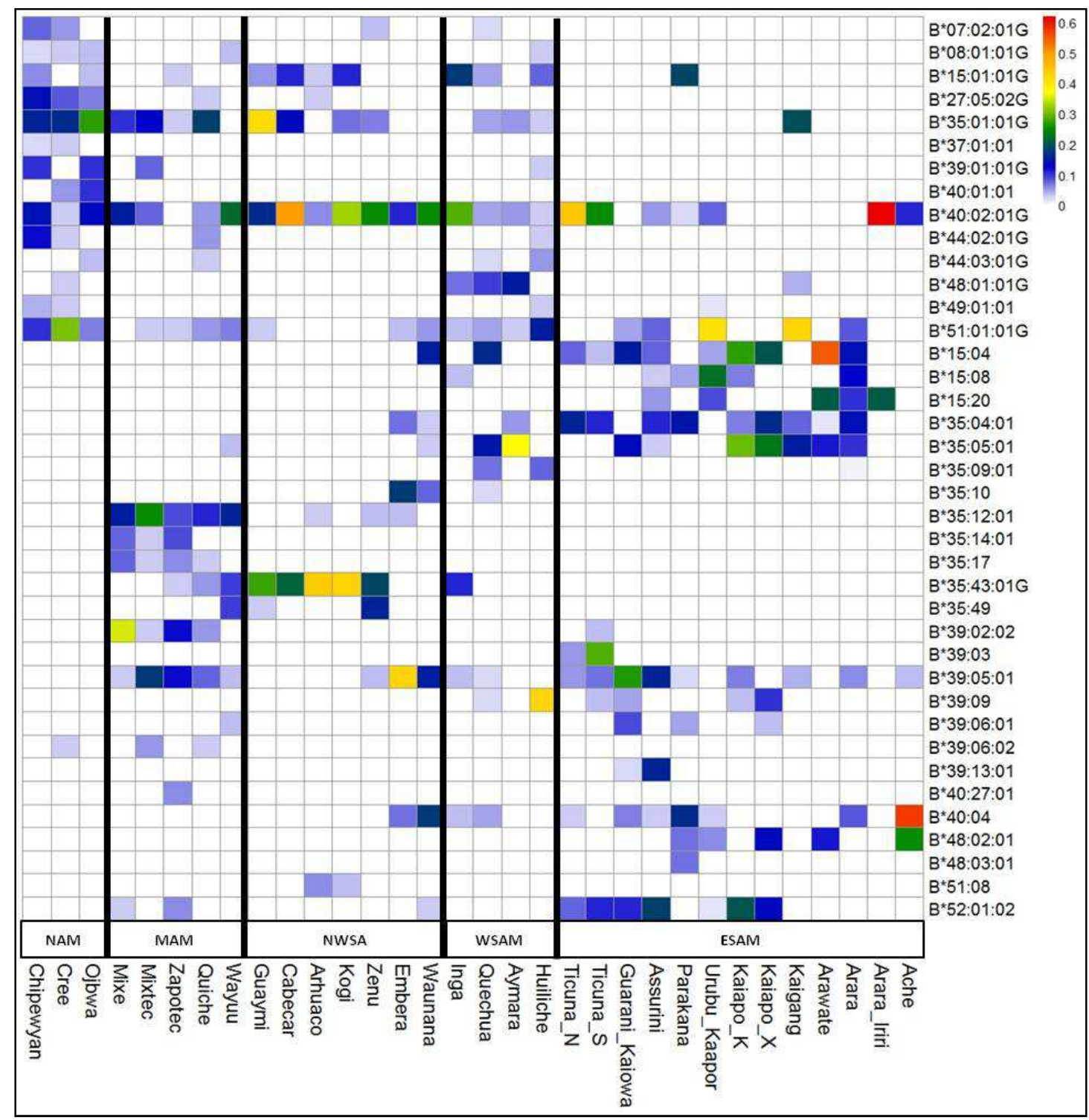

Figure 2.9. Color grid representing the $H L A-B$ allelic frequencies along the American Continent (part 1): the populations are represented as columns and are grouped by geographic region, where NAM, MAM, NWSA, WSAM and ESAM represent North America, Meso-America, Northwest South America, West South America and East South America, respectively. Alleles were represented at the rows. 


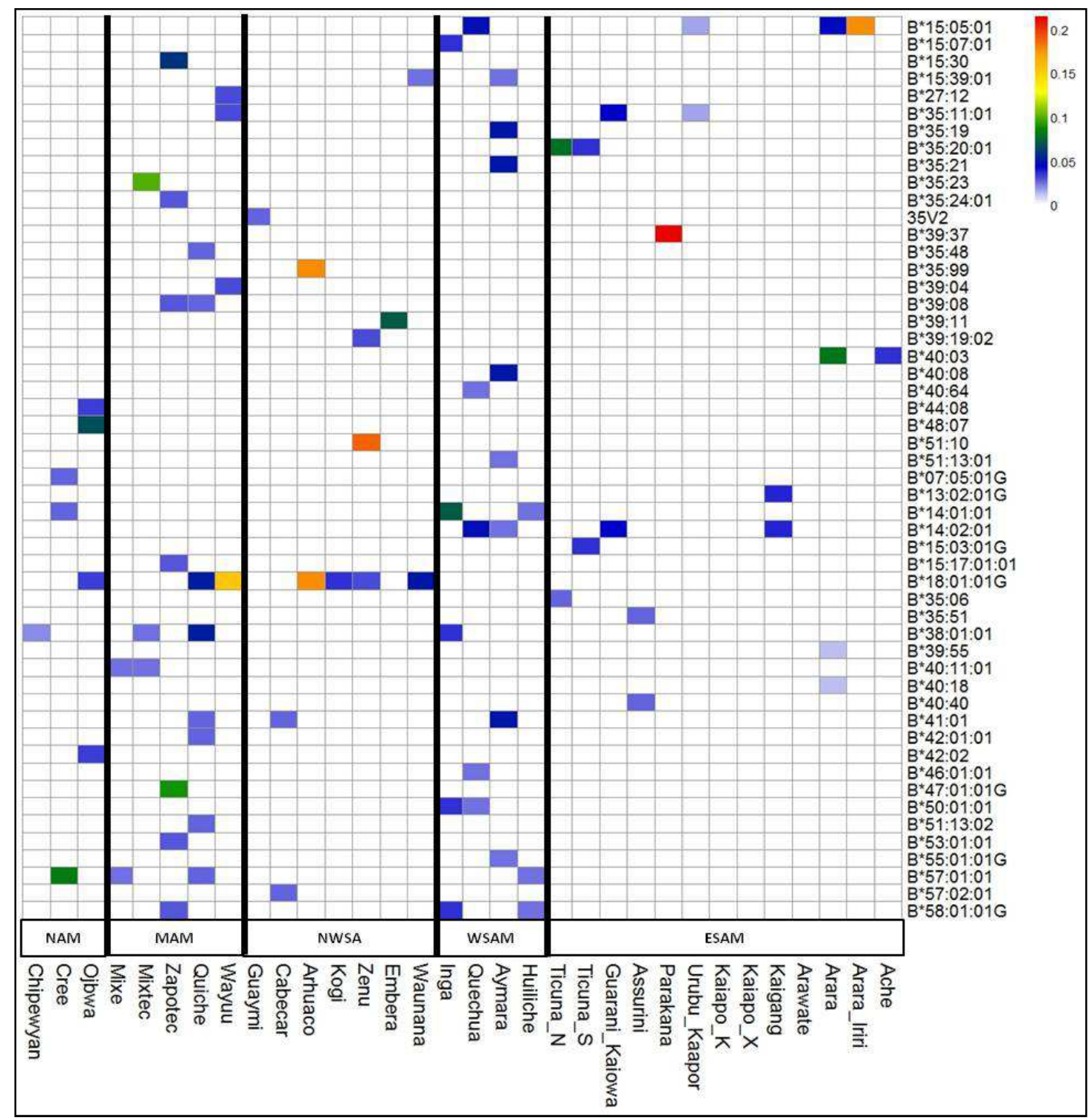

Figure 2.10. Color grid representing the $H L A-B$ allelic frequencies along the American Continent (part 2): the populations were represented at the columns and grouped by geographic region, where NAM, MAM, NWSA, WSAM and ESAM mean North America, Meso-America, South America Northwest, West South America and East South America, respectively. Alleles were represented at the rows.

Differently from what we observed at $H L A-B$ locus, the $H L A-C$ alleles we observed at the southern region of the American continent proved to be a subset from those we found in north American populations. The $C^{*} 01: 02: 01 G, C^{*} 02: 02: 02 G$, $C^{*}$ 03:04:01G,$\quad C^{*}$ 04:01:01G $, \quad C^{*} 04: 04: 01, \quad C^{*} 05: 01: 01 G, \quad C^{*} 06: 02: 01 G, \quad C^{*} 07: 01: 01 G$,

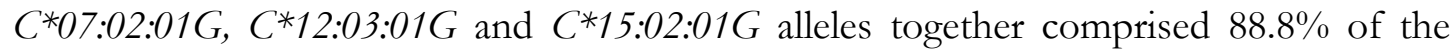
variation in North American native populations. From these alleles, $C^{*} 02: 02: 02 G$, 


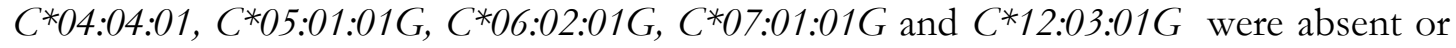
found at lower frequencies outside North America, but the remaining alleles were found along all the American continent (figure 2.5).

More than half of the allelic frequency $(55.1 \%)$ at Meso-American populations was contributed by $C^{*} 04: 01: 01 G$ and $C^{*} 07: 02: 01 G$ alleles. Furthermore, the

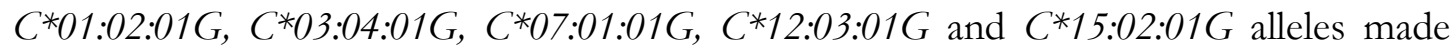
up together an additional $27.5 \%$ of the distribution (figure 2.5). As we observed for $H L A-B$ locus, the Chibcha and Paezan populations also differed on the allelic composition for HLA-C. The more common allele we found at the Chibcha populations was $C^{*} 01: 02: 01 G$ (at the cumulative frequency of $36.9 \%$ ) followed by $C^{*} 03: 05$ (at the accumulated frequency of $25.6 \%$ )(figure 2.5). The $C^{*} 03: 05$ allele was previously described at Northeast Asia (Gonzalez-Galarza et al. 2011; Solberg et al. 2008) and its origin cannot be associated to a single gene conversion or recombination event involving others HLA-C alleles we observed in this study (Robinson 2003). The more common alleles at Paezan populations were $C^{*}$ 03:04:01G, $C^{*}$ 07:02:01 $G$ and $C^{*} 04: 01: 01 G$ at the accumulated frequency of 35.3, 27.9 and $16.2 \%$, respectively (figure 2-5).

At the west region of the South American continent, the $C^{*} 01: 02: 01 G$, $C^{*}$ 03:04:01G, $C^{*}$ 04:01:01G, $C^{*} 07: 02: 01 G$ and $C^{*} 15: 02: 01 G$ alleles made up 77.9\% of the frequency distribution (figure 2-5). We also observed $C^{*} 08$ alleles at relatively higher frequencies $\left(C^{*} 08: 01: 01, C^{*} 08: 02: 01 G\right.$ and $C^{*} 08: 03: 01 G$, at the accumulated frequency of $11.4 \%$ ). We also observed $C^{*} 08$ alleles in North American populations but at lower frequencies (figure 2-5) and these alleles were previously described in Asiatic, African and European populations (Gonzalez-Galarza et al. 2011; Solberg et al. 2008).

At the eastern regions of the South American continent we found the $C^{*}$ 03:04:01G, $C^{*}$ 04:01:01G, $C^{*} 07: 02: 01 G$ and $C^{*}$ 15:02:01 $G$ alleles at the accumulated frequency of 78\% (figure 2-5). Apart from these, we found the $C^{*} 03: 03: 01 G$ allele at 
relatively high frequency $(15.2 \%)$ (figure $2-5)$. This allele was found in other American regions but at lower frequencies, and its sequence differs from $C^{*} 03: 04: 01 G$ in only one nucleotide at the last position of the exon 2 (Robinson 2003).

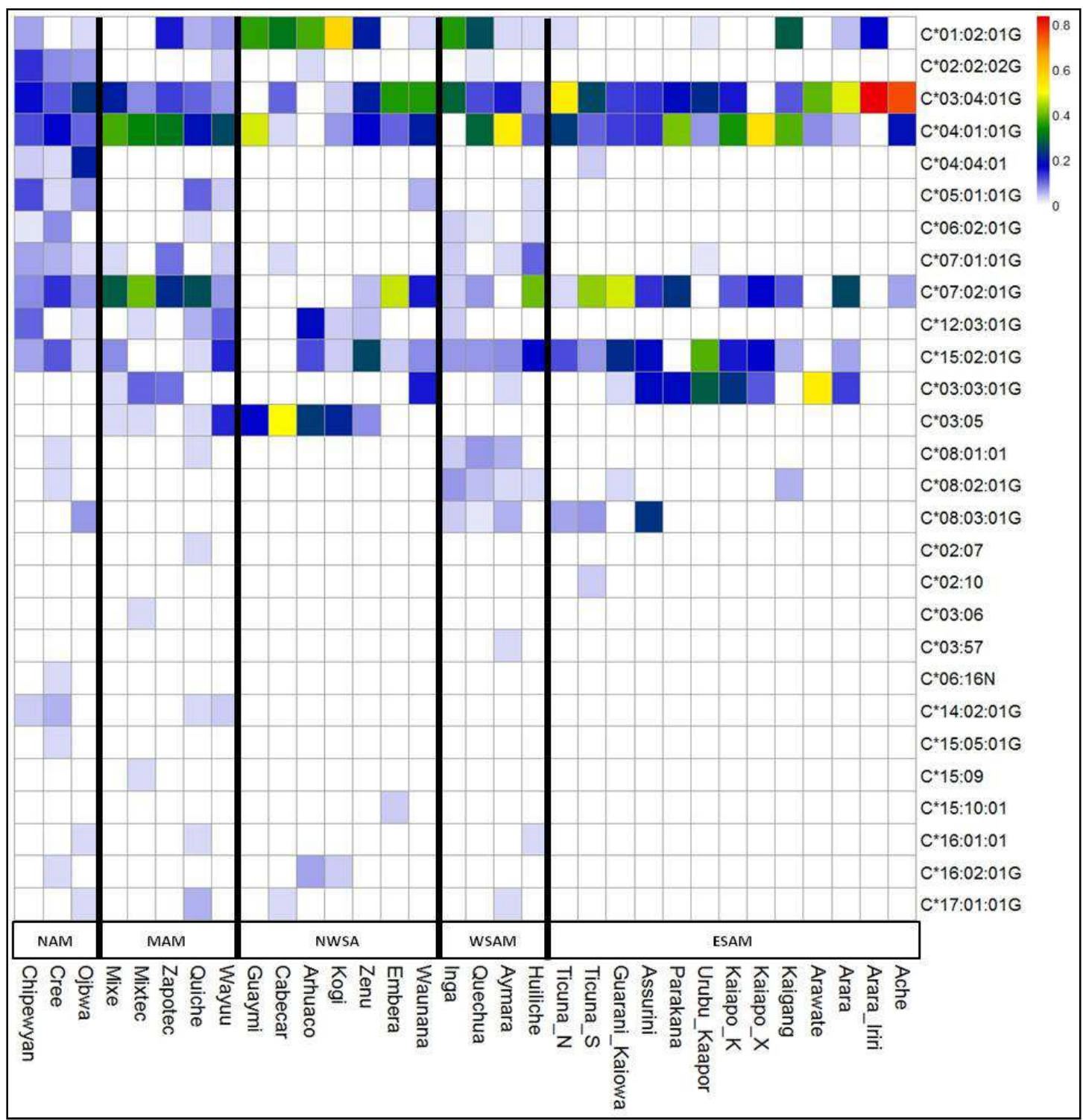

Figure 2.11. Color grid representing the $H L A-C$ allelic frequencies along the American Continent: the populations were represented at the columns and grouped by geographic region, where NAM, MAM, NWSA, WSAM and ESAM mean North America, Meso-America, South America Northwest, West South America and East South America, respectively. Alleles were represented at the rows. 
As the same way we observed for $H L A-C$, the North American populations collect several of the frequent alleles we observed at the American continent (except by $D R B 1 * 04: 11: 01, D R B 1 * 08: 07$ and $D R B 1 * 14: 06: 01$ )(figure 2.6). On the other hand, HLA-DRB1 locus presented a higher difference on the allelic frequencies between populations than the observed for $H L A-C$ (figure 2.1) getting close to the pattern we found for HLA-B locus.

The more frequent alleles we observed in North America were DRB1*04:07:01G, DRB1*07:01:01 G, DRB1*08:11, DRB1*09:01:02, DRB1*14:01:01G and DRB1*14:02, at the accumulated frequency of $60.3 \%$ (figure 2.6). Heading south to the Meso-American region, we have found a second set of allele at elevated frequency. The DRB1*04:04:01, DRB1*04:07:01G, DRB1*08:02:01, DRB1*14:02, DRB1*14:06:01 and DRB1*16:02:01 were found at the accumulated frequency of $78.8 \%$ and except by $D R B 1 * 14: 06: 01$, all of them have been observed in North American populations (figure 2.6). The DRB1*14:06:01 allele were previously described outside the Americas presenting elevated frequencies at Northeast Asia (Gonzalez-Galarza et al. 2011; Robinson 2003; Solberg et al. 2008). We also observed the $D R B 1 * 04: 11: 01$ and $D R B 1 * 15: 01: 01 G$ allele at relatively high frequencies (16.7 and $13.3 \%$, respectively) in the Wayuu population. $D R B 1 * 04: 11: 01$ were found at high frequencies in South American populations as we will discuss later and $D R B 1 * 15: 01: 01 G$ presents elevated frequency in Europeans and Asiatic populations, but is very rare in other Amerindian populations (Gonzalez-Galarza et al. 2011; Solberg et al. 2008).

The Chibcha-Paezam population (NWSAM) presented a less uniform pattern on the allelic content for HLA-DRB1 when compared with the other loci. Two alleles were found in all population: $D R B 1 * 04: 07: 01 G$ and $D R B 1 * 14: 02$, with frequencies ranging from 7.5 to $50 \%$ and 2.8 to $47.5 \%$, respectively (figure 2.6 ). The $D R B 1 * 04: 03: 01$, $D R B 1 * 08: 02: 01$ and DRB1*16:02:01 were also observed, but not at all populations 
(figure 2.6). The $D R B 1 * 03: 02: 02, D R B 1 * 04: 05: 02$ and $D R B 1 * 15: 01: 01 G$ alleles were observed in the Zenu, Guaymi and Arhuaco populations and are very common at nonAmerindian populations (Gonzalez-Galarza et al. 2011; Solberg et al. 2008), suggesting a recent introgression into the continent by gene flow.

West South American populations were very similar to North American population regarding the allelic content (figure 2.6). We observed the DRB1*04:04:01, DRB1*04:07:01G, DRB1*08:02:01,DRB1*09:01:02, DRB1*14:02 and DRB1*16:02:01 at the accumulated frequency of $73.7 \%$ (figure 2.6) and all of them were observed in North American populations. The DRB1*09:01:02 alongside DRB1*01:01:01G and $D R B 1 * 03: 01: 01 G$ which were very rare or absent at Meso-American and Chibcha-Paezan population, have appeared again at the west South American populations.

At the populations from East South America we have found the DRB1*04:04:01, $D R B 1 * 04: 07: 01 G, \quad D R B 1 * 08: 02: 01, \quad D R B 1 * 09: 01: 02, \quad D R B 1 * 14: 02$ and $D R B 1 * 16: 02: 01$ alleles at the accumulated frequency 55.2\%. These alleles were also found at the North American populations (figure 2.6). The $D R B 1 * 04: 11: 01$ and $D R B 1 * 08: 07$ alleles, which we did not observe in North American population, reached high frequencies in eastern South American population (at the accumulated frequencies of 30.3 and 11.4\%, respectively). The patterns of frequency distribution from these two alleles resemble the one we described for $H L A-B$, but the origin of these two $H L A-D R B 1$ alleles cannot be associated to single recombination/gene conversion/mutation events involving alleles found in North American or other region of the continent (S2). 


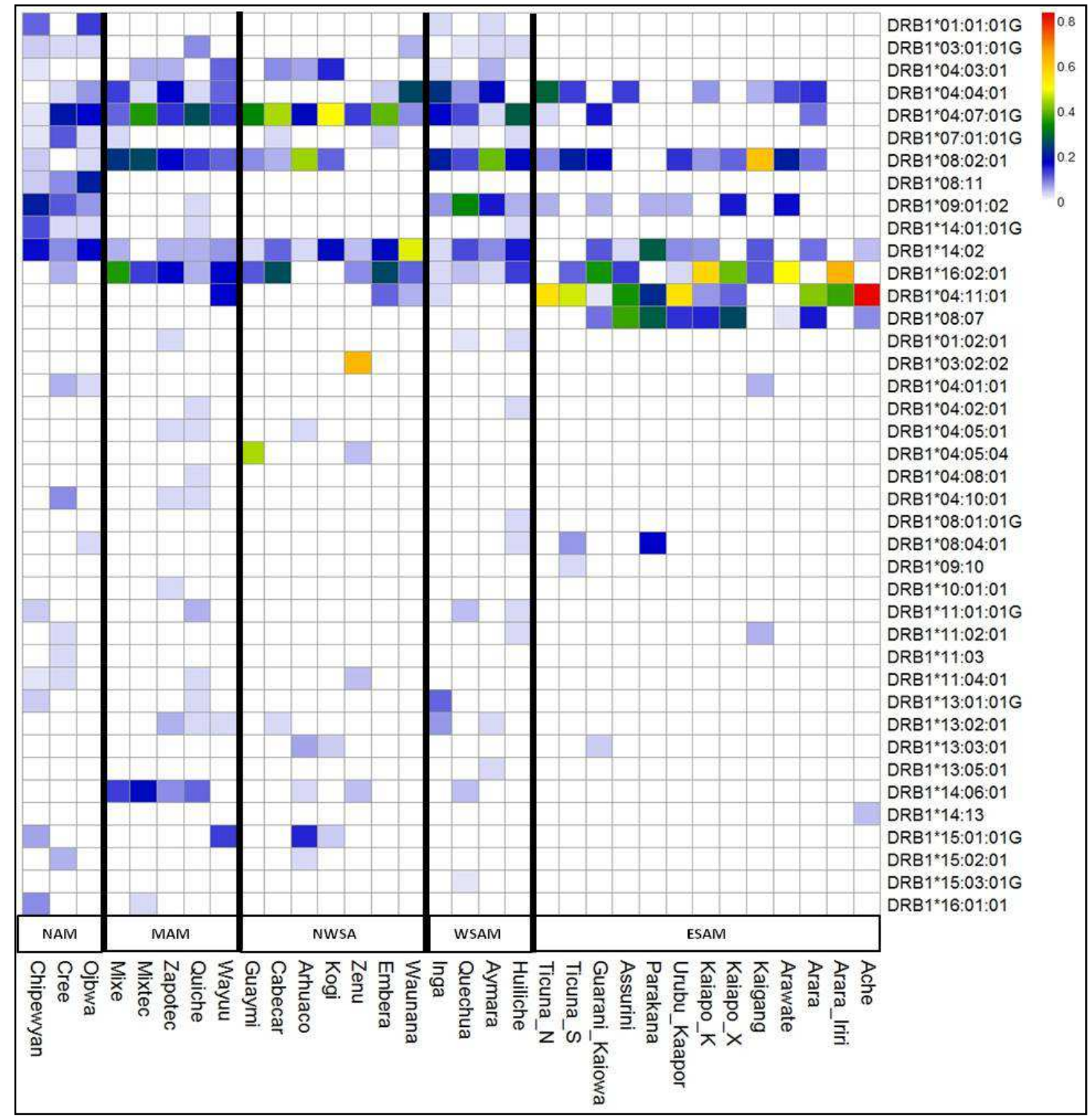

Figure 2.12. Color grid representing the $H L A-D R B 1$ allelic frequencies along the American Continent: the populations were represented at the columns and grouped by geographic region, where NAM, MAM, NWSA, WSAM and ESAM mean North America, Meso-America, South America Northwest, West South America and East South America, respectively. Alleles were represented at the rows.

The HLA-C and -DRB1 allelic distributions were very similar and distinct from which we observed for $H L A-B$ locus: most of the alleles we have observed for the formers loci was found on the North American populations (figure 2.5 and 2.6) while at least other two allelic components beside the one observed in North America could be observed on the HLA-B locus, one at the Meso-American populations and other at the east South America (figure 2.2). 


\subsection{Main Haplotypes Frequency Distribution.}

We observed an incredible high number of haplotypes involving $H L A-B,-C$ and -DRB1 alleles (a total of 180), even after the removal of the estimations with poor accuracy. Even taking only the haplotypes involving the $H L A-B$ and $-C$ loci, which are physically linked, 123 different haplotypes were observed (the entire haplotype list is provided in Supplementary Material 2 (S2)).

Multiple HLA-DRB1 alleles were observed in combination with individuals $H L A-B /-C$ haplotype (figure 2.7 ) which is expected due to the distance between $H L A$ DRB1 and the other genes (1330 megabases (MB)). Despite this pattern, we observed some haplotypes spread over vast geographical regions at high frequencies. We selected the haplotypes which were observed at least in three populations and presented them on table 2.2. Six $\pi$ of the ten haplotypes that fulfilled this criterion contained a HLA-B allele which probably originated by gene conversion (or recombination in the case of $B *$ 35:43:01G). The other four haplotypes included the $B * 40: 02: 01 G$ allele, two of them with $C^{*}$ 03:04:01 and the other two with $C^{*} 03: 05$ (table 2.2). The DRB1*04:11:01 and $D R B 1 * 16: 02: 01$ were observed in four haplotype, two of them being the most frequent in this study (table 2.2).

Considering only the $H L A-B$ and $-C$ loci, a general pattern can be drawn: the $H L A-B$ gene conversion/recombination alleles were often observed in association with the same $-C$ alleles then their parental alleles, except by $B * 15: 04$ which was associated with $C^{*}$ 03:03:01 $G$ while $B * 15: 01: 01 G$ was linked to $C^{*}$ 01:02:01 $G$ ) (figure 2.7). 
Table 1.2. Main $H L A-C /-B /-D R B 1$ haplotypes frequencies.

\begin{tabular}{|c|c|c|c|}
\hline$H L A-C /-B /-D R B 1$ Haplotype & Populations & Average Frequency & $\min -\max$ \\
\hline$C * 03: 03: 01 G / B * 15: 04 / D R B 1 * 16: 02: 01$ & Assurini, Kaiapo_K and Arawete & $24.02 \%$ & $9.09-43.75 \%$ \\
\hline$C * 03: 04: 01 G / B * 40: 04 / D R B 1 * 04: 11: 01$ & Ticuna_N, Arara and Ache & $21.58 \%$ & $2.94-56.25 \%$ \\
\hline$C * 01: 02: 01 G / B * 35: 43: 01 G / D R B 1 * 04: 07: 01 G$ & $\begin{array}{l}\text { Quiche, Wayuu, Guaymi, Cabecar, } \\
\text { Arhuaco, Kogi and Inga }\end{array}$ & $17.17 \%$ & $5.26-39.29 \%$ \\
\hline$C * 03: 04: 01 G / B * 40: 02: 01 G / D R B 1 * 04: 11: 01$ & Wayuu, Ticuna_N and Ticuna_S & $13.98 \%$ & $7.14-26.47 \%$ \\
\hline$C * 07: 02: 01 G / B * 39: 05: 01 / D R B 1 * 04: 07: 01 G$ & $\begin{array}{l}\text { Mixe, Mixtec, Zapotec, Embera } \\
\text { and Guarani Kaiowá }\end{array}$ & $13.42 \%$ & $2.5-28.57 \%$ \\
\hline$C * 04: 01: 01 / B * 35: 12: 01 / D R B 1 * 08: 02: 01$ & Mixe, Mixtec, Zapotec and Quiche & $11.19 \%$ & $7.89-15 \%$ \\
\hline$C * 03: 05 / B * 40: 02: 01 G / D R B 1 * 04: 07: 01 G$ & $\begin{array}{l}\text { Mixtec, Guaymi, Cabecar and } \\
\text { Zenu }\end{array}$ & $10.02 \%$ & $2.5-23.68 \%$ \\
\hline$C * 03: 04: 01 G / B * 40: 02: 01 G / D R B 1 * 04: 01: 01$ & $\begin{array}{l}\text { Waunana, Embera, Ticuna_N and } \\
\text { Ticuna_S }\end{array}$ & $9.68 \%$ & $3.57-17.65 \%$ \\
\hline$C * 03: 05 / B * 40: 02: 01 G / D R B 1 * 04: 03: 01$ & Cabecar, Arhuaco and Kogi & $8.48 \%$ & $5.26-14.29 \%$ \\
\hline$C * 15: 02: 01 G / B * 52: 01: 02 / D R B 1 * 16: 02: 01$ & $\begin{array}{l}\text { Waunana, Ticuna_S and } \\
\text { Kaiapo_K }\end{array}$ & $6.75 \%$ & $2.5-8.33 \%$ \\
\hline
\end{tabular}




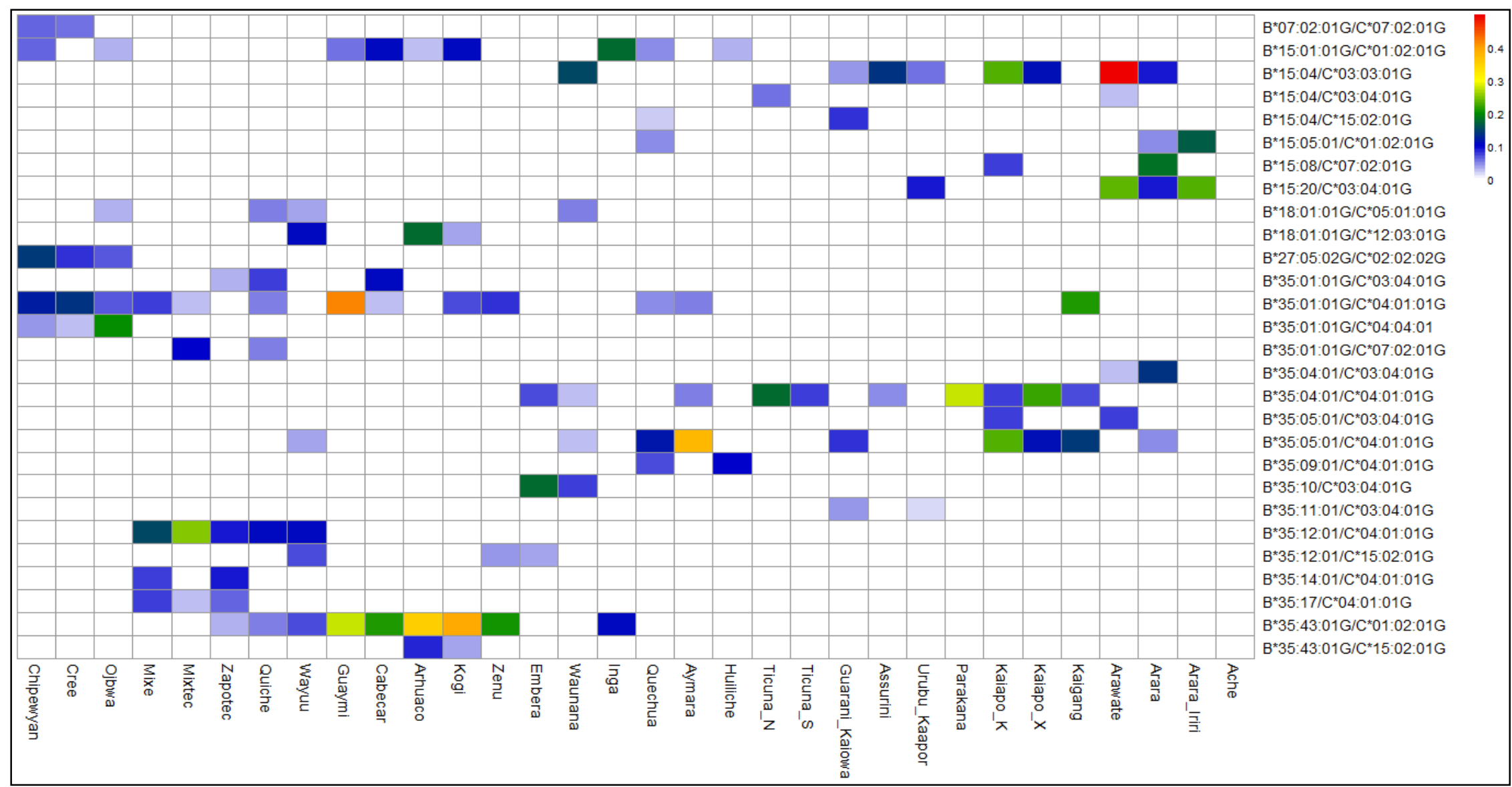

Figure 2.13. Color grid representing the $H L A-B /-C$ haplotypes along the American Continent (part 1): the populations were represented at the columns. Alleles were represented at the rows. 


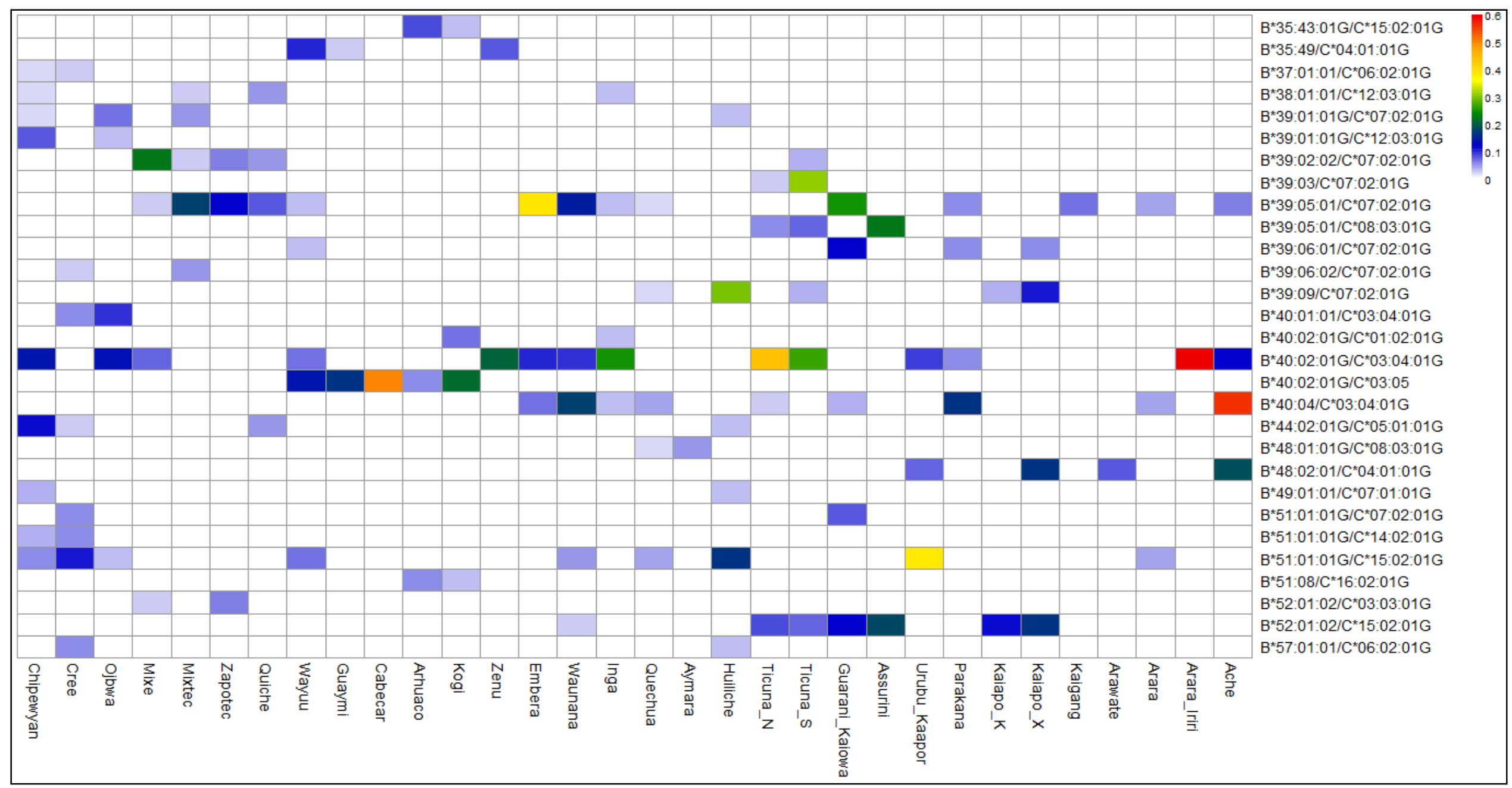

Figure 2.12. Color grid representing the $H L A-B /-C$ haplotypes along the American Continent (part 2): the populations were represented at the columns. Alleles were represented at the rows. 
Considerações Finais 
Referenceias Bibliograficas

Albrechtsen, Anders, Ida Moltke, and Rasmus Nielsen. 2010. "Natural selection and the distribution of identity-by-descent in the human genome." Genetics 186(1): 295-308.

http:/ / www.pubmedcentral.nih.gov/articlerender.fcgi?artid=2940294\& tool $=$ pmcentrez\&rendertype $=$ abstract (August 7, 2013).

Apanius, V, D Penn, P R Slev, L R Ruff, and W K Potts. 1997. "The nature of selection on the major histocompatibility complex." Critical reviews in immunology 17(2): 179-224.

http://www.ncbi.nlm.nih.gov/pubmed/9094452 (August 19, 2012).

Bamshad, Michael, and Stephen P Wooding. 2003. "Signatures of natural selection in the human genome." Nature reviews. Genetics 4(2): 99-111. http://www.ncbi.nlm.nih.gov/pubmed/12560807 (September 20, 2013).

Borghans, José A M, Joost B Beltman, and Rob J De Boer. 2004. "MHC polymorphism under host-pathogen coevolution." Immunogenetics 55(11): 732-9. http://www.ncbi.nlm.nih.gov/pubmed/14722687 (August 14, 2013).

Buhler, Stéphane, and Alicia Sanchez-Mazas. 2011. "HLA DNA sequence variation among human populations: molecular signatures of demographic and selective events." PloS one 6(2): e14643.

http://www.pubmedcentral.nih.gov/articlerender.fcgi? artid=3051395\& tool $=$ pmcentrez\&rendertype $=$ abstract $($ September 12, 2011).

Bustamante, Carlos D, Adi Fledel-Alon, Scott Williamson, Rasmus Nielsen, Melissa Todd Hubisz, Stephen Glanowski, David M Tanenbaum, Thomas J White, John J Sninsky, Ryan D Hernandez, Daniel Civello, Mark D Adams, Michele Cargill, and Andrew G Clark. 2005. "Natural selection on protein-coding genes in the human genome." Nature 437(7062): 1153-7. http://www.ncbi.nlm.nih.gov/pubmed/16237444 (July 18, 2011).

Campos-Lima, P O, V Levitsky, M P Imreh, R Gavioli, and M G Masucci. 1997. "Epitope-dependent selection of highly restricted or diverse T cell receptor repertoires in response to persistent infection by EpsteinBarr virus." The Journal of experimental medicine 186(1): 83-9. http://www.pubmedcentral.nih.gov/articlerender.fcgi?artid=2198955\& tool $=$ pmcentrez\&rendertype $=$ abstract (August 19, 2012). 
Carrington, M, G W Nelson, M P Martin, T Kissner, D Vlahov, J J

Goedert, R Kaslow, S Buchbinder, K Hoots, and S J O’Brien. 1999.

"HLA and HIV-1: heterozygote advantage and B*35-Cw*04

disadvantage." Science (New York, N.Y.) 283(5408): 1748-52.

http://www.ncbi.nlm.nih.gov/pubmed/10073943 (August 19, 2012).

Chakraborty, Sajib, Taibur Rahman, Rajib Chakravorty, Alison Kuchta, Atai Rabby, and Munsi Sahiuzzaman. 2013. "HLA supertypes contribute in HIV type 1 cytotoxic T lymphocyte epitope clustering in Nef and Gag proteins." AIDS research and human retroviruses 29(2): 270-8. http://www.ncbi.nlm.nih.gov/pubmed/23061377 (September 13, 2013).

Cordery, Damien V, Allison Martin, Janaki Amin, Anthony D Kelleher, Sean Emery, and David A Cooper. 2012. "The influence of HLA supertype on thymidine analogue associated with low peripheral fat in HIV." AIDS (London, England) 26(18): 2337-44. http://www.ncbi.nlm.nih.gov/pubmed/23032422 (September 13, 2013).

Doherty, P C, and R M Zinkernagel. 1975. "A biological role for the major histocompatibility antigens.” Lancet 1(7922): 1406-9.

http://www.ncbi.nlm.nih.gov/pubmed/49564 (August 19, 2012).

Ewens, W J. 1972. "The sampling theory of selectively neutral alleles." Theoretical population biology 3(1): 87-112.

http:/ /www.ncbi.nlm.nih.gov/pubmed/4667078 (August 26, 2013).

Excoffier, Laurent, and Heidi E L Lischer. 2010. "Arlequin suite ver 3.5: a new series of programs to perform population genetics analyses under Linux and Windows." Molecular ecology resources 10(3): 564-7.

http://www.ncbi.nlm.nih.gov/pubmed/21565059 (July 8, 2011).

Garrigan, Daniel, and Philip W Hedrick. 2003. "Perspective: detecting adaptive molecular polymorphism: lessons from the MHC." Evolution; international journal of organic evolution 57(8): 1707-22. http://www.ncbi.nlm.nih.gov/pubmed/14503614.

Gilchuk, Pavlo, Charles T Spencer, Stephanie B Conant, Timothy Hill, Jennifer J Gray, Xinnan Niu, Mu Zheng, John J Erickson, Kelli L Boyd, K Jill McAfee, Carla Oseroff, Sine R Hadrup, Jack R Bennink, William Hildebrand, Kathryn M Edwards, James E Crowe, John V Williams, Søren Buus, Alessandro Sette, Ton N M Schumacher, Andrew J Link, and Sebastian Joyce. 2013. "Discovering naturally processed antigenic 
determinants that confer protective T cell immunity." The Journal of clinical investigation 123(5): 1976-87.

http://www.pubmedcentral.nih.gov/articlerender.fcgi?artid=3635741\& tool $=$ pmcentrez\&rendertype $=$ abstract (August 8, 2013).

Gillespie, J H. 1977. "Sampling theory for alleles in a random environment." Nature 266(5601): 443-5.

http://www.ncbi.nlm.nih.gov/pubmed/859613 (August 19, 2012).

Gonzalez-Galarza, Faviel F, Stephen Christmas, Derek Middleton, and Andrew R Jones. 2011. "Allele frequency net: a database and online repository for immune gene frequencies in worldwide populations." Nucleic acids research 39(Database issue): D913-9.

http://www.pubmedcentral.nih.gov/articlerender.fcgi?artid=3013710\& tool $=$ pmcentrez\&rendertype $=$ abstract (August 7, 2013).

Guo, S W, and E A Thompson. 1992. "Performing the exact test of HardyWeinberg proportion for multiple alleles." Biometrics 48(2): 361-72. http://www.ncbi.nlm.nih.gov/pubmed/1637966 (August 19, 2012).

Hammer, Michael F, Felisa Blackmer, Dan Garrigan, Michael W Nachman, and Jason A Wilder. 2003. "Human population structure and its effects on sampling Y chromosome sequence variation.” Genetics 164(4): 1495509.

http:/ / www.pubmedcentral.nih.gov/articlerender.fcgi?artid=1462677\& tool $=$ pmcentrez\&rendertype $=$ abstract $($ September 18, 2013).

Hill, A V, A Jepson, M Plebanski, and S C Gilbert. 1997. "Genetic analysis of host-parasite coevolution in human malaria." Philosophical transactions of the Royal Society of London. Series B, Biological sciences 352(1359): 1317-25. http:/ / www.pubmedcentral.nih.gov/articlerender.fcgi?artid=1692024\& tool $=$ pmcentrez\&rendertype $=$ abstract (August 3, 2012).

Hraber, Peter, Carla Kuiken, and Karina Yusim. 2007. "Evidence for human leukocyte antigen heterozygote advantage against hepatitis $\mathrm{C}$ virus infection." Hepatology (Baltimore, Md.) 46(6): 1713-21. http://www.ncbi.nlm.nih.gov/pubmed/17935228 (August 19, 2012).

Hughes, A L, and M Nei. 1988. "Pattern of nucleotide substitution at major histocompatibility complex class I loci reveals overdominant selection." Nature 335(6186): 167-70.

http://www.ncbi.nlm.nih.gov/pubmed/3412472 (September 26, 2011).

Jaruzelska, J, E Zietkiewicz, M Batzer, D E Cole, J P Moisan, R Scozzari, S Tavaré, and D Labuda. 1999. "Spatial and temporal distribution of the 
neutral polymorphisms in the last ZFX intron: analysis of the haplotype structure and genealogy." Genetics 152(3): 1091-101.

http://www.pubmedcentral.nih.gov/articlerender.fcgi?artid=1460666\& tool $=$ pmcentrez\&rendertype $=$ abstract $($ September 18, 2013).

Jost, Lou. 2008. "G ST and its relatives do not measure differentiation." Molecular Ecology 17(18): 4015-4026.

http://doi.wiley.com/10.1111/j.1365-294X.2008.03887.x (June 16, 2011).

Karlsson, Ingrid, Lea Brandt, Lasse Vinner, Ingrid Kromann, Lars Vibe Andreasen, Peter Andersen, Jan Gerstoft, Gitte Kronborg, and Anders Fomsgaard. 2013. "Adjuvanted HLA-supertype restricted subdominant peptides induce new T-cell immunity during untreated HIV-1infection." Clinical immunology (Orlando, Fla.) 146(2): 120-30. http://www.ncbi.nlm.nih.gov/pubmed/23314272 (September 13, 2013).

Karlsson, Ingrid, Henrik Kløverpris, Kristoffer Jarlov Jensen, Anette Stryhn, Søren Buus, Annika Karlsson, Lasse Vinner, Philip Goulder, and Anders Fomsgaard. 2012. "Identification of conserved subdominant HIV Type 1 CD8(+) T Cell epitopes restricted within common HLA Supertypes for therapeutic HIV Type 1 vaccines." AIDS research and human retroviruses 28(11): 1434-43. http://www.ncbi.nlm.nih.gov/pubmed/22747336 (September 13, 2013).

Kaslow, R A, M Carrington, R Apple, L Park, A Muñoz, A J Saah, J J Goedert, C Winkler, S J O'Brien, C Rinaldo, R Detels, W Blattner, J Phair, H Erlich, and D L Mann. 1996. "Influence of combinations of human major histocompatibility complex genes on the course of HIV-1 infection." Nature medicine 2(4): 405-11.

http://www.ncbi.nlm.nih.gov/pubmed/8597949 (August 19, 2012).

Knowles, L. L. 2003. "The burgeoning field of statistical phylogeography." Journal of Evolutionary Biology 17(1): 1-10. http://doi.wiley.com/10.1046/j.1420-9101.2003.00644.x (July 22, 2011).

Kuniholm, M H, K Anastos, A Kovacs, X Gao, D Marti, A Sette, R M Greenblatt, M Peters, M H Cohen, H Minkoff, S J Gange, C L Thio, M A Young, X Xue, M Carrington, and H D Strickler. 2013. "Relation of HLA class I and II supertypes with spontaneous clearance of hepatitis C virus." Genes and immunity 14(5): 330-5. 
http://www.ncbi.nlm.nih.gov/pubmed/23636221 (September 13, 2013).

Lazaryan, Aleksandr, Elena Lobashevsky, Joseph Mulenga, Etienne Karita, Susan Allen, Jianming Tang, and Richard A Kaslow. 2006. "Human leukocyte antigen B58 supertype and human immunodeficiency virus type 1 infection in native Africans." Journal of virology 80(12): 6056-60. http://www.pubmedcentral.nih.gov/articlerender.fcgi?artid=1472610\& tool $=$ pmcentrez\&rendertype $=$ abstract $($ September 13, 2013).

Meyer, D, and G Thomson. 2001. "How selection shapes variation of the human major histocompatibility complex: a review." Annals of human genetics 65(Pt 1): 1-26.

http://www.ncbi.nlm.nih.gov/pubmed/11415519 (December 16, 2011).

Naugler, Christopher, and Robert Liwski. 2008. "An evolutionary approach to major histocompatibility diversity based on allele supertypes." Medical bypotheses 70(5): 933-7.

http://www.ncbi.nlm.nih.gov/pubmed/18063318 (October 8, 2011).

Nei, M, and R K Chesser. 1983. "Estimation of fixation indices and gene diversities." Annals of buman genetics 47(Pt 3): 253-9.

http://www.ncbi.nlm.nih.gov/pubmed/6614868 (September 13, 2013).

Nei, Masatoshi. 1987. "Molecular Evolutionary Genetics."

Ovsyannikova, Inna G, Robert A Vierkant, V Shane Pankratz, Megan M

O’Byrne, Robert M Jacobson, and Gregory A Poland. 2009. "HLA haplotype and supertype associations with cellular immune responses and cytokine production in healthy children after rubella vaccine." Vaccine 27(25-26): 3349-58.

http://www.pubmedcentral.nih.gov/articlerender.fcgi?artid=2693336\& tool $=$ pmcentrez\&rendertype $=$ abstract $($ September 13, 2013).

Parham, P, K L Arnett, E J Adams, A M Little, K Tees, L D Barber, S G Marsh, T Ohta, T Markow, and M L Petzl-Erler. 1997. "Episodic evolution and turnover of HLA-B in the indigenous human populations of the Americas." Tissue antigens 50(3): 219-32. http://www.ncbi.nlm.nih.gov/pubmed/9331945 (December 16, 2011).

Parham, Peter. 2005. "MHC class I molecules and KIRs in human history, health and survival." Nature reviews. Immunology 5(3): 201-14.

http://www.ncbi.nlm.nih.gov/pubmed/15719024 (July 15, 2012). 
Piertney, S B, and M K Oliver. 2006. "The evolutionary ecology of the major histocompatibility complex." Heredity 96(1): 7-21. http://www.ncbi.nlm.nih.gov/pubmed/16094301 (June 20, 2011).

Prevosti, A., J. Ocaña, and G. Alonso. 1975. "Distances between populations ofDrosophila subobscura, based on chromosome arrangement frequencies." Theoretical and Applied Genetics 45(6): 231-241. http://link.springer.com/10.1007/BF00831894 (August 16, 2013).

Prugnolle, Franck, Andrea Manica, Marie Charpentier, Jean François Guégan, and François Balloux. 2007. "UKPMC Funders Group Pathogen-driven selection and worldwide HLA class I diversity." Genetics 15(11): 1022-1027.

Prugnolle, Franck, Andrea Manica, Marie Charpentier, Jean François Guégan, Vanina Guernier, and François Balloux. 2005. "Pathogendriven selection and worldwide HLA class I diversity." Current biology: CB 15(11): 1022-7. http://www.ncbi.nlm.nih.gov/pubmed/15936272 (July 30, 2012).

Qutob, Nouar, Francois Balloux, Towfique Raj, Hua Liu, Sophie Marion de Procé, John Trowsdale, and Andrea Manica. 2011. "Signatures of historical demography and pathogen richness on MHC class I genes." Immunogenetics. http:/ /www.ncbi.nlm.nih.gov/pubmed/21947542 (November 30, 2011).

Reich, David, Nick Patterson, Desmond Campbell, Arti Tandon, Stéphane Mazieres, Nicolas Ray, et al. 2012. "Reconstructing Native American population history." Nature: $1-6$.

http://www.nature.com/doifinder/10.1038/nature11258 (July 12, 2012).

Robinson, James. 2003. "IMGT/HLA and IMGT/MHC: sequence databases for the study of the major histocompatibility complex." Nucleic Acids Research 31(1): 311-314. http://nar.oxfordjournals.org/content/31/1/311.short (July 6, 2011).

Robinson, James, Kavita Mistry, Hamish McWilliam, Rodrigo Lopez, Peter Parham, and Steven G E Marsh. 2011. "The IMGT/HLA database." Nucleic acids research 39(Database issue): D1171-6. http:/ /www.pubmedcentral.nih.gov/articlerender.fcgi?artid=3013815\& tool $=$ pmcentrez\&rendertype $=$ abstract $($ September 1, 2013).

Sanchez-Mazas, Alicia, Jean-François Lemaître, and Mathias Currat. 2012. "Distinct evolutionary strategies of human leucocyte antigen loci in 
pathogen-rich environments." Philosophical transactions of the Royal Society of London. Series B, Biological sciences 367(1590): 830-9. http://www.ncbi.nlm.nih.gov/pubmed/22312050 (August 19, 2012).

Saper, M A, P J Bjorkman, and D C Wiley. 1991. "Refined structure of the human histocompatibility antigen HLA-A2 at 2.6 A resolution." Journal of molecular biology 219(2): 277-319.

http://www.ncbi.nlm.nih.gov/pubmed/2038058 (December 16, 2011).

Sette, a, and J Sidney. 1999. "Nine major HLA class I supertypes account for the vast preponderance of HLA-A and -B polymorphism." Immunogenetics 50(3-4): 201-12. http://www.ncbi.nlm.nih.gov/pubmed/10602880.

Shehzadi, Abida, Shahid Ur Rehman, and Tayyab Husnain. 2012. "Selection of epitope-based vaccine targets of HCV genotype 1 of Asian origin: a systematic in silico approach." Bioinformation 8(20): 957-62.

http://www.pubmedcentral.nih.gov/articlerender.fcgi?artid=3524940\& tool=pmcentrez\&rendertype $=$ abstract $($ September 13, 2013).

Sidney, John, Howard M Grey, Ralph T Kubo, and Alessandro Sette. 1996. "Practical, biochemical and evolutionary implications of the discovery of HLA class I supermotifs." Immunology today 17(6): 261-266.

Sidney, John, Bjoern Peters, Nicole Frahm, Christian Brander, and Alessandro Sette. 2008. "HLA class I supertypes: a revised and updated classification." BMC immunology 9: 1.

http:/ / www.pubmedcentral.nih.gov/articlerender.fcgi?artid=2245908\& tool $=$ pmcentrez\&rendertype $=$ abstract $($ July 17, 2011).

Slatkin, M, and L Excoffier. 1996. "Testing for linkage disequilibrium in genotypic data using the Expectation-Maximization algorithm." Heredity 76 ( Pt 4): 377-83. http://www.ncbi.nlm.nih.gov/pubmed/8626222 (August 26, 2013).

Solberg, Owen D, Steven J Mack, Alex K Lancaster, Richard M Single, Yingssu Tsai, Alicia Sanchez-Mazas, and Glenys Thomson. 2008. "Balancing selection and heterogeneity across the classical human leukocyte antigen loci: a meta-analytic review of 497 population studies." Human immunology 69(7): 443-64.

http:/ / www.pubmedcentral.nih.gov/articlerender.fcgi?artid=2632948\& tool $=$ pmcentrez\&rendertype $=$ abstract $($ June 13,2011$)$.

Tajima, F. 1983. "Evolutionary relationship of DNA sequences in finite populations." Genetics 105(2): 437-60. 
http://www.pubmedcentral.nih.gov/articlerender.fcgi?artid=1202167\& tool $=$ pmcentrez\&rendertype $=$ abstract.

Takahata, N, Y Satta, and J Klein. 1992. "Polymorphism and balancing selection at major histocompatibility complex loci." Genetics 130(4): 925-38.

http://www.pubmedcentral.nih.gov/articlerender.fcgi?artid=1204941\& tool=pmcentrez\&rendertype $=$ abstract $($ September 13, 2012).

The MHC sequencing consortium. 1999. "Complete sequence and gene map of a human major histocompatibility complex." 401(October): 921-923.

Trachtenberg, Elizabeth, Bette Korber, Cristina Sollars, Thomas B Kepler, Peter T Hraber, Elizabeth Hayes, Robert Funkhouser, Michael Fugate, James Theiler, Yen S Hsu, Kevin Kunstman, Samuel Wu, John Phair, Henry Erlich, and Steven Wolinsky. 2003. "Advantage of rare HLA supertype in HIV disease progression." Nature medicine 9(7): 928-35. http://www.ncbi.nlm.nih.gov/pubmed/12819779 (September 13, 2013).

Wang, Sijia, Cecil M Lewis, Mattias Jakobsson, Sohini Ramachandran, Nicolas Ray, Gabriel Bedoya, Winston Rojas, Maria V Parra, Julio A Molina, Carla Gallo, Guido Mazzotti, Giovanni Poletti, Kim Hill, Ana M Hurtado, Damian Labuda, William Klitz, Ramiro Barrantes, Maria Cátira Bortolini, Francisco M Salzano, Maria Luiza Petzl-Erler, Luiza T Tsuneto, Elena Llop, Francisco Rothhammer, Laurent Excoffier, Marcus W Feldman, Noah A Rosenberg, and Andrés Ruiz-Linares. 2007. "Genetic variation and population structure in native Americans." PLoS genetics 3(11): e185. http:/ / www.pubmedcentral.nih.gov/articlerender.fcgi?artid=2082466\& tool $=$ pmcentrez\&rendertype $=$ abstract (August 7, 2013).

Watterson, G A. 1978. “The homozygosity test of neutrality." Genetics 88(2): 405-17.

http://www.pubmedcentral.nih.gov/articlerender.fcoi?artid=1213809\& tool $=$ pmcentrez\&rendertype $=$ abstract $($ December 16, 2011).

Wright, Sewall. 1978. Evolution and the Genetics of Populations. Chicago: University of Chicago.

Xavier Eurico de Alencar, Liciana, Ulisses de Mendonça Braga-Neto, Eduardo José Moura do Nascimento, Marli Tenório Cordeiro, Ana Maria Silva, Carlos Alexandre Antunes de Brito, Maria da Paz Carvalho 
da Silva, Laura Helena Vega Gonzales Gil, Silvia Maria Lucena Montenegro, and Ernesto Torres de Azevedo Marques. 2013. "HLA$\mathrm{B} * 44$ Is Associated with Dengue Severity Caused by DENV-3 in a Brazilian Population." Journal of tropical medicine 2013: 648475. http:/ / www.pubmedcentral.nih.gov/articlerender.fcgi?artid=3684019\& tool $=$ pmcentrez\&rendertype $=$ abstract $($ September 13, 2013). 
Supplementary Material 1

(S1) 
Table 1-S1. Samples sizes and geografic distribution.

\begin{tabular}{|c|c|c|c|}
\hline \multirow[t]{2}{*}{ Populations } & \multirow[t]{2}{*}{ Regions } & \multicolumn{2}{|c|}{$\mathbf{N}$} \\
\hline & & $H L A-A$ & $H L A-B$ \\
\hline Zulu & SSA & 186 & 201 \\
\hline Zambia & SSA & 43 & 44 \\
\hline Kenyan & SSA & 143 & 143 \\
\hline Kenyan_Highlanders & SSA & 241 & 240 \\
\hline Kenyan_Lowlanders & SSA & 265 & 265 \\
\hline Uganda & SSA & 163 & 161 \\
\hline Mali & SSA & 138 & 138 \\
\hline Chaouya & NAF & 67 & 68 \\
\hline Metalsa & NAF & 72 & 68 \\
\hline Druze & SWA & 100 & 100 \\
\hline Jewish & SWA & 117 & 109 \\
\hline Georgian & SWA & 105 & 107 \\
\hline Kurisk & SWA & 30 & 29 \\
\hline Omani & SWA & 119 & 120 \\
\hline New_Delhi & SWA & 66 & 66 \\
\hline Tamil & SWA & 50 & 49 \\
\hline Golla & SWA & 88 & 104 \\
\hline Czech & EUR & 105 & 106 \\
\hline Croatian & EUR & 150 & 150 \\
\hline Finnish & EUR & 90 & 90 \\
\hline Ireland & EUR & 999 & 1000 \\
\hline Chinese1 & SEA & 149 & 149 \\
\hline Singapour_Chinese & SEA & 86 & 86 \\
\hline South_Chinese & SEA & 282 & 281 \\
\hline
\end{tabular}




\begin{tabular}{|c|c|c|c|}
\hline Okinawa & SEA & 105 & 104 \\
\hline Thai & SEA & 98 & 99 \\
\hline Malay & SEA & 124 & 101 \\
\hline Ami & SEA & 98 & 98 \\
\hline Atayal & SEA & 106 & 106 \\
\hline Bunun & SEA & 101 & 101 \\
\hline Hakka & SEA & 55 & 55 \\
\hline Minnan & SEA & 102 & 102 \\
\hline Paiwan & SEA & 51 & 51 \\
\hline Pazeh & SEA & 55 & 55 \\
\hline Puyuma & SEA & 50 & 50 \\
\hline Rukai & SEA & 50 & 50 \\
\hline Saisiat & SEA & 51 & 51 \\
\hline Siraya & SEA & 51 & 51 \\
\hline Thao & SEA & 30 & 30 \\
\hline Toroko & SEA & 55 & 55 \\
\hline Tsou & SEA & 51 & 51 \\
\hline Yami & SEA & 50 & 50 \\
\hline Indonesian & SEA & 50 & 49 \\
\hline Filipino & SEA & 94 & 94 \\
\hline PNG_Highlands & PAC & 92 & 75 \\
\hline Samoan & PAC & 50 & 50 \\
\hline Ivatan & PAC & 50 & 50 \\
\hline Cape_York & AUS & 103 & 100 \\
\hline Groote_Eylandt & AUS & 75 & 75 \\
\hline Kimberly & AUS & 36 & 38 \\
\hline Yuendumu & AUS & 191 & 193 \\
\hline
\end{tabular}




\begin{tabular}{llll} 
Korean & NEA & 191 & 200 \\
Tuva & NEA & 188 & 180 \\
Pima & AME & 86 & 89 \\
Bari & AME & 92 & 82 \\
\hline
\end{tabular}

Table 2-S1. Supertypes frequencies

\begin{tabular}{|c|c|c|c|c|c|c|c|c|c|c|c|c|}
\hline \multirow[t]{2}{*}{ Populations } & \multirow[t]{2}{*}{ Region } & \multicolumn{5}{|l|}{ HLA-A } & \multicolumn{6}{|l|}{ HLA-B } \\
\hline & & A1 & A2 & A3 & A24 & NCA & B7 & B27 & B44 & B58 & B62 & $\mathrm{NCB}$ \\
\hline Zulu & SSA & 0.201613 & 0.204301 & 0.206989 & 0.123656 & 0.263441 & 0.283582 & 0.233831 & 0.169154 & 0.189055 & 0.004975 & 0.119403 \\
\hline Zambia & SSA & 0.337209 & 0.22093 & 0.151163 & 0.081395 & 0.209302 & 0.409091 & 0.193182 & 0.181818 & 0.113636 & 0.022727 & 0.079545 \\
\hline Kenyan & SSA & 0.20979 & 0.276224 & 0.248252 & 0.090909 & 0.174825 & 0.297203 & 0.143357 & 0.157343 & 0.237762 & 0.003497 & 0.160839 \\
\hline $\begin{array}{l}\text { Kenyan_Highland } \\
\text { ers }\end{array}$ & SSA & 0.215768 & 0.396266 & 0.172199 & 0.080913 & 0.134855 & 0.302083 & 0.145833 & 0.158333 & 0.247917 & 0 & 0.145833 \\
\hline $\begin{array}{l}\text { Kenyan_Lowlande } \\
\text { rs }\end{array}$ & SSA & 0.209434 & 0.266038 & 0.298113 & 0.09434 & 0.132075 & 0.30566 & 0.216981 & 0.15283 & 0.232075 & 0.003774 & 0.088679 \\
\hline Uganda & SSA & 0.196319 & 0.303681 & 0.312883 & 0.116564 & 0.070552 & 0.273292 & 0.18323 & 0.21118 & 0.136646 & 0.049689 & 0.145963 \\
\hline Mali & SSA & 0.068841 & 0.246377 & 0.264493 & 0.235507 & 0.184783 & 0.597826 & 0.126812 & 0.101449 & 0.054348 & 0.083333 & 0.036232 \\
\hline Chaouya & NAF & 0.268657 & 0.268657 & 0.19403 & 0.11194 & 0.156716 & 0.235294 & 0.117647 & 0.397059 & 0.102941 & 0.014706 & 0.132353 \\
\hline Metalsa & $\mathrm{NAF}$ & 0.291667 & 0.222222 & 0.284722 & 0.145833 & 0.055556 & 0.176471 & 0.117647 & 0.507353 & 0.036765 & 0.007353 & 0.154412 \\
\hline Druze & SWA & 0.185 & 0.25 & 0.245 & 0.21 & 0.11 & 0.4 & 0.08 & 0.365 & 0.035 & 0.01 & 0.11 \\
\hline Jewish & SWA & 0.307692 & 0.247863 & 0.25641 & 0.123932 & 0.064103 & 0.275229 & 0.16055 & 0.261468 & 0.077982 & 0.077982 & 0.146789 \\
\hline Georgian & SWA & 0.147619 & 0.342857 & 0.3 & 0.195238 & 0.014286 & 0.490654 & 0.107477 & 0.168224 & 0.037383 & 0.065421 & 0.130841 \\
\hline Kurisk & SWA & 0.266667 & 0.133333 & 0.316667 & 0.183333 & 0.1 & 0.482759 & 0.068966 & 0.206897 & 0 & 0.103448 & 0.137931 \\
\hline Omani & SWA & 0.340336 & 0.252101 & 0.302521 & 0.088235 & 0.016807 & 0.404167 & 0.120833 & 0.2 & 0.104167 & 0.045833 & 0.125 \\
\hline New_Delhi & SWA & 0.143939 & 0.19697 & 0.507576 & 0.136364 & 0.015152 & 0.356061 & 0.030303 & 0.310606 & 0.113636 & 0.068182 & 0.121212 \\
\hline Tamil & SWA & 0.2 & 0.15 & 0.45 & 0.16 & 0.04 & 0.255102 & 0.05102 & 0.265306 & 0.153061 & 0.142857 & 0.132653 \\
\hline
\end{tabular}




\begin{tabular}{|c|c|c|c|c|c|c|c|c|c|c|c|c|}
\hline Golla & SWA & 0.181818 & 0.193182 & 0.443182 & 0.153409 & 0.028409 & 0.307692 & 0.052885 & 0.259615 & 0.100962 & 0.158654 & 0.120192 \\
\hline Czech & EUR & 0.22381 & 0.328571 & 0.290476 & 0.12381 & 0.033333 & 0.292453 & 0.141509 & 0.320755 & 0.051887 & 0.04717 & 0.146226 \\
\hline Croatian & EUR & 0.253333 & 0.283333 & 0.253333 & 0.183333 & 0.026667 & 0.353333 & 0.176667 & 0.283333 & 0.036667 & 0.063333 & 0.086667 \\
\hline Finnish & EUR & 0.138889 & 0.344444 & 0.394444 & 0.1 & 0.022222 & 0.355556 & 0.122222 & 0.272222 & 0.016667 & 0.122222 & 0.111111 \\
\hline ireland & EUR & 0.284785 & 0.295295 & 0.286286 & 0.074074 & 0.05956 & 0.2905 & 0.1195 & 0.317 & 0.0415 & 0.042 & 0.1895 \\
\hline Chinese1 & SEA & 0.030201 & 0.342282 & 0.422819 & 0.16443 & 0.040268 & 0.218121 & 0.057047 & 0.208054 & 0.104027 & 0.244966 & 0.167785 \\
\hline $\begin{array}{l}\text { Singapour_Chines } \\
\text { e }\end{array}$ & SEA & 0.034884 & 0.343023 & 0.389535 & 0.215116 & 0.017442 & 0.19186 & 0.081395 & 0.168605 & 0.063953 & 0.319767 & 0.174419 \\
\hline South_Chinese & SEA & 0.021277 & 0.29078 & 0.45922 & 0.179078 & 0.049645 & 0.181495 & 0.085409 & 0.213523 & 0.088968 & 0.252669 & 0.177936 \\
\hline Okinawa & SEA & 0.214286 & 0.247619 & 0.190476 & 0.342857 & 0.004762 & 0.403846 & 0.120192 & 0.235577 & 0 & 0.163462 & 0.076923 \\
\hline Thai & SEA & 0.010204 & 0.316327 & 0.44898 & 0.127551 & 0.096939 & 0.176768 & 0.090909 & 0.186869 & 0.090909 & 0.287879 & 0.166667 \\
\hline Malay & SEA & 0.056452 & 0.181452 & 0.318548 & 0.221774 & 0.221774 & 0.237624 & 0.029703 & 0.292079 & 0.069307 & 0.222772 & 0.148515 \\
\hline Ami & SEA & 0 & 0.040816 & 0.112245 & 0.627551 & 0.219388 & 0.22449 & 0.372449 & 0.377551 & 0 & 0.02551 & 0 \\
\hline Atayal & SEA & 0.080189 & 0.169811 & 0.132075 & 0.617925 & 0 & 0.136792 & 0.448113 & 0.382076 & 0 & 0.033019 & 0 \\
\hline Bunun & SEA & 0.193069 & 0.113861 & 0.108911 & 0.584158 & 0 & 0.188119 & 0.237624 & 0.237624 & 0 & 0.069307 & 0.267327 \\
\hline Minnan & SEA & 0.044118 & 0.29902 & 0.455882 & 0.186275 & 0.014706 & 0.147059 & 0.078431 & 0.264706 & 0.088235 & 0.259804 & 0.161765 \\
\hline Paiwan & SEA & 0.039216 & 0.068627 & 0.019608 & 0.862745 & 0.009804 & 0.078431 & 0.137255 & 0.470588 & 0.009804 & 0.04902 & 0.254902 \\
\hline Pazeh & SEA & 0.027273 & 0.2 & 0.436364 & 0.336364 & 0 & 0.136364 & 0.181818 & 0.254546 & 0.036364 & 0.254545 & 0.136364 \\
\hline Puyuma & SEA & 0.03 & 0.2 & 0.09 & 0.64 & 0.04 & 0.08 & 0.26 & 0.23 & 0 & 0.25 & 0.18 \\
\hline Rukai & SEA & 0.14 & 0.06 & 0.04 & 0.76 & 0 & 0.07 & 0.2 & 0.32 & 0 & 0.13 & 0.28 \\
\hline Saisiat & SEA & 0.04902 & 0.137255 & 0.245098 & 0.568627 & 0 & 0.04902 & 0.588235 & 0.323529 & 0 & 0 & 0.039216 \\
\hline Siraya & SEA & 0.019608 & 0.186275 & 0.313725 & 0.470588 & 0.009804 & 0.127451 & 0.127451 & 0.352941 & 0.058824 & 0.127451 & 0.205882 \\
\hline Thao & SEA & 0.016667 & 0.116667 & 0.266667 & 0.6 & 0 & 0.116667 & 0.216667 & 0.25 & 0.05 & 0.15 & 0.216667 \\
\hline Toroko & SEA & 0.218182 & 0.245455 & 0.090909 & 0.445455 & 0 & 0.145455 & 0.418182 & 0.427273 & 0 & 0 & 0.009091 \\
\hline Tsou & SEA & 0.04902 & 0.029412 & 0.137255 & 0.784314 & 0 & 0.137255 & 0.362745 & 0.264706 & 0 & 0.058824 & 0.176471 \\
\hline Yami & SEA & 0 & 0.02 & 0.39 & 0.54 & 0.05 & 0 & 0.07 & 0.26 & 0 & 0.52 & 0.15 \\
\hline Indonesian & SEA & 0.11 & 0.18 & 0.31 & 0.21 & 0.19 & 0.204082 & 0.030612 & 0.316327 & 0.05102 & 0.285714 & 0.112245 \\
\hline
\end{tabular}




\begin{tabular}{|c|c|c|c|c|c|c|c|c|c|c|c|c|}
\hline Filipino & SEA & 0.031915 & 0.106383 & 0.340426 & 0.244681 & 0.276596 & 0.180851 & 0.101064 & 0.207447 & 0.074468 & 0.18617 & 0.25 \\
\hline PNG_Highlands & PAC & 0 & 0.005435 & 0.108696 & 0.782609 & 0.103261 & 0.46 & 0.033333 & 0.193333 & 0 & 0.08 & 0.233333 \\
\hline Samoan & PAC & 0.06 & 0.26 & 0.22 & 0.35 & 0.11 & 0.3 & 0.23 & 0.35 & 0 & 0.05 & 0.07 \\
\hline Ivatan & PAC & 0 & 0.34 & 0.12 & 0.32 & 0.22 & 0.1 & 0.12 & 0.38 & 0 & 0.27 & 0.13 \\
\hline Cape_York & AUS & 0.072816 & 0.174757 & 0.237864 & 0.223301 & 0.291262 & 0.255 & 0.07 & 0.195 & 0.025 & 0 & 0.455 \\
\hline Groote_Eylandt & AUS & 0.033333 & 0.106667 & 0.246667 & 0.293333 & 0.32 & 0.213333 & 0.006667 & 0.373333 & 0.006667 & 0.086667 & 0.313333 \\
\hline Kimberly & AUS & 0 & 0.111111 & 0.111111 & 0.097222 & 0.680556 & 0.368421 & 0.013158 & 0.460526 & 0 & 0 & 0.157895 \\
\hline Korean & NEA & 0.094241 & 0.32199 & 0.301047 & 0.227749 & 0.054974 & 0.3175 & 0.125 & 0.215 & 0.06 & 0.185 & 0.0975 \\
\hline Tuva & NEA & 0.140957 & 0.255319 & 0.340426 & 0.25 & 0.013298 & 0.313889 & 0.102778 & 0.3 & 0.108333 & 0.105556 & 0.069444 \\
\hline Pima & AME & 0.011628 & 0.511628 & 0.104651 & 0.360465 & 0.011628 & 0.286517 & 0.382022 & 0.308989 & 0 & 0.016854 & 0.005618 \\
\hline Bari & AME & 0.005435 & 0.407609 & 0 & 0.586957 & 0 & 0.207317 & 0.27439 & 0.329268 & 0 & 0.176829 & 0.012195 \\
\hline
\end{tabular}


Supplementary Material 2 (S2) 
Table.1-S2. Sample size and Hardy Weimberg Results

\begin{tabular}{|c|c|c|c|c|c|c|c|c|c|c|c|c|}
\hline \multirow[b]{2}{*}{ Population } & \multicolumn{4}{|c|}{ HLA-B } & \multicolumn{4}{|c|}{ HLA-C } & \multicolumn{4}{|c|}{ HLA-DRB1 } \\
\hline & $\mathrm{N}$ & Ho & $\mathrm{He}$ & $\mathrm{p}$ value & $\mathrm{N}$ & Ho & $\mathrm{He}$ & $\mathrm{p}$ value & $\mathrm{N}$ & Ho & $\mathrm{He}$ & $\mathrm{p}$ value \\
\hline Arara do Iriri & 17 & 0.58824 & 0.5615 & 0.53409 & 15 & 0.2 & 0.28736 & 0.3255 & 15 & 0.46667 & 0.48046 & 1 \\
\hline Arara & 43 & 0.90698 & 0.90752 & 0.05803 & 24 & 0.66667 & 0.69947 & 0.63685 & 32 & 0.71875 & 0.76339 & 0.04898 \\
\hline Kayapo Xicrim & 15 & 0.8 & 0.85977 & 0.35033 & 9 & 0.666667 & 0.66013 & 0.51475 & 10 & 0.8 & 0.77368 & 0.70502 \\
\hline Kaigang & 13 & 0.69231 & 0.77846 & 0.35637 & 9 & 0.66667 & 0.78431 & 0.65168 & 9 & 0.55556 & 0.62745 & 0.16931 \\
\hline Urubu Kaapor & 33 & 0.66667 & 0.7711 & 0.04183 & 27 & 0.59259 & 0.72956 & 0.0787 & 18 & 0.61111 & 0.66032 & 0.71206 \\
\hline Asurini & 19 & 0.89474 & 0.90754 & 0.64608 & 11 & 0.72727 & 0.8658 & 0.72504 & 19 & 0.84211 & 0.73115 & 0.80232 \\
\hline Guarani Kaiowá & 23 & 0.91304 & 0.87923 & 0.79707 & 16 & 0.75 & 0.72177 & 0.49221 & 26 & 0.92308 & 0.81448 & 0.4781 \\
\hline Ticuna Tarapaca & 19 & 0.52632 & 0.76956 & 0.00585 & 17 & 0.58824 & 0.66488 & 0.59683 & 19 & 0.63158 & 0.61735 & 0.22038 \\
\hline Ticuna Arara & 14 & 0.71429 & 0.85185 & 0.53674 & 14 & 0.5 & 0.75661 & 0.07315 & 15 & 0.73333 & 0.73333 & 0.54713 \\
\hline Ache & 14 & 0.71429 & 0.61905 & 0.92019 & 8 & 0.5 & 0.425 & 1 & 12 & 0.33333 & 0.30797 & 1 \\
\hline Inga & 14 & 0.85714 & 0.88624 & 0.36519 & 14 & 0.71429 & 0.80159 & 0.51534 & 15 & 0.86667 & 0.88276 & 0.6023 \\
\hline Arhuaco & 17 & 0.82353 & 0.75579 & 0.56484 & 17 & 0.82353 & 0.77184 & 0.52942 & 17 & 0.82353 & 0.76471 & 0.08495 \\
\hline Kogi & 14 & 0.85714 & 0.71958 & 0.02552 & 14 & 0.78571 & 0.64021 & 0.30864 & 14 & 0.92857 & 0.70899 & 0.05985 \\
\hline Zenu & 16 & 0.875 & 0.86089 & 0.96299 & 12 & 0.91667 & 0.84783 & 0.72766 & 12 & 0.58333 & 0.60507 & 0.49621 \\
\hline Embera & 14 & 0.78571 & 0.78307 & 0.61628 & 14 & 0.64286 & 0.66667 & 0.13631 & 14 & 0.85714 & 0.76455 & 0.51877 \\
\hline Waunana & 20 & 0.85 & 0.87051 & 0.22489 & 20 & 0.9 & 0.80385 & 0.3255 & 20 & 0.65 & 0.70897 & 0.00483 \\
\hline
\end{tabular}




\begin{tabular}{lrrrrrrrrrrrr} 
Cabecar & 19 & 0.73684 & 0.69417 & 0.95656 & 19 & 0.63158 & 0.65434 & 0.96628 & 19 & 0.78947 & 0.72831 & 0.98609 \\
Guaymi & 18 & 0.94444 & 0.73651 & 0.22566 & 18 & 0.77778 & 0.63651 & 0.70566 & 18 & 0.88889 & 0.69048 & 0.50665 \\
Wayuu & 16 & 0.9375 & 0.90323 & 0.9402 & 14 & 0.78571 & 0.89683 & 0.60618 & 15 & 1 & 0.90345 & 0.98649 \\
Quiche & 19 & 0.94737 & 0.94737 & 0.88759 & 19 & 0.89474 & 0.88478 & 0.04635 & 19 & 0.94737 & 0.90469 & 0.95519 \\
Mixe & 20 & 0.9 & 0.82949 & 0.74194 & 20 & 0.75 & 0.75513 & 1 & 20 & 0.8 & 0.80256 & 0.22438 \\
Mixtec & 20 & 0.95 & 0.8859 & 0.83949 & 20 & 0.75 & 0.73462 & 0.95553 & 20 & 0.75 & 0.78462 & 0.68665 \\
Zapotec & 17 & 0.94118 & 0.95544 & 0.77936 & 16 & 0.875 & 0.82258 & 0.76997 & 18 & 1 & 0.90317 & 0.63683 \\
Chipewyan & 25 & 0.88 & 0.90612 & 0.26628 & 25 & 0.92 & 0.91347 & 0.60298 & 25 & 0.96 & 0.90857 & 0.31021 \\
Cree & 18 & 0.83333 & 0.87619 & 0.6194 & 18 & 0.88889 & 0.92857 & 0.82419 & 18 & 0.88889 & 0.92857 & 0.21939 \\
Ojbwa & 15 & 0.93333 & 0.90115 & 0.85763 & 15 & 0.93333 & 0.90115 & 0.60412 & 15 & 1 & 0.90115 & 0.99548 \\
\hline
\end{tabular}




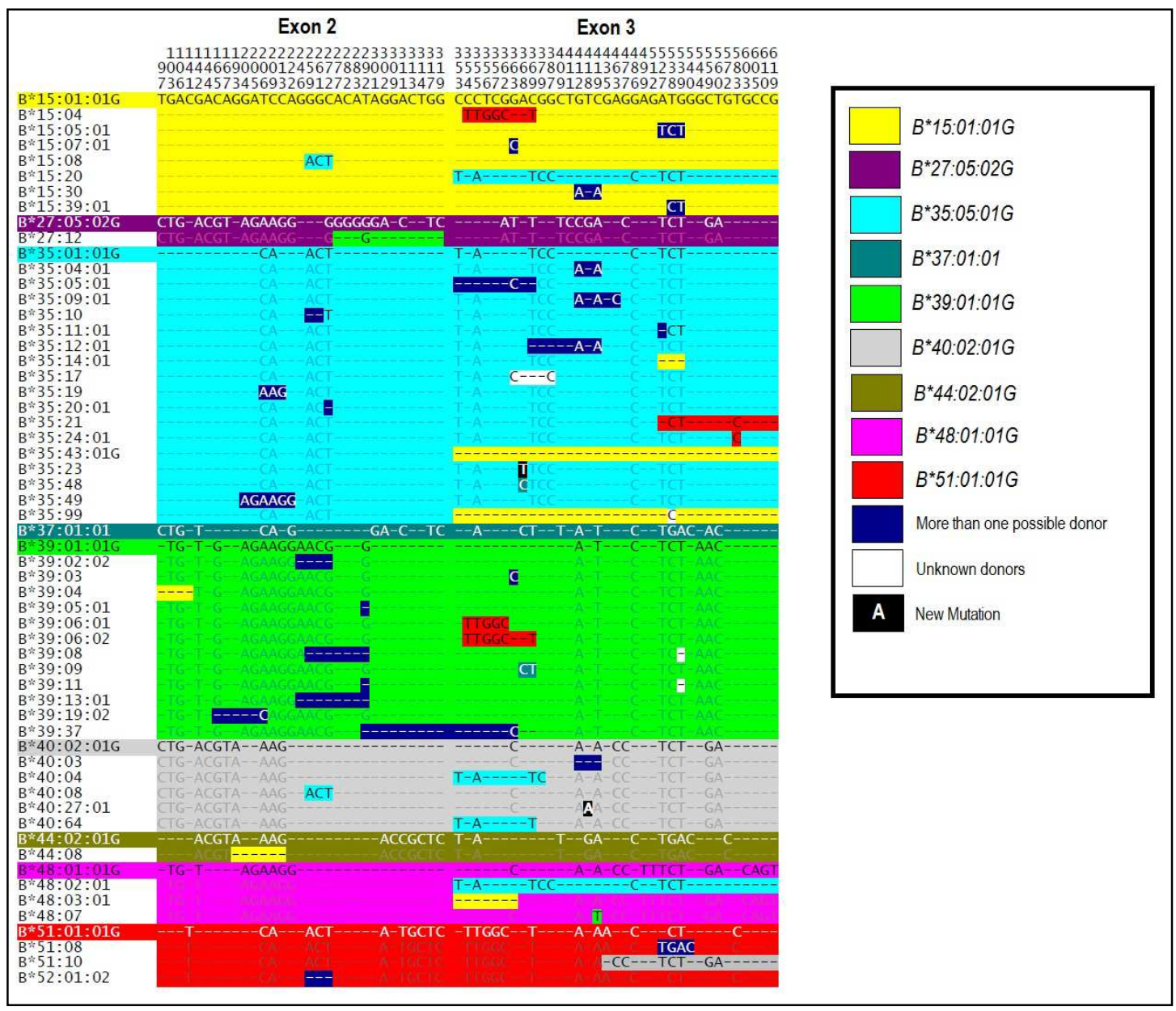

Figure 1-S2: Aligment of the recombinant/gene conversion alleles. 
Table 2-S2. Ewens-Watterson test results.

\begin{tabular}{|c|c|c|c|c|c|c|c|c|c|c|c|c|}
\hline \multirow[b]{2}{*}{ pop_name } & \multicolumn{4}{|c|}{ HLA-B } & \multicolumn{4}{|c|}{ HLA-C } & \multicolumn{4}{|c|}{ HLA-DRB1 } \\
\hline & $2 n$ & Fo & $\mathrm{Fe}$ & P-value & $2 n$ & $\mathrm{Fo}$ & $\mathrm{Fe}$ & P-value & $2 n$ & Fo & $\mathrm{Fe}$ & $\mathrm{P}$-value \\
\hline Arara do Iriri & 34 & 0.45502 & 0.60138 & 0.1979 & 30 & 0.72222 & 0.75615 & 0.4381 & 30 & 0.53556 & 0.75586 & 0.1583 \\
\hline Arara & 86 & $\underline{0.10303}$ & $\underline{0.19715}$ & $\underline{0.0015}$ & 48 & 0.3151 & 0.37297 & 0.3789 & 64 & 0.24854 & 0.39367 & 0.0856 \\
\hline Kaiapo_K & 30 & 0.21556 & 0.28249 & 0.2031 & 26 & $\underline{0.23373}$ & $\underline{0.38174}$ & $\underline{0.0206}$ & 28 & 0.36735 & 0.32441 & 0.7402 \\
\hline Kaiapo_X & 60 & $\underline{0.16889}$ & $\underline{0.33974}$ & $\underline{0.0021}$ & 18 & 0.37654 & 0.42959 & 0.4039 & 20 & 0.265 & 0.35601 & 0.1638 \\
\hline Kaigang & 26 & 0.25148 & 0.23235 & $\overline{0.721}$ & 18 & 0.25926 & 0.284 & 0.472 & 18 & 0.40741 & 0.28332 & 0.9376 \\
\hline Parakanã & 42 & 0.14626 & 0.21113 & 0.081 & 22 & $\underline{0.28512}$ & $\underline{0.45271}$ & $\underline{0.0397}$ & 18 & $\underline{0.23457}$ & $\underline{0.34543}$ & $\underline{0.0485}$ \\
\hline Arawete & 62 & 0.37045 & 0.45519 & 0.337 & 38 & 0.43906 & 0.61239 & 0.153 & 50 & 0.3304 & 0.43819 & 0.2403 \\
\hline Urubu Kaapor & 66 & 0.24059 & 0.21963 & 0.7059 & 54 & 0.28395 & 0.38343 & 0.2242 & 36 & 0.35802 & 0.34612 & 0.6301 \\
\hline Assurini & 38 & 0.11634 & 0.14652 & 0.1729 & 22 & $\underline{0.17355}$ & $\underline{0.30312}$ & $\underline{0.0004}$ & 38 & 0.28809 & 0.41672 & 0.1283 \\
\hline Guarani Kaiowa & 46 & 0.13989 & 0.19573 & 0.1133 & 32 & 0.30078 & 0.33782 & 0.444 & 62 & 0.20118 & 0.28568 & 0.1466 \\
\hline Ticuna_N & 38 & 0.25069 & 0.23126 & 0.7058 & 34 & 0.35467 & 0.34273 & 0.6374 & 38 & 0.39889 & 0.41392 & 0.5447 \\
\hline Ticuna_S & 28 & 0.17857 & 0.18049 & 0.5865 & 28 & 0.27041 & 0.27674 & 0.5698 & 30 & 0.29111 & 0.33182 & 0.4152 \\
\hline Ache & 28 & 0.40306 & 0.39078 & 0.6426 & 16 & 0.60156 & 0.54115 & 0.742 & 24 & $\underline{0.70486}$ & $\underline{0.45743}$ & $\underline{0.9706}$ \\
\hline Quechua & 42 & 0.08277 & 0.09101 & 0.3723 & 42 & 0.18367 & 0.21143 & 0.4026 & 42 & 0.1678 & 0.16958 & 0.5957 \\
\hline Aymara & 40 & 0.18375 & 0.13619 & 0.9174 & 40 & $\underline{0.3125}$ & $\underline{0.18578}$ & $\underline{0.9697}$ & 40 & 0.225 & 0.18535 & 0.8263 \\
\hline Huilliche & 40 & $\underline{0.2225}$ & $\underline{0.13647}$ & $\underline{0.9726}$ & 30 & 0.21778 & 0.18617 & 0.8138 & 40 & 0.1525 & 0.13617 & 0.7653 \\
\hline Inga & 28 & 0.14541 & 0.1274 & 0.8228 & 28 & 0.22704 & 0.18113 & 0.8589 & 30 & 0.14667 & 0.1652 & 0.4012 \\
\hline Arhuaco & 34 & 0.26644 & 0.25461 & 0.6575 & 34 & 0.25087 & 0.34239 & 0.1726 & 34 & 0.25779 & 0.22213 & 0.7814 \\
\hline Kogi & 28 & 0.30612 & 0.32407 & 0.5152 & 28 & 0.38265 & 0.27701 & 0.898 & 28 & 0.31633 & 0.32619 & 0.5643 \\
\hline Zenu & 32 & 0.16602 & 0.19112 & 0.3769 & 24 & 0.1875 & 0.2614 & 0.0844 & 24 & $\underline{0.42014}$ & $\underline{0.26216}$ & $\underline{0.9688}$ \\
\hline
\end{tabular}




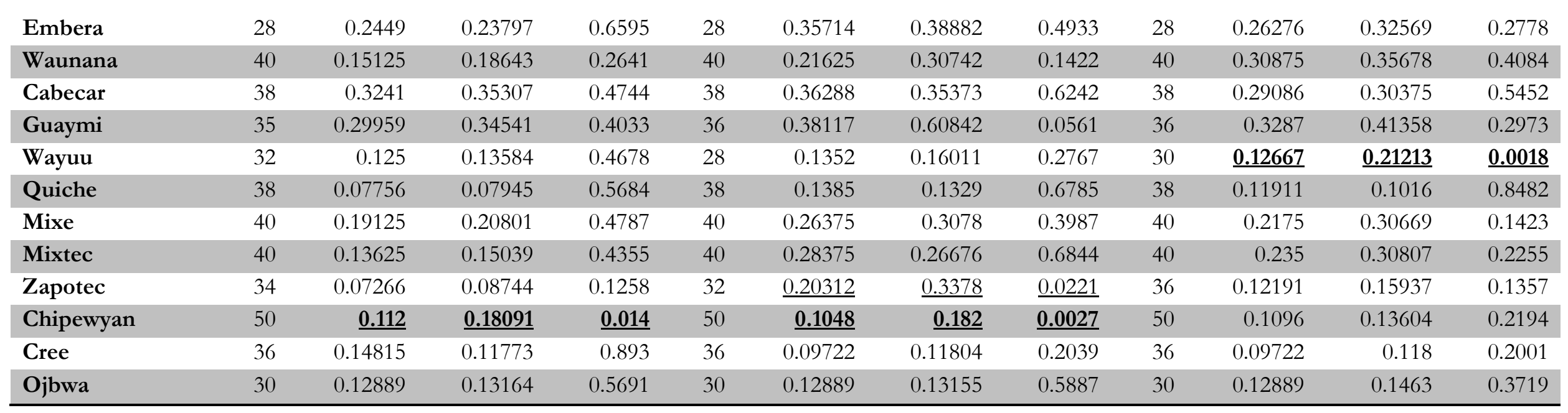


Table 3-S2. Tajima's D test results.

\begin{tabular}{|c|c|c|c|c|c|c|c|c|c|}
\hline \multirow[b]{2}{*}{ pop_name } & \multicolumn{3}{|c|}{ HLA-B } & \multicolumn{3}{|c|}{ HLA-C } & \multicolumn{3}{|c|}{ HLA-DRB1 } \\
\hline & $2 n$ & Tajima's D & P-value & $2 n$ & Tajima's D & P-value & $2 n$ & Tajima's D & P-value \\
\hline Arara do Iriri & 34 & $\underline{2.901102}$ & $\underline{0.9994}$ & 30 & 0.484689 & 0.738 & 30 & 3.191907 & 1 \\
\hline Arara & 86 & 2.255566 & $\underline{0.9909}$ & 48 & 1.165555 & 0.9068 & 64 & 3.10497 & 0.9996 \\
\hline Kaiapo_K & 30 & $\underline{1.498306}$ & $\underline{0.9553}$ & 26 & 2.365598 & $\underline{0.9972}$ & 28 & 1.678131 & 0.9664 \\
\hline Kaiapo_X & 60 & $\underline{2.44449}$ & $\underline{0.9934}$ & 18 & 1.344724 & 0.9401 & 20 & 1.690865 & 0.9747 \\
\hline Kaigang & 26 & 0.29117 & 0.6746 & 18 & 1.027998 & 0.89 & 18 & 0.120702 & 0.5962 \\
\hline Parakanã & 42 & $\underline{2.283072}$ & $\underline{0.9917}$ & 22 & $\underline{2.759251}$ & $\underline{0.9994}$ & 18 & 1.049376 & 0.8976 \\
\hline Arawete & 62 & $\underline{1.864597}$ & $\underline{0.9739}$ & 38 & -1.06374 & 0.1476 & 50 & 2.412669 & 0.9963 \\
\hline Urubu Kaapor & 66 & $\underline{2.395515}$ & $\underline{0.9933}$ & 54 & 0.735853 & 0.8151 & 36 & 0.919014 & 0.8659 \\
\hline Assurini & 38 & $\underline{2.484834}$ & $\underline{0.9977}$ & 22 & $\underline{1.564884}$ & $\underline{0.9635}$ & 38 & $\underline{2.646943}$ & $\underline{0.9985}$ \\
\hline Guarani Kaiowa & 46 & $\underline{2.82927}$ & $\underline{0.9877}$ & 32 & $\underline{1.547453}$ & $\underline{0.9561}$ & 62 & $\underline{1.87893}$ & $\underline{0.977}$ \\
\hline Ticuna_N & 38 & $\underline{1.702371}$ & $\underline{0.9685}$ & 34 & 1.042047 & 0.8855 & 38 & -0.67065 & 0.2766 \\
\hline Ticuna_S & 28 & $\underline{1.527817}$ & $\underline{0.9556}$ & 28 & 1.318537 & 0.9297 & 30 & 0.845631 & 0.8489 \\
\hline Ache & 28 & 1.100747 & 0.8988 & 16 & 0.078052 & 0.5833 & 24 & -0.50356 & 0.3441 \\
\hline Quechua & 42 & 0.850133 & 0.8542 & 42 & 1.459493 & 0.9477 & 42 & $\underline{1.769513}$ & $\underline{0.9754}$ \\
\hline Aymara & 40 & 0.520051 & 0.7685 & 40 & 0.705586 & 0.8136 & 40 & 1.347757 & 0.9359 \\
\hline Huilliche & 40 & 1.077851 & 0.8976 & 30 & 0.729486 & 0.8216 & 40 & 0.820287 & 0.8403 \\
\hline Inga & 28 & 0.431261 & 0.7208 & 28 & 1.039216 & 0.8865 & 30 & 0.829592 & 0.8497 \\
\hline Arhuaco & 34 & -0.53976 & 0.3265 & 34 & 1.969984 & $\underline{0.9834}$ & 34 & 2.266925 & 0.9928 \\
\hline Kogi & 28 & 0.526885 & 0.7631 & 28 & 0.79871 & 0.831 & 28 & 0.290425 & 0.6741 \\
\hline Zenu & 32 & 1.245103 & 0.9203 & 24 & $\underline{1.557685}$ & $\underline{0.9576}$ & 24 & 0.261279 & 0.6683 \\
\hline Embera & 28 & 1.035601 & 0.8905 & 28 & $\underline{1.935543}$ & $\underline{0.9841}$ & 28 & 0.856211 & 0.8469 \\
\hline Waunana & 40 & $\underline{2.08943}$ & $\underline{0.9892}$ & 40 & $\underline{1.573751}$ & $\underline{0.9594}$ & 40 & 1.197821 & 0.9122 \\
\hline Cabecar & 38 & 0.549131 & 0.7701 & 38 & 0.688681 & 0.8057 & 38 & 0.64597 & 0.7951 \\
\hline Guaymi & 35 & 0.21451 & 0.6463 & 36 & 2.664837 & $\underline{0.9971}$ & 36 & 0.599609 & 0.7754 \\
\hline
\end{tabular}




\begin{tabular}{lrrrrrrrrr} 
Wayuu & 32 & 1.058406 & 0.8935 & 28 & 1.294624 & 0.9312 & 30 & $\underline{2.12534}$ & $\underline{0.9899}$ \\
Quiche & 38 & 0.702254 & 0.8126 & 38 & 0.777405 & 0.8324 & 38 & 0.686991 & 0.8095 \\
Mixe & 40 & 0.51594 & 0.7612 & 40 & $\underline{\mathbf{2 . 5 5 9 0 5 7}}$ & $\underline{\mathbf{0 . 9 9 6 7}}$ & 40 & $\underline{\mathbf{1 . 7 3 4 9 8 6}}$ & $\underline{0.9721}$ \\
Mixtec & 40 & 0.912205 & 0.86 & 40 & $\underline{\mathbf{1 . 9 5 2 7 4 6}}$ & $\underline{\mathbf{0 . 9 8 0 4}}$ & 40 & $\mathbf{2 . 7 1 1 5 9}$ & $\mathbf{0 . 9 9 8 2}$ \\
Zapotec & 34 & 1.115692 & 0.9045 & 32 & $\mathbf{2 . 6 2 7 0 7 2}$ & $\mathbf{0 . 9 9 7 9}$ & 36 & 1.166305 & 0.9121 \\
Chipewyan & 50 & $\underline{\mathbf{2 . 5 8 6 6 7 2}}$ & $\underline{\mathbf{0 . 9 9 7 3}}$ & 50 & 1.736498 & 0.9696 & 50 & $\underline{\mathbf{2 . 8 9 7 1 7}}$ & $\underline{0.9894}$ \\
Cree & 36 & $\underline{1.7149}$ & $\underline{\mathbf{0 . 9 7 2 5}}$ & 36 & 1.317669 & 0.9296 & 36 & $\underline{\mathbf{1 . 7 0 0 4 9 5}}$ & $\underline{\underline{0.9639}}$ \\
Ojbwa & 30 & 1.340873 & 0.9351 & 30 & 0.91977 & 0.8654 & 30 & 1.080667 & 0.8937 \\
\hline
\end{tabular}

